\title{
Using a Species Distribution Model and Site-Specific Microclimatic Variables to Model Presence of Spodic Soil Properties and Relative Occurrence Rate of Picea rubens (Red Spruce) to Inform Red Spruce Management
}

Adrienne Nottingham

Follow this and additional works at: https://researchrepository.wvu.edu/etd

\section{Recommended Citation}

Nottingham, Adrienne, "Using a Species Distribution Model and Site-Specific Microclimatic Variables to Model Presence of Spodic Soil Properties and Relative Occurrence Rate of Picea rubens (Red Spruce) to Inform Red Spruce Management" (2017). Graduate Theses, Dissertations, and Problem Reports. 6329. https://researchrepository.wvu.edu/etd/6329

This Thesis is protected by copyright and/or related rights. It has been brought to you by the The Research Repository @ WVU with permission from the rights-holder(s). You are free to use this Thesis in any way that is permitted by the copyright and related rights legislation that applies to your use. For other uses you must obtain permission from the rights-holder(s) directly, unless additional rights are indicated by a Creative Commons license in the record and/ or on the work itself. This Thesis has been accepted for inclusion in WVU Graduate Theses, Dissertations, and Problem Reports collection by an authorized administrator of The Research Repository @ WVU. For more information, please contact researchrepository@mail.wvu.edu. 
Using a Species Distribution Model and Site-Specific Microclimatic Variables to Model Presence of Spodic Soil Properties and Relative Occurrence Rate of Picea rubens (Red Spruce) to Inform Red Spruce Management

Adrienne Nottingham

Thesis submitted to the Davis College of Agriculture, Natural Resources and Design at West Virginia University

in partial fulfilment of the requirements for the degree of Masters in Science in Plant and Soil Sciences.

\author{
James A. Thompson, Ph.D., Chair \\ Pamela J. Edwards, Ph.D. \\ Michael Strager, Ph.D. \\ Department of Plant and Soil Sciences \\ Morgantown, West Virgina \\ 2017
}

Keywords: High Elevation, Red Spruce, Spodosols, Pedomemory, Species Distribution Modeling, Maximum Entropy, Microclimate Copyright 2017 Nottingham 


\begin{abstract}
Using a Species Distribution Model and Site-Specific Microclimatic Variables to Model Presence of Spodic Soil Properties and Relative Occurrence Rate of Picea rubens (Red Spruce) to Inform Red Spruce Management
\end{abstract}

\title{
Adrienne Nottingham
}

Red spruce restoration efforts in the central Appalachians are of interest to land managers because of the reduced current extent and the numerous ecosystem services provided by red spruce forests. These land managers require information regarding the best places to focus restoration efforts. Studies attempting to locate optimal locations for red spruce restoration have been conducted to in the central Appalachians, most of which utilize modeling. In particular, podzolization, a soil formation pathway present under conifer vegetation in the central Appalachians has been used to help select areas for red spruce restoration. The effectiveness of using recent podzolization (as evidenced by spodic soil properties) to predict historic vegetative cover has been found to be useful in prioritizing areas for red spruce restoration. The objectives of this research were twofold: evaluate the efficacy of the model, Maximum Entropy (MaxEnt), to model presence of spodic soil properties and evaluate the efficacy of modeling red spruce relative occurrence rates using topographic and microclimatic variables.

For the first objective, MaxEnt was used to model presence of spodic properties in 124,687 ha in the central Appalachians using 221 presence-only soil observations and a suite of topographic and satellite-derived variables. Results of this study were compared to a model output generated using Random Forest (a presence/absence model). The results showed approximately $62 \%$ agreement (both models predicted high, or both predicted low probability of presence), and 38\% disagreement (one model predicted high probability of presence, while another predicted low, or vice-versa). However, without field validation, it is not known which model output is better. No variables used in this exercise were found to be particularly important to spodic property presence, which is likely due to the relatively coarse scale of variables used.

To evaluate the second objective, air temperature, soil temperature, and soil moisture were measured in situ for approximately one year in a small $\left(5.4 \mathrm{~km}^{2}\right)$ high elevation (700-900 m) watershed in the central Appalachians. The raw data collected was summarized into variables believed to be important to red spruce relative occurrence rates and largely based on available literature. Four preliminary MaxEnt models were run using (i) only topographic variables, (ii) only air temperature variables, (iii) only soil temperature variables, and (iv) only soil moisture variables. The most important variables (as evidenced by permutation importance value) were utilized in a final model run. Altitude above channel network was the most important variable in the preliminary run which utilized only topographic variables, and the final run which used the most important variables. The relationship between altitude above channel network and red spruce relative occurrence rate was inverse: as altitude above channel network increased, red spruce relative occurrence rate decreased. The second most important in the final model run was August absolute maximum air temperature. Lack of importance of other microclimatic data is most likely due to poorly interpolated surfaces and missing data. Model outputs from both the preliminary run that utilized only topographic variables, and the final run both predicted the lowest red spruce relative occurrence rate at the highest elevations in the watershed on ridgetops 
and shoulders. The highest red spruce relative occurrence rates were found at the lowest elevations of the watershed. This, coupled with the importance of altitude above channel network, suggest that higher red spruce relative occurrence rates occur in concave landscape positions that promote cooler air and soil temperatures, and increased soil moisture. Agreement between the preliminary model run that used only topographic variables and the final model run was approximately $82 \%$, while disagreement between the two was only $18 \%$. The limited success of creating soil temperature and soil moisture variables, coupled with the fact that there was little difference between the model that utilized only topographic variables and the model that incorporated microclimatic variables, suggests that it may be feasible to utilize only topographic variables in future efforts. If microclimatic variables are desired, air temperature was found to be important in this model, and would be easier to measure in the field. Red spruce restoration should continue to target the highest elevations of the central Appalachian landscape, but should not necessarily be limited to the highest ridgetops and shoulder landscape positions. Instead, red spruce restoration should target high elevation concave landscape positions like cold air drainage ways which promote cooler air and soil temperatures as well as soil moisture. 


\section{Dedication}

I dedicate this work to my Great-Grandfather, June W. Galford, who instilled in me a love of the land. The time I spent with him on the farm fostered my interest in natural resources and made me appreciate the value of hard work. Although born in 1916, Pappy was probably the first feminist I knew. He never gendered work-I worked beside him no matter the task, and it made me confident when trying something new. His tireless spirit also made me forever appreciate the grit and determination of the Appalachian farmer. I know that my path would have made him proud and I hope that I can use the knowledge I gained during my time as a Master's student to help protect the unique lands of West Virginia.

I also dedicate this work to my parents, June Taylor and Shawn Nottingham. You both supported me unconditionally and allowed me to choose my own path, no matter how unconventional. I am sure that when I enrolled at WVU, neither of you thought I would emerge a soil scientist. In retrospect, every second I spent exploring the farm brought me closer to recognizing my passion: soils. You both always put my happiness and success above your own, and for that I will forever be grateful.

\section{Acknowledgements}

In general I want to thank and acknowledge my entire committee. You all made me a better scientist, critical thinker, writer, and professional. My advisor, Dr. James Thompson, supported me throughout the journey that is graduate school and helped me to navigate professional relationships. No matter how busy, Dr. Thompson always found time to assist me. When I started graduate school, I received a position at the Monongahela National Forest that required me to work there throughout my time as a student at WVU. Dr. Thompson recognized that this was a tremendous opportunity for me and was understanding of the time I had to spend 
working on projects other than my thesis. I cannot stress enough my gratitude for all of Dr. Thompson's encouragement and support.

I also want to acknowledge the help of Dr. Michael Strager at WVU. Dr. Strager sat on my committee as the reigning GIS expert. He assisted me with the technical work of GIS analysis. But Dr. Strager is very unique in that he has the ability to think about this technical work with management in mind. I appreciate all his guidance and support during the development and execution of this research.

Finally, I want to thank another instrumental member of my committee, Dr. Pamela Edwards. Pam made every effort to help me through each step of this process-even letting me live with her and her spouse, Frederica Wood, for nearly five years! Before graduate school, I used to think that I was an excellent writer, but after Pam started editing my manuscripts, I realized I still had much to learn. Pam taught me the difference between 'stake' and 'steak', and that Microsoft Word doesn't catch every mistake. In retrospect, I know I am a better writer because of Pam.

Although not on my committee, I would also like to thank Frederica Wood for all of her help. Freddie, thank you so much for helping me with all of my data management and analysis. I know you probably had better things to do on your Saturday afternoons than talk to me about the inner-workings of ArcGIS. I am so thankful for all of the time you dedicated to assist me in finishing this research.

I have also had the pleasure of working with many on the Monongahela National Forest. I met Stephanie Connolly, the Forest Soil Scientist on the MNF, when I was just a junior in high school. Stephanie told me that if I had a passion for soil science and was willing to put in the work, she would help me become a professional soil scientist, and she has. Stephanie, none of 
this would have been possible without you in my corner, and words cannot express my gratitude. You pushed me to step outside my comfort zone, and while it was difficult, I am not only a better soil scientist, but a better professional because of it. Thank you for every time you offered me counsel, and thank you for keeping me sane during graduate school.

Last, but not least, I would like to thank the many people that assisted me during my field work. Digging, describing, and sampling soil pits is not for the faint of heart. I would like to thank my Dad, Shawn Nottingham, and partner, Bryan Weimer, for helping me to dig the 20 soil pits for my project. You all were great pack-mules, diggers, and had some good questions to boot. I would also like to thank Steffany Scagline and Pamela Edwards for assisting my monthly data downloads in Snorting Lick Run.

Finally, I would also like to acknowledge the financial and institutional support of WVU and the Monongahela National Forest. Without this financial support, this research would not have been possible. I would also like to thank Clyde Thompson, Forest Supervisor of the MNF, for his support in pursing these research efforts. 


\section{Table of Contents}

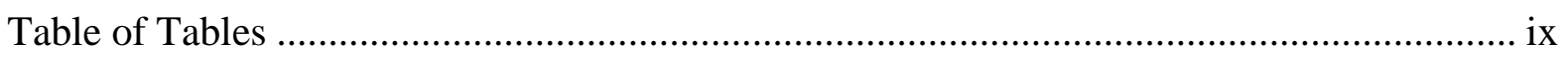

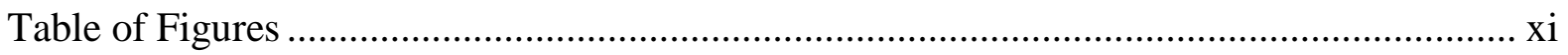

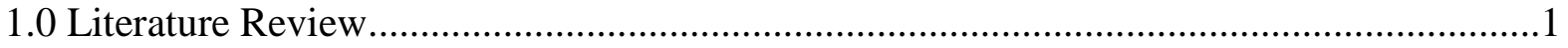

1.1 Red Spruce Forests: Historical Extent and Typical Site Conditions ................................. 1

1.2 Red Spruce and Soil: Podzolization .................................................................................. 3

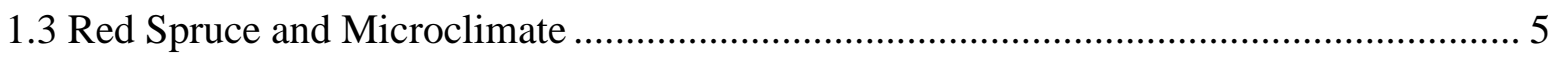

1.4 Application of Models for Red Spruce Restoration ...................................................... 7

1.4.1 Maximum Entropy Modeling ……............................................................................. 8

1.5 Interpolation Methods for use in Modeling: Kriging and Cokriging ............................. 15

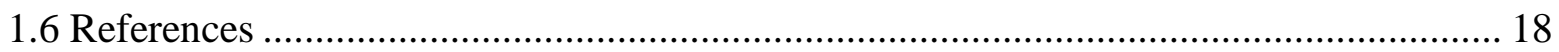

2.0 Mapping Pedomemory of Spodic Morphology Using a Species Distribution

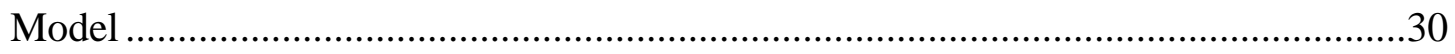

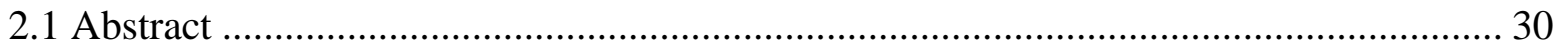

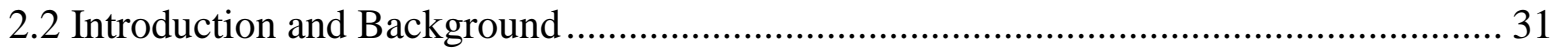

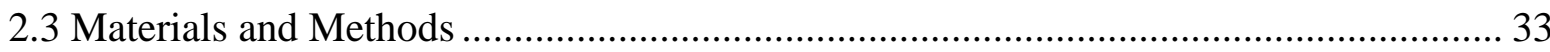

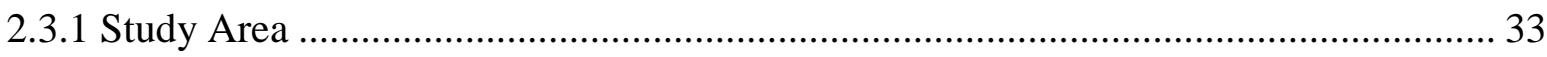

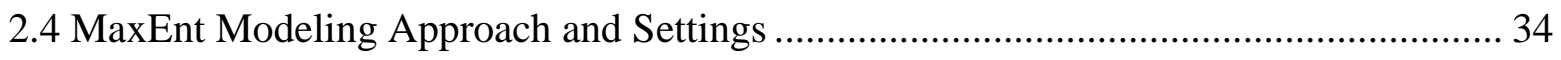

2.5 Model Comparison Techniques.................................................................................. 37

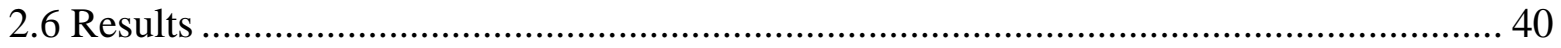

2.6.1 MaxEnt Comparisons...................................................................................... 40

2.6.2 MaxEnt and Random Forests Output Comparisons................................................... 42

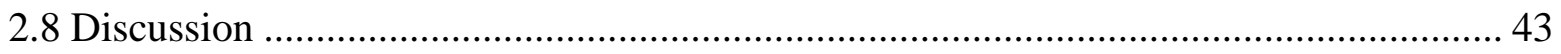

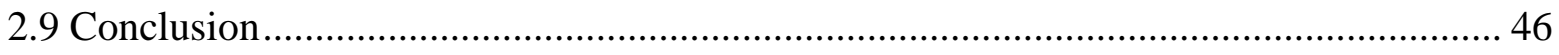

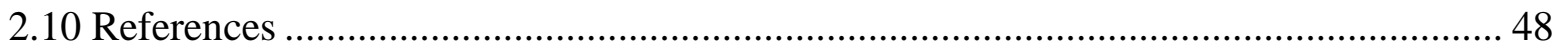

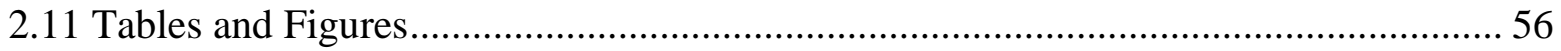

3.0 The Effects of Soil Moisture, Soil Temperature, and Air Temperature on Red Spruce Distribution: Maximum Entropy Modeling in a Small Forested

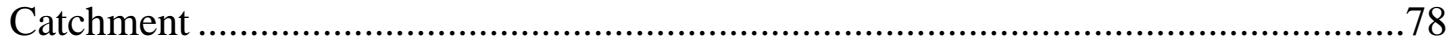

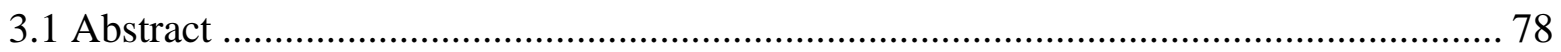

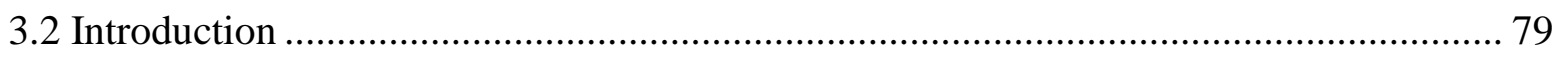

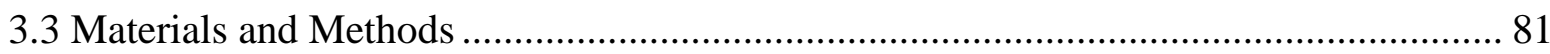




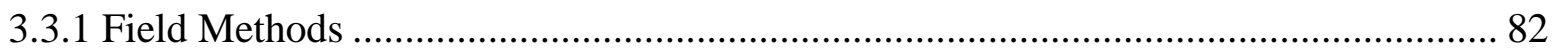

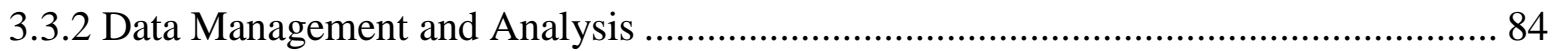

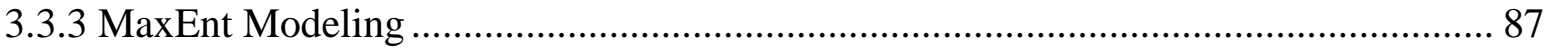

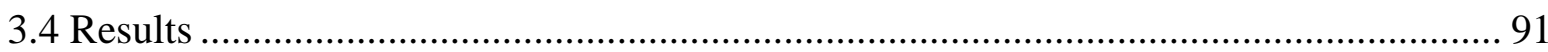

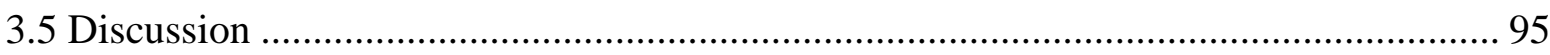

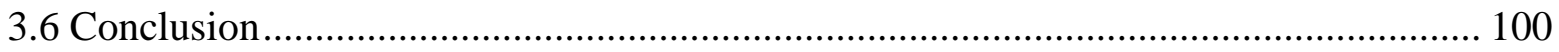

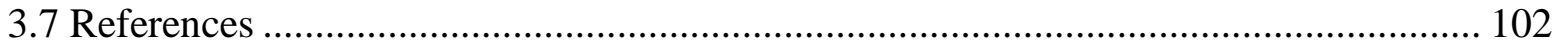

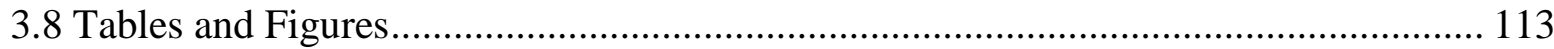

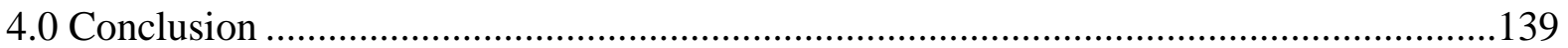

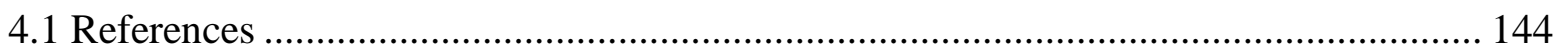

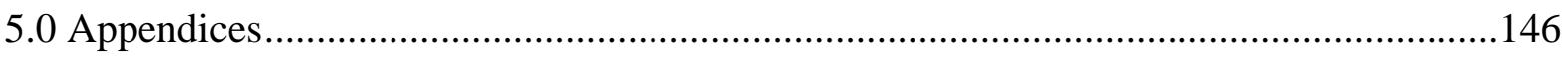

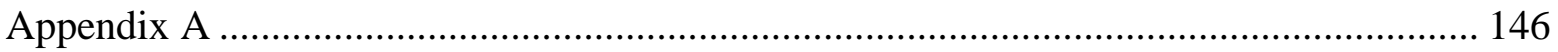

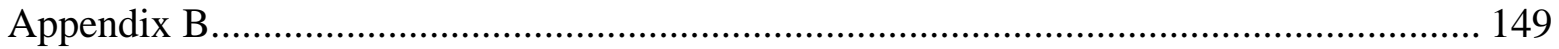

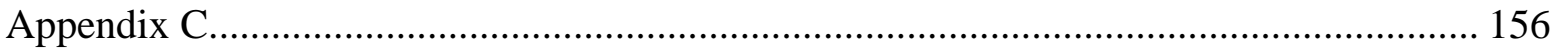




\section{Table of Tables}

\subsection{Literature Review}

Table 1. Requirements of a Spodosol (from Soil Survey Staff, 1999)

2.0 Mapping Pedomemory of Spodic Morphology Using a Species Distribution Model

Table 1. Spodic intensity classes and respective characteristics (adapted from

Nauman et al., 2015a).

Table 2.. Number of samples by spodic intensity (left), and number of samples by

MaxEnt modeling classes. Points with a spodic intensity of 0.0 represent

spodic absences, so they were not used for MaxEnt modeling because it

employs presence-only data.

Table 3. Digital elevation model-derived and Landsat Geocover environmental variables used to map spodic properties in MaxEnt (taken from Nauman et al., 2015b).

Table 4. MaxEnt settings used in this analysis and the justification for the setting choice. Model defaults were used for settings not listed in this table.

Table 5. Percentages of agreement and disagreement probability of presence for the pairwise comparisons produced by the three spodic intensity classes $(0.5-2.0$, 1.0-2.0 and 2.0) using MaxEnt.

Table 6. Number of cells and percent of cells (or area) in the high probability $(\geq 0.60)$ and low probability $(<0.6)$ classes for the MaxEnt models for each spodic intensity class.

Table 7. Permutation importance values for each of the 29 environmental covariates for the three MaxEnt spodic intensity class outputs. Variable definitions are provided in Table 3 .

Table 8. Percentages of agreement and disagreement probability of presence for the MaxEnt-random forests comparison.

Table 9. Mean, minimum, and maximum environmental variable values for the top 40 percent of highest probability cells where MaxEnt and random forests models were in agreement.

Table 10. Mean, minimum, and maximum environmental variable values for the top 40 percent of highest probability cells where MaxEnt and random forests models did not agree. All means were significantly different, with Wilcoxon rank-sum test probability values $<0.0001$ 
3.0 The Effects of Soil Moisture, Soil Temperature, and Air Temperature on Red Spruce Distribution: Maximum Entropy Modeling in a Small Forested Catchment

Table 1. Summary of missing soil moisture and soil temperature data for the period December 2015 through September 2016.

Table 2. Correlation statistics for correlation among plots (Pearson) and serial correlation (Durbin-Watson).

Table 3. All topographic and microclimatic variables used in preliminary model runs.

Table 4. Classification of model results into low or high relative occurrence rates (ROR) for agreement/disagreement analysis. The median ROR for each model was used as the classification break point for that model.

Table 5. Area under the receiver operating curve (AUC) values for the four preliminary models.

Table 6. Permutation importance (PI) values for model runs employing only topographic variables, only air temperature variables, only soil temperature variables and only soil moisture variables.

Table 7. Correlation coefficients for the most important variables from the four preliminary models used in the final model.

Table 8. Permutation importance values for all variables in the final model.

Table 9. Agreement/disagreement results for the topographic-only model compared to the topographic and microclimatic model, when classified into high and low relative occurrence rate (ROR) classes. The value column refers to the possible sums in Table 4.

Table 10. Minimum, maximum and mean data values for topographic and microclimatic variables in areas of disagreement between the model that utilized only topographic variables and the final model that used the five most important topographic and microclimatic variables. Means within each row were significantly different $(\mathrm{p}<0.0001)$, except for variable baselevel $(\mathrm{p}=$ $0.1827)$. 


\section{Table of Figures}

2.0 Mapping Pedomemory of Spodic Morphology Using a Species Distribution Model

Figure 1. Location of sample points across the Monongahela National Forest in eastern West Virginia.

Figure 2. Soil sampling and description points within the study area. Symbols denote the spodic intensity recorded at each point.

Figure 3. A generalized example of an area under the receiver operating characteristic (ROC) curve value. The dashed line is included in all generated AUC values and is not reflective of data used in the model; it indicates an AUC value of 0.5 , and represents a model that performs no better than one with random output. A model that performs perfectly would have an AUC value of 1 . The red and blue lines represent actual model runs (from Pearson, 2010).

Figure 4. The three MaxEnt spodic intensity model outputs: (A) spodic intensity class $=0.5-2.0,(\mathrm{~B})$ spodic intensity class $=1.0-2.0$, and $(\mathrm{C})$ spodic intensity class $=$ 2.0 .

Figure 5. Frequency distributions of MaxEnt probability of presence of spodic expression for the $0.5-2.0,1.0-2.0$, and 2.0 spodic intensity classes.

Figure 6. Comparison of MaxEnt (A) and random forests (B) outputs. The MaxEnt model employed presence data using the range of $0.5-2.0$ spodic intensity, while random forests used 0-2.0 spodic intensity data, since random forests includes absence data. Cells were separated into five equal cell quantiles to compare these outputs by rank. Colors represent probability that spodic properties exist, not intensity of spodic expression.

Figure 7. Spatial comparison of the MaxEnt and random forests agreement and disagreement, using the top 40 percent of probabilities for each model. White areas are cells in the lower $60 \%$ of probabilities for both the MaxEnt and random forests outputs, so they were not included in this comparison.

3.0 The Effects of Soil Moisture, Soil Temperature, and Air Temperature on Red Spruce Distribution: Maximum Entropy Modeling in a Small Forested Catchment

Figure 1. Response curve for topographical variable aacn when all other variables are held constant at their mean. The black line shows the mean (over 10 runs)

ROR response to aacn. The mean $+/$ - one standard deviation is represented in light blue.

Figure 2. Response curve for air temperature variable augabsmaxanyday when all other variables are held constant at their mean. The black line shows the mean (over 10 runs) ROR response to augabsmaxanyday. The mean $+/$ - one standard deviation is represented in light blue 
Figure 3. Response curve for air temperature variable augabsmaxanyday0 $\mathrm{cm}$ when all other variables are held constant at their mean. The black line shows the mean (over 10 runs) ROR response to augabsmaxanyday $0 \mathrm{~cm}$. The mean $+/$ - one standard deviation is represented in light blue.

Figure 4. Jackknife analysis for final model run. The dark blue bar represents the AUC value if only that variable was used. The light blue bar represents the AUC value if that variable was omitted. The red bar at the bottom is the AUC value when all variables are included in the model.

Figure 5. Model results using only topographic variables (A) and topographic and microclimatic variables (B). Pink color indicates high relative occurrence rate (ROR) (defined as greater than median ROR) and blue indicates low ROR (defined as less than median ROR) for red spruce.

Figure 6. Agreement/disagreement comparison between the model that used only topographic variables and the model that used both topographic and microclimatic variables 


\subsection{Literature Review}

\subsection{Red Spruce Forests: Historical Extent and Typical Site Conditions}

Red spruce forests were historically valued for their commercial value (Clarkson, 1964;

Lewis, 1998). Prior to the late $19^{\text {th }}$ century, it is estimated that red spruce forest existed on 600,000 ha of forest in WV (Rentch, 2007). By the early $20^{\text {th }}$ century, the red spruce forests throughout the central Appalachians had been extensively logged (Clarkson, 1964; Lewis, 1998). Wildfires (often resulting from sparks from coal-fired engines used to move timber) also impacted the landscape. Historical documentation indicates that the wildfires sometimes consumed all soil and organic materials above bedrock (Allard and Leonard, 1952; Lewis, 1998). Predictably, severe water and wind erosion further degraded the landscape (Allard and Leonard, 1952) such that poor red spruce regeneration was common (Allard and Leonard, 1952). Burned areas typically regenerated to hardwood stands that contained only minor red spruce or conifer components (Rentch, 2007). As a result, red spruce forests within the Appalachian Mountains now are considered to be one of the most endangered forest types in the United States (Christensen et al., 1966; Noss et al., 1995).

Nauman et al., (2015a,b) demonstrated that current soil properties might be useful for predicting previous environmental conditions because certain soil characteristics can persist even after some environmental factors change — a concept termed pedomemory (Targuilian and Goryachkin, 2010; Lin, 2011; Monger and Rachal, 2013; Nauman et al., 2015a,b;). Soils formed beneath red spruce forests serve as particularly good examples of this phenomenon, given the unique and long-lasting soil characteristics that develop under conifer cover in cool wet climates typical of high elevations in the Appalachians (Oosting and Billings, 1951; Stanley and Ciolkosz, 1981) (see section 3.4, Red Spruce and Soil: Podzolization). 
Red spruce forests occur on high elevation peaks and ridges of the Allegheny Mountains (Oosting and Billings, 1951; Rentch, 2007; Adams et al., 2010; Byers et al., 2013). The surficial geology of these mountain positions typically consists of Pennsylvanian sandstone and shale that, respectively, form sandy loams or silt loams (Losche and Beverage, 1967; Flegel, 1998). These soils are highly acidic and infertile (Flegel, 1998). Climate of red spruce forests are characterized by high precipitation, frequent fog, and cold temperatures (Flegel, 1998).

Soil moisture is an influential factor for determining red spruce survival or death (Murphy, 1917; Kaufmann and Eckard, 1977; Siccama et al., 1982; Sullivan, 1993; Mohlenbrock, 1995; Greenwood et al., 2008). Surface soil conditions that promote water retention are beneficial to red spruce given their shallow rooting system and inability to reach deeper ground water tables (Murphy, 1917; Sullivan, 1993; Mohlenbrock, 1995). Red spruce is one of the most shade-tolerant tree species in the central Appalachians (Murphy, 1917; Bliss and Vogelmann, 1982; Johnson et al., 1986; Sullivan, 1993). The ability to grow in environments that are unhospitable to its competitors is considered to be a reason red spruce has persisted throughout the Appalachians (Murphy, 1917; Sullivan, 1993; Mohlenbrock, 1995). Consequently, it typically grows where conditions are inadequate or too harsh for most other tree species (Murphy, 1917; Sullivan, 1993; Mohlenbrock, 1995).

Red spruce has limited risk for pest or disease infestation (Sullivan, 1993), which makes it a viable species to replace dead or dying eastern hemlock (Tsuga canadensis) stands that succumb to hemlock wooly adelgid (Adelges tsugae) (Jenkins et al., 1999; Ward et al., 2004). However, red spruce (like many other plant species) can become more susceptible to pests and disease when under stress (Sullivan, 1993). This could become a notable issue as some scientists 
suspect that increased stress associated with a changing climate could further reduce red spruce vitality (Butler et al., 2015).

\subsection{Red Spruce and Soil: Podzolization}

Spodosols are a type of soil that typically form beneath conifer or ericaceous cover through a process called podzolization (McDonald and Wood, 1984; Schaetzl and Isard, 1996; Lundstrom et al., 2000a,b; Sauer et al., 2007). This soil order is characterized by thick organic layers, a bleached E horizon, and an illuvial horizon with accumulations of amorphous soil organic matter and Al and Fe sesquioxides (a Bhs or Bs horizon) (Stanley and Ciolkosz, 1981; Lundstrom et al., 2000a; Sauer et al., 2007). These latter constituents (organic matter and Al and Fe sesquioxides) are referred to as spodic materials. Spodic materials have specific $\mathrm{pH}$, color and chemical compositions requirements (Soil Survey Staff, 1999).

Spodic materials make up spodic horizons (Soil Survey Staff, 1999). A spodic horizon must contain at least $85 \%$ spodic materials (Soil Survey Staff, 1999). Varying degrees and amounts of podzolization can occur (referred to as spodic intensity), but a spodic horizon must be present for a soil to be classified as a Spodosol. For a horizon or soil to meet the diagnostic requirements of a Spodosol, certain criteria must be met (see Table 1) (Soil Survey Staff, 1999).

Table 1. Requirements of a Spodosol (from Soil Survey Staff, 1999)

\begin{tabular}{|c|c|}
\hline \multicolumn{2}{|c|}{ A spodic horizon must have all of the following: } \\
\hline & $\begin{array}{l}\text { - } 2.5 \mathrm{~cm} \text { thick } \\
\text { - } \\
\text { - } \\
\text { - }\end{array}$ \\
\hline \multicolumn{2}{|c|}{ Spodosols must exhibit at least 1 of the following: } \\
\hline & 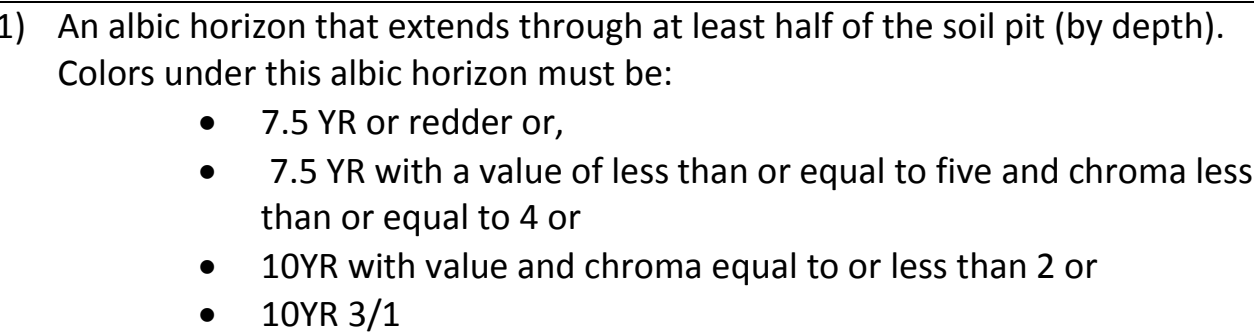 \\
\hline
\end{tabular}


2) An albic horizon, one of the colors listed above and at least one of the following:

- organic matter and aluminum cementation in at least half of the pit with firm consistency or

- $10 \%$ or more cracked coatings on sand particles or

- Al and $1 / 2$ Fe percentages (via ammonium oxalate extractions) equal to at least 0.50 with 0.25 or less in an overlying horizon or

- optical density of oxalate extract value of at least 0.25 with 0.125 or less in an overlying horizon.

The formation of Spodosols is driven by climate, organisms (biologic activity), relief/topography, parent material and time (Jenny, 1941). Spodosols typically form where the climate is cool with large amounts of precipitation, much of which occurs as snow (Lundstrom et al., 2000a). Vegetative cover consisting of ericaceous is known to be one of the biological soilforming factors of Spodosol formation, where nutrient poor, slow-to-decompose organic matter is deposited on the soil surface (Lundstrom et al., 2000a; Sauer et al., 2007). Podzolization can occur in many topographic positions, but those that retain water, such as north-facing slopes and footslopes promote Spodosol formation (Lundstrom et al., 2000a). Podzolization is further facilitated by the presence of acidic, nutrient-poor and base cation-poor parent materials (Lundstrom et al., 2000a; Sauer et al., 2007).

Although little research exists describing how long spodic characteristics persist in the soil, one study in Hungary found that these specific horizon sequences could persist for hundreds of years following climatic and ecosystem changes (Willis et al., 1997). Similarly, Fe and Al sesquioxides found in the Bhs or Bs horizon of the subsoil can persist between 150 and 250 years (Barrett and Schaetzl, 1998; Lundstrom et al., 2000b). This persistence enables the identification of historical conifer forests through examination of soil characteristics (Nauman et al., 2015). 


\subsection{Red Spruce and Microclimate}

Microclimatic variables, such as local air temperature, soil temperature, and soil moisture affect a variety of processes including soil chemical reactions (Yli-Halla and Mokma, 1998), microbial activity (Monson et al., 2005; Waldrop and Firestone, 2006), seed germination (Lindstrom et al., 1975; Anda and Pinter, 1990), and the distribution of plant species (Billings, 1952; Whittaker, 1967; Stephenson, 1990). Soil moisture, soil temperature, and air temperature often are estimated from known, larger scale climatic data (Whittaker, 1978; Zheng et al., 1993; Elias et al., 2004). However, it is local air temperature, soil temperature, and soil moisture conditions that influence conifer germination, photosynthesis, and respiration (Arris and Eagleson, 1989; Day et al., 1991; Schwarz et al., 1997), so estimates from larger scales may not be sufficiently accurate to predict reproduction and growth success.

Specific air temperature, soil temperature, and soil moisture optimums for red spruce are lacking, and most of what is in the literature is dated and was conducted to evaluate the relatively recent red spruce decline that has since been attributed to warming climate, winter injury, and acid deposition (Hamburg and Cogbill, 1988; Johnson et al., 1988; McLaughlin et al., 1987; Fincher and Alscher, 1992; Hadley et al., 1993; Strimbeck et al., 1995; Day, 1991; Dumais and Prevost, 2007). The optimal air temperature for red spruce photosynthesis has been cited as $20^{\circ} \mathrm{C}$ (Alexander, 1995); $15^{\circ} \mathrm{C}$ and $30^{\circ} \mathrm{C}$ (Schwarz et al., 1997) and $16-32^{\circ} \mathrm{C}$ (Day, 1991). Piekle, (1981) concluded that red spruce seedlings exposed to air temperatures at or above $34^{\circ} \mathrm{C}$ for extended periods of time were injured and unable to recover. Day (2000) concluded that air temperatures above $32^{\circ} \mathrm{C}$ resulted in a large decrease in photosynthesis in red spruce seedlings and samplings. This is supported by Fincher and Alscher (1992) and Vann et al. (1994) who both concluded that temperatures above $32^{\circ} \mathrm{C}$ result in permanent needle damage in both saplings and adult red spruce trees. Previous studies found that conifer gas exchange (a proxy for 
photosynthesis) decreases on days where near- or below-freezing air temperatures were reached the night before (Schwarz et al., 1997). They evaluated these relationships, but focused on photosynthesis in spring (at the beginning of the growing season) and fall (at the end of the growing season). They concluded that minimum air temperatures decreased spring and fall photosynthetic rates. Others have also noted that large temperature ranges during the winter months (quick declines or increases in air temperature) negatively impact red spruce seedlings and adults due to needle winter injury (DeyHayes et al, 1990; DeHayes, 1992; Hadley et al., 1993; Strimbeck et al., 1995; Dumais and Prevost, 2007).

Beneficial soil temperature ranges have not been determined specifically for red spruce, but other conifer species (Picea glaucua, Pinus banksiana, Pseudotsuga menziesii) require soil temperatures between $15^{\circ} \mathrm{C}$ and $27^{\circ} \mathrm{C}$ (Heninger and White, 1974). Day et al. (1991) reported decreased photosynthesis in Pinus taeda when soil temperature decreased. Schwarz et al. (1997) found that minimum soil temperatures during spring and fall significantly influenced photosynthesis and were more limiting to photosynthesis than low air temperatures (Schwarz et al., 1997). Baldwin (1934) found soil surface temperatures between 20 and $30^{\circ} \mathrm{C}$ were conducive to red spruce germination, but soil surface temperatures above $33^{\circ} \mathrm{C}$ could permanently damage red spruce seedlings.

An optimal soil moisture range has not been identified for red spruce. In a general sense, it is known that low soil moisture levels or droughty conditions are not conducive to red spruce germination, growth, or survival (Johnson et al., 1988). Greenwood et al. (2008) studied the effects that soil moisture on germination and survival of red spruce seedlings. Soil moisture was limiting below 25 percent (by volume). However, negative effects were more severe when drought-like conditions were imposed on 2- and 5-month old red spruce seedlings. Only 30 
percent of the 2-month old seedlings recovered after droughty conditions were imposed, but the seedlings that were 5 months old responded even more poorly to drought conditions; only 12 percent of them recovered following cessation of the drought stress.

\subsection{Application of Models for Red Spruce Restoration}

Modeling has become an important tool in red spruce restoration. It primarily has been used to identify locations or environmental variables (covariates) that can help identify locations where spruce restoration will be most successful. Early modeling was done using what are now considered relatively simple techniques, such as regression or logistic regression (Gaston and Garcia-Vinas, 2011). Use of species distribution models to model species distribution eventually replaced regression techniques and has increased over recent years (Gaston and Garcia-Vinas, 2011). Spatial models have become particularly useful for targeting restoration. Consequently, predictive spatial models are increasingly applied to red spruce restoration objectives (Beane et al., 2013; Nauman et al., 2015a).

Species distribution models (SDM) are used to make predictions of the distribution of a species across a landscape (Phillips et al., 2006; Pearson, 2007; Elith and Leathwick, 2009; Pearson, 2010; Elith et al., 2011; Beane et al., 2013). SDM can be used to predict the habitat of both mobile and stationary organisms based on the environmental conditions found where the species are known to exist (Elith and Leathwick, 2009; Pearson, 2010). Use of SDM also can help determine which environmental variables or conditions are important to the species of concern (Beane et al., 2013).

Two categories of SDM exist: mechanistic and correlative (Pearson, 2007; Pearson, 2010). Mechanistic SDM attempt to incorporate limiting factors to species survival into the model (e.g., the limiting soil moisture conditions for the species of concern) (Pearson, 2010). Mechanistic SDM are only useful when there is a complete understanding of plant response to 
environmental effects (Pearson, 2007; Pearson, 2010). Correlative SDM use environmental data to identify conditions that are suitable for a species of concern (e.g., growing season degree days) (Pearson, 2007; Pearson, 2010).

\subsubsection{Maximum Entropy Modeling}

Maximum entropy modeling, a type of correlative SDM, as implemented by the MaxEnt software package (Phillips et al., 2004; Phillips et al., 2006; http://www.cs.princeton.edu/ حschapire/maxent/) was selected for use in this project. This model shares attributes typical of other SDM and has been used to map animal and plant distributions at various extents in many regions (Fleishman et al., 2001; Phillips et al., 2004; Elith et al., 2006; Pearson, 2010; Phillips et al., 2004). The ability of MaxEnt to create highly competitive outputs (i.e., significantly better than what a random model would provide) from incomplete information (i.e., presence-only data), makes it a valuable species mapping tool (Hernandez et al., 2006; Pearson et al., 2007; Elith et al., 2011). MaxEnt is especially useful when a species with very specific habitat requirements is modeled (Beane et al., 2013). A general description of MaxEnt features and data requirements is provided in the following paragraphs. For more detailed mathematical and statistical descriptions of the MaxEnt model, see D'Or (2003) and Elith et al. (2011), respectively.

A key difference among SDM is the type of data they can utilize. Some SDM use presence-absence data (e.g., geographic coordinates where a species is known to be present or absent) (Pearson, 2007; Pearson, 2010). MaxEnt belongs to a group of SDM that use presenceonly data (Phillips et al., 2006; Pearson, 2007; Pearson, 2010; Elith et al., 2011; Beane et al., 2013). Presence-only data consists of locations where a species is known to occur (Phillips et al., 2004), which can be subject to sampling bias (Hastie and Fithian, 2013). This is particularly useful given the large amounts of legacy data (typically presence-only) available for use (Phillips 
et al., 2004). This approach eliminates some of the bias associated with absence data (e.g., false absences) (Phillips et al., 2004). Bias is not completely eliminated as presence-only records are predisposed to other types of bias (e.g., false presence, inconsistent survey methods, spatial autocorrelation, and clustered sampling) (Elith and Leathwick, 2009; Elith et al., 2011; Phillips et al., 2004).

MaxEnt has the capability to utilize both continuous (numerical data, such as elevation) and categorical (class data, such as geologic formation) data sets (Phillips et al., 2006; Pearson, 2007; Pearson, 2010; Elith et al., 2011; Beane et al., 2013). Typical data inputs for MaxEnt include presence data (points where the species is known to occur), as well as environmental data (referred to as features) for the area to be modeled (Pearson, 2007; Pearson, 2010). When selecting environmental data to use in MaxEnt, studies have stressed the importance of choosing environmental factors that have been proven to affect the species of interest (Pearson, 2007; Pearson, 2010). Merow et al. (2013) suggested testing environmental data for correlation and eliminating datasets that are highly correlated since model gain observed is often not worth the additional noise added to the model by using both datasets.

Continuous or categorical data types must be specified before running the model (Pearson, 2007; Pearson, 2010). Various model and output settings can be adjusted on the MaxEnt interface. MaxEnt evaluates the relationships between environmental data at the presence locations and a larger (in geographic space) sample of environmental data from the entire study area (Phillips et al., 2004; Phillips et al., 2006; Pearson, 2007; Elith and Leathwick, 2009; Pearson, 2010; Elith et al., 2011; Beane et al., 2013).

MaxEnt evaluates the relationships between environmental data at presence locations and a larger sample of environmental data from the entire study area by taking what is called a 
'background sample' across the landscape of interest. As a default, MaxEnt uses 10,000 points as a background sample (Elith et al., 2011). Each model run has the potential to select a different set of 10,000 points, so individual model outputs using the same data and settings may differ slightly. It is possible to manually set the number of background points for MaxEnt to sample (Elith et al., 2011). These points may or may not include species presence locations, but at every point all environmental data (features) are collected and analyzed (Elith et al., 2011).

Phillips and Dudik (2008) tested the effects of using the default background sample settings and user-supplied background samples on model gain using a variety of case studies with varying number of presence locations and environmental data. They also used varying amounts of background sample in order to determine how many background samples would be required for acceptable model gain. Better predictions were made when the user supplied a set of spatially-distributed, random background points rather than using the MaxEnt defaults. Model gain increased with increased number of background samples but model gain plateaued after 10,000 background samples.

MaxEnt treats all environmental variables as constraints and attempts to choose a model that meets all provided feature constraints based on provided presence data (Pearson, 2010; Beane et al., 2013). These constraints are imposed so that MaxEnt will not model outside of the environmental dataset range. For example, if air temperature is used as an environmental dataset, and the minimum and maximum air temperatures in the data are $15^{\circ} \mathrm{C}$ and $30^{\circ} \mathrm{C}$, respectively, MaxEnt will not predict species occurrence outside the observed range of the presence points (Pearson, 2007; Pearson, 2010).

Unlike other SDM, MaxEnt's raw output is continuous (values range from 0 to 1) rather than binary $(0=$ unsuitable, $1=$ suitable $)$ (Pearson, 2007; Pearson, 2010) with each cell probability 
based on how environmentally suitable it is for the species of concern (Pearson, 2007; Pearson, 2010). In other words, sites that share similarities (in terms of environmental characteristics) to the supplied presence locations have a higher probability of species occurrence (Pearson, 2010; Phillips et al., 2013). If the cumulative output type is requested in MaxEnt, each cell value is reported as a cumulative percentage of the number of cells having a value equal to or less than its value (Pearson, 2007; Pearson, 2010). If logistic output type is requested in MaxEnt, the very small probability densities in the raw results are transformed from the exponential form to the logistic form (Elith et al., 2011).

Model outputs can be interpreted differently depending on the intended use of the outputs. If the model output is to be used to focus future sampling efforts, the user will want to ensure that mapped probabilities are accurate. However, if the desired use of the model output is for restoration efforts (where a species can be reintroduced), then a model output that displays all suitable environmental areas will be useful (Pearson, 2007; Pearson, 2010).

Replication may be used during MaxEnt model development to quantify the variation in the model results (Pearson 2007; Pearson, 2010; Beane et al., 2013). The number of replicated runs and method of data selection is selected in the model settings. The types of data selection available are cross-validation, bootstrapping and subsample.

Cross-validation 'splits' data multiple times (i.e., for as many replicates (n) as specified by the MaxEnt user) (Elith et al., 2011; Merow et al., 2013). In each replicate run, a different one of the $\mathrm{n}$ data sets is reserved for model testing and the other $\mathrm{n}-1$ data sets are used to train the model (Elith et al., 2011; Merow et al., 2013). Thus, if cross-validation is used, the same point cannot be used in the test data more than once (Elith et al., 2011; Merow et al., 2013). 
Bootstrapping samples the same number of points as is specified for the background sample. Each time a bootstrap analysis is run, it randomly selects the specified number of points, placing each point back into the 'pool'(Pearson, 2007; Pearson, 2010; Beane et al., 2013); thus, the same occurrence records can be used in the test data more than one time (Pearson, 2007; Pearson, 2010). Bootstrapping used with the random seed option ensures that each replicate data set is independent (Pearson, 2007; Pearson, 2010). Using replication creates multiple model outputs, which allow means and variances for validation statistics (described below) to be presented (Pearson, 2007; Pearson, 2010).

There are a variety of options available to test MaxEnt output performance or model validity. The random test percentage option is widely used. With this setting, users can specify the amount of data they want withheld from the model to be used for model validation (Pearson et al., 2007; Pearson et al., 2010; Elith et al., 2011; Beane et al., 2013; Merow et al., 2013). Phillips et al. (2008) recommended using 60\% training data and 40\% test data, though others have used different proportions of training and test data (Elith et al., 2006; Beane et al., 2013). MaxEnt also has settings which can be selected to test variable importance. These include jackknife tests and area-under-the-curve (AUC) scores (Elith et al., 2011; Beane et al., 2013; Merow et al., 2013). When the jackknife option is selected MaxEnt analyzes how important a variable is to model gain (model improvement) alone, and when used with all other variables. This approach can help improve the model by, respectively, removing or retaining features that have limited or extensive impacts on model gain (Pearson, 2007). The results are reported as AUC scores, which can be used to evaluate the relationship between the number of presence points correctly predicted and the number of absence points incorrectly predicted. 
The AUC is derived from a receiver operating characteristic (ROC) curve, which plots sensitivity, against 1-specificity (Pearson, 2007; Pearson, 2010). This is a meaningful graph because it captures both the complexities and generalities within the model (Pearson, 2007; Pearson, 2010). The ROC curve represents the correctly predicted presences, incorrectly predicted presences, correctly predicted absences, and incorrectly predicted absences (Pearson, 2007; Pearson, 2010). A model that predicts presences and absences perfectly, displays a curve that hugs the left axis and top of the plot (Pearson, 2007; Pearson, 2010). Therefore, models which make accurate predictions have more area under the curve than models that do not (Pearson, 2007; Pearson, 2010). An AUC score of 0.5 suggests that the model performed no better than a random model, while AUC scores of $\geq 0.9$ suggest the model excelled (Pearson, 2007; Pearson, 2010; Young et al., 2011).

Once a model output has been created, its validity must be evaluated (Pearson, 2007; Pearson, 2010; Elith et al., 2011). Validity of the model is partially dependent upon desired use of the model output (Pearson, 2007; Pearson, 2010; Elith et al., 2011; Beane et al., 2013). The validity of a model output designed to help prioritize sampling efforts might have stricter requirements than a model designed to help select areas suitable for the reintroduction of a species (Pearson, 2007). There are multiple ways to test model validity. One way is to compare the model output to a set of points where species presence or absence is known. Some have attempted to validate model output using the presence locations originally supplied; however, this is not recommended because MaxEnt is prone to overfitting to known presence data (Pearson, 2007). This bias leads to an overestimation of model performance (Pearson, 2007; Pearson, 2010). Ideally an independent set of presence or presence-absence data would be used to test model validity Another option for testing model validity is to assess the proportions of 
true and false presence and absence observations given the model output (referred to as a confusion matrix) (Pearson, 2007).

Like all models, MaxEnt has both advantages and limitations. The severity of these depends largely on the overall purpose of developing the SDM. Use of specific settings in MaxEnt has not been studied enough to understand how they affect model accuracy. The lack of understanding the use of MaxEnt settings (like regularization) has led to a misuse of MaxEnt in some situations (Phillips et al., 2006; Phillips et al., 2013). MaxEnt uses constraints to ensure that the model does not predict data values outside of the supplied data range. When MaxEnt is used to extrapolate to geographic areas outside the range of the supplied data, or extrapolate to different times, constraints for those areas or times are not available. This can lead to MaxEnt predicting very large values for probability of presence (Phillips et al., 2006).

All model outputs can be described as realistic, precise, or generalized (Levins, 1966). SDM outputs also can be described in this manner (Levins, 1966; Guisan and Zimmmermann, 2000). A SDM that outputs highly precise results might be useful for designing sampling efforts for a rare species. Conversely, a SDM which generalizes well would be useful for landscapescale planning where reintroduction of a species is the goal. A SDM output that is realistic might underestimate the historic distribution of a species. Only two of the three output characteristics (realistic, precision, and generality) can be achieved for one model output (Levins, 1966). MaxEnt is typically thought to sacrifice generality for improved reality and precision (Guisan and Zimmermann, 2000; Phillips et al., 2006; Elith and Leathwick, 2009). For this reason, MaxEnt is prone to overfitting (Phillips et al., 2006; Elith and Leathwick, 2009). Overfitting can be avoided using 'regularization' (Elith et al., 2006; Phillips et al., 2006; Elith and Leathwick, 2009; Elith et al., 2011), which is the process of smoothing a model or reducing the complexity 
of a model (Elith et al., 2011). A customized regularization multiplication factor can be set in MaxEnt to increase or decrease smoothing (Elith et al., 2011).

Considerable research has been conducted in the use of MaxEnt to predict in past or future climate scenarios. While species prediction in different climate change scenarios have been conducted using MaxEnt (Cordellier and Pfenninger, 2009; Beane, 2010; Elith et al., 2011), it is known that this is based on many assumptions (Elith and Leathwick, 2009; Pearson, 2010; Phillips et al., 2013). These assumptions must be acknowledged, and there use means that definitive statements regarding the model results cannot be made (Elith et al., 2011).

Clustered known-presence locations could result in diminished accuracy of the model output (Pearson, 2010). This is especially true when studying generalized species (such as all oaks) with large distributions. When generalized species are the focus of MaxEnt modeling, if only a clustered set of presence locations are used the full suite of suitable environmental conditions are not represented in the model output (as a result of sampling bias) (Pearson, 2007; Pearson, 2010).

\subsection{Interpolation Methods for use in Modeling: Kriging and Cokriging}

Most spatial models, including MaxEnt, require environmental covariates to be in raster or surface format. Interpolation is the method by which values at unsampled locations are predicted from sampled locations (Mitas and Mitsova, 1999; Childs, 2004; Oliver and Webster, 2007; Bodnar, 2010; ESRI Geostatistical Analyst Tutorial, 2010). There are many interpolation methods available, but all are based upon the premise of spatial autocorrelation (Mitas and Mitsova, 1999; Childs, 2004; Oliver and Webster, 2007; Bodnar, 2010), which is the concept that locations closer to each other are more similar than locations farther away (Childs, 2004). Interpolation is required for the microclimate data collected for most research due to the nature of field sampling (point observations) in conjunction with proposed modeling methods that 
require gridded datasets (surfaces) (Mitas and Mitasava, 1999; Bodnar, 2010). After interpolation, each cell in a grid (surface) are assigned an estimated value based upon the values at sampled locations (Childs, 2004; Oliver and Webster, 2007; Bodnar, 2010). There are, however, known caveats and problems that exist when interpolating surfaces (Mitas and Mitasova, 1999).

Interpolation methods can generally be broken into two categories: locality based and geostatistical (Mitas and Mitasova, 1999; Childs, 2004). Locality based interpolation methods, such as inverse distance weighting are relatively simplistic (Mitas and Mitasova, 1999). Kriging and cokriging are examples of geostatistical methods and are unique because they offer measures of statistical accuracy (Mitas and Mitasova, 1999; Childs, 2004; Bodnar, 2010) that are ideal for complex landscapes. Geostatistical methods also are valuable because they produce statistical metrics, such as means, ranges and standard errors that are useful for determining the best estimated surface (Mitas and Mitasova, 1999; Bodnar, 2010).

Kriging is based upon the concepts of spatial autocorrelation (Mitas and Mitsova, 1999; Childs, 2004; Lefohn et al., 2005; Oliver and Webster, 2007; Bodnar, 2010). Kriging attempts to explain spatial variation by fitting a model to points in the dataset based on their values and the distance between the points (Mitas and Misova, 1999; Childs, 2004; Lefohn et al., 2005; Oliver and Webster, 2007; Bodnar, 2010). Cokriging also is based on the concept of spatial autocorrelation, but it uses other data to help explain spatial variation or patterns (Mitas and Mistova, 1999; Childs, 2004; Oliver and Webster, 2007; Bodnar, 2010). For cokriging to be used effectively, the explanatory data must have a relationship (i.e., be correlated) to the variable being predicted (Lefohn et al., 2005; Bodnar, 2010; ESRI Geostatistical Analyst Tutorial, 2010). 
One frequently cited drawback of kriging and cokriging is the large number and complexity of settings available for use, particularly since these often are chosen arbitrarily (Mitas and Mistova, 1999; Bodnar, 2010; Rodriguez, 2015). Exploratory spatial data analyses are available and help users assess the normality, distribution and trends present in datasets (Mitas and Mistova, 1999; Bodnar, 2010; ESRI Geostatistical Analyst Tutorial, 2010). It is imperative that users conduct exploratory spatial data analyses before kriging to better understand the data and make the best possible decisions regarding available settings (Mitas and Mistova, 1999; Bodnar, 2010; Rodriguez, 2015).

Both kriging and cokriging have been used successfully and extensively in soil modeling efforts (Odeh et al., 1995; Voltz and Webster, 1990; and Hengle et al., 2004). However, like all modeling efforts, kriging has limitations largely rooted in required assumptions (McBratney et al., 2000). Foremost, all interpolation methods assume a normal distribution of data (Mitas and Mistova, 1999; McBratney et al., 2000; Childs, 2004; Oliver and Webster, 2007), which is often violated in natural systems. Kriging and cokriging also assume stationarity (constancy over time) (McBratney et al., 2000). Finally kriging may be less successful in complex terrain (McBratney et al., 2000).

Validation of interpolated surfaces can prove challenging (Gyalistras, 2003; Daly et al., 2008). The ArcGIS Geostatistical Analyst and Wizard provide statistical metrics that can be used to assess the accuracy of the surface produced through the kriging or cokriging process (Mitas and Mitsova, 1999; Childs, 2004; Oliver and Webster, 2007; Bodnar, 2010; ESRI Geostatistical Analyst Tutorial, 2010) and to select the best possible surface modeled (Mitas and Mitsova, 1999; Childs, 2004; Oliver and Webster, 2007; Bodnar, 2010; ESRI Geostatistical Analyst 
Tutorial, 2010). These metrics include means, standardized means, root mean square errors, standardized root mean square errors and average prediction errors.

\subsection{References}

Adams, H.S., Stephenson, S.L., Rollins, A.W., Adams, M.B., 2010. The isolated red spruce communities of Virginia and West Virginia, in: Rentch, J.S., Schuler, T.M. (Eds.), Proceedings from the Conference on the Ecology and Management of High-Elevation Forests in the Central and Southern Appalachian Mountains. GTR-NRS-P-64. USDA Forest Service, Northern Research Station, Newtown Square, PA, pp. 1-12.

Alexander, J.D., Donnelly, J.R., Shane, J.B. 1995. Photosynthetic and transpirational responses of red spruce understory trees to light and temperature. Tree Physiology. 15.6: 393-398.

Allard, H.A. and E.C. Leonard. 1952. The Canaan and Stony River Valleys of West Virginia, their former magnificent spruce forests, their vegetation and floristics today. Journal of the Southern Appalachian Botanical Club. 17(1): 2-59.

Anda A. and L. Pinter. 1990. Sorghum germination and development as influenced by soil temperature and water content. Agronomy Journal. 86(4):621-624.

Arris, L.L. and P.S. Eagleson. 1989. Evidence for a physiological basis for the boreal-deciduous forest ecotone in North America.Vegetatio 82: 55-58.Baldwin, 1934

Barrett, L.R. and R.J. Schaetzl. 1998. Regressive pedogenesis following a century of deforestation: evidence for depodzolization. Soil Science Society of America Journal. 163(6): 482-497.

Beane, N.R., J.S. Rentch, and T.M. Schuler. 2013. Using maximum entropy modeling to identify and prioritize red spruce forest habitat in West Virginia. Research Paper NRS-23. Newton Square, PA: U.S. Department of Agriculture, Forest Service, Northern Research Station. 16. 
Billings, W.D. 1952. The environmental complex in relation to plant growth and distribution. Quarterly Review Biology. 27:261-265.

Bliss, M. and H.W. Vogelmann. 1982. Decline of red spruce in the green mountains of Vermont. Bulletin of the Torrey Botanical Club. 109(2): 162-168.

Bodnar, L. 2010. The use of ArcGIS geostatistical analyst exploratory spatial data analysis and an integrated regionalization of Colorado precipitation and elevation data.

Butler, P.R., L. Iverson, F.R. Thompson, L. Brandt, S. Handler, M. Janowiak, P.D. Shannon, C. Sweanston, K. Karriker, J. Bartig, S. Connolly, W. Dijak, S. Bearer, S. Blatt, A. Brandon, E. Byers, C. Coon, T. Culbreth, J. Daly, W. Dorsey, D. Ede, C. Euler, N. Gillies, D.M. Hix, C. Johnson, L. Lyte, S. Matthews, D. McCarthy, D. Minney, D. Murphy, C. O’Dea R. Orwan, M. Peters, A. Prasad, C. Randall, J. Reed, C. Sandeno., T. Schuler, L. Sneddon, B. Standley, A. Steele, S. Stout, R. Swaty, J. Teets, T. Tomon, J. Vanderhorst, J. Whatley, and N. Zegre. 2015. Central Appalachians forest ecosystem vulnerability assessment and synthesis; a report from Central Appalachians climate change response framework project. Gen. Tech. Rep. NRS-146. Newtown Square, PA: U.S. Department of Agriculture, Forest Service, Northern Research Station. 310 p.

Byers, E.A., Love, K.C. Haider, K.R., Burks, E.J., Rowan, J.E. 2013. Red spruce (Picea rubens) cover in West Virginia 2013, Version 1.0. West Virginia Division of Natural Resources, Central Appalachian Spruce Restoration Initiative, Appalachian Forest Heritage Area Americorps, Monongahela National Forest and U.S. Fish and Wildlife Service. Childs, Colin. 2004. Interpolating surfaces in ArcGIS spatial analyst. ArcUser, July-September 3235. 
Christensen, N. L., A. M. Bartuska, J. H. Brown, S. C. Carpenter, D. D’Antonio, and R. Francis. 1966. The report of the Ecological Society of America Committee on the scientific basis for ecosystem management. Ecological Applications 6(3):665-691.

Clarkson, R.B. 1964. Tumult on the mountains: Lumbering in West Virginia, 1770-1920. Parsons, WV: McClain Printing Company. 410 p.

Cordellier, M and M. Pfenninger. 2009. Inferring the past to predict the future: climate modelling predictions and phylogeography for the freshwater gastropod. Molecular Ecology. 18(3): 534-544.

Daly, C., Halbeib, M., Smith, J.I., Gibson, W.P., Doggett, M.K., Taylor, G., Curtis, J., and P.P. Pasteris. 2008. Physiographically sensitive mapping of climatological temperature and precipitation across the conterminous United States. International Journal of Climatology. 28 (15): 2031-2064.

Day, T.A., S.A. Heckathorn, and E.H. DeLucia. 1991. Limitations of photosynthesis in Pinus taeda L. (loblolly pine) at low soil temperatures. Plant Physiology. 96 (4): 1246-1254.

Day, M.E. 2000. Influence of temperature and leaf-to-air vapor pressure deficit on net photosynthesis and stomatal conductance in red spruce (Picea rubens). Tree Physiol. 20: $57-63$.

DeHayes, D.H., White, C.E., Ingle, M.A., Williams, M.W. 1990. Winter injury susceptibility and cold tolerance of current and year old of red spruce trees from several provenances. For. Sci. 36: 982-994.

DeHayes, D.H. 1992. Winter injury and developmental cold tolerance of red spruce. In C. Eagar and M.B. Adams (eds.). Ecology and decline of red spruce in the eastern United States. pp. 295-337. Ecological Studies 96, Springer-Verlag, New York. 
D’Or, D. 2003. Spatial prediction of soil properties, the Bayesian Maximum Entropy approach. PhD Dissertation. UCL. Belgium.

Dumais, D., Prevost, M. 2007. Management for red spruce conservation in Quebec: The importance of some physiological and ecological characteristics- a review. The Forestry Chronicle. 83(3): 378-391.

Elias, E.A., R. Cichota, H.H. Torriani and Q. VanLier. 2004. Analytical soil temperature model: correction for temporal variation of daily amplitude. Soil Science Society of America Journal. 68(3):784-788.

Elith, J., C.H. Graham, R.P. Anderson, M. Dudik, S. Ferrier, Al. Guisan, R.J. Hijmans, F. Huettman, J.R. Leathwick, A. Lehmann, J. Li, L.G. Lohmann, B.A. Loiselle, G. Manion, C. Moritz, M. Nakamura, Y. Nakazawa, J. Overton, A.T. Peterson, S.J. Phillips, K.S. Richardson, R. Scachetti-Pereira, R.E. Schapire, J. Soberon, S. Williams, M.S. Wisz, and N.E. Zimmermann. 2006. Novel methods improve prediction of species' distributions from occurrence data. Ecography. 29(2):129-151.

Elith, J.E. and J.R. Leathwick. 2009. Species distribution models: ecological explanation and prediction across space and time. Annual Review of Ecology, Evolution and Systematics 40(1): 677-697.

Elith, J., Phillips, S.J., Hastie, T., Dudik, M., Chee, Y.E., and C.J. Yates. 2011. A statistical explanation of MaxEnt for ecologists. Diversity and Distributions. 17(1): 43-57.

ESRI. 2010. Geostatistical analyst tutorial. http://help.arcgis.com/en/arcgisdesktop/10.0/pdf/ geostatistical-analyst-tutorial.pdf

Fincher, J., Alscher, R.G. 1992. The effect of long-term ozone exposure on injury in seedlings of red spruce (Picea rubens Sarg.) New phytologist. 120 (1): 49-59. 
Flegel, D.G. 1998. Soil Survey of Pocahontas County, West Virginia. USDA-NRCS. U.S. Gov. Print. Office, Washington, DC. 301 p.

Fleishman, E., R.M. Nally, J.P. Fay, and D.D. Murphy. 2001. Modeling and predicting species occurrence using broad scale environmental variables: An example with butterflies of the Great Basin. Conservation Biology. 15(6):1674-1685.

Greenwood, M.S., C.L. O’Brien, J.D. Shatz, C.A Diggins, M.E. Day, G.L. Jacobson, A.S. White, and R.G. Wagner. 2008. Is early life cycle success a determinant of the abundance of red spruce and balsam fir? Canadian Journal of Forest Research. 38 (8):2295-2305.

Gaston, A., and J.I. Garcia-Vinas. 2011. Modelling species distributions with penalized logistic regressions: a comparison with maximum entropy models. Ecological modelling. 222.13: 2037-2041.

Guisan, A. and N.E. Zimmermann. 2000. Predictive habitat distribution models in ecology. Ecological Modelling. 135(2):147-186.

Gyalistras, D., 2003. Development and validation of high-resolution monthly gridded temperature and precipitation data set for Switzerland. Climate Research. 25: 5583.Hadley, J.L., Amundson, R.G., Laurence, J.A.,Kohut, R.J. 1993. Red spruce bud mortality at Whiteface mountain, New York. Can. J. For. Bot. 71:827-833.

Hamburg, S.P., Cogbill, C.V. 1988. Historical decline of red spruce populations and climatic warming. Nature. 331 (6155): 428-431.

Hengl, T., Heuvelink, G.B., and A Stein. 2004. A generic framework for spatial prediction of soil variables based on regression kriging. Geoderma. 120.1: 75-93.

Heninger, R.L., and D.P. White. 1974. Tree seedling growth at different soil temperatures. Forest Science. 20 (4): 363-365. 
Hernandez, P.A., C.H. Graham, L.L. Master, and D.L. Albert. 2006. The effect of sample size and species characteristics on performance of different species distribution modeling methods. Ecography. 29(5):773-785.

Jenkins, J.C., J.D. Aber, and C.D. Canham. 1999. Hemlock woolly adelgid impacts on community structure and $\mathrm{N}$ cycling rates in eastern hemlock forests. Canadian Journal of Forest Research. 29(5): 630-645.

Jenny, H. 1941. Factors of Soil Formation. McGraw-Hill, New York. New York. 300 p.

Johnson, A.H., A.J. Friedland, and J.G. Dushoff. 1986. Recent and historic red spruce mortality: evidence of climatic influence. Water Air and Soil Pollution. 30(1):319-330.

Johnson, A.H., Cook, E.R., Siccama, T.G. 1988. Climate and red spruce growth and decline in the northern Appalachians. Proc. of the National Academy of Sciences, USA. 85: 53695373.

Kaufmann M.R., Eckard, A.N. 1977. Water potential and temperature effects on germination of Engelmann spruce and Lodgepole pine seeds. Forest Science. 23(1): 27-33.

Lefohn A.S., Knudsen, H.P., Shadwick, D.S. 2005. Using ordinary kriging to estimate the seasonal W126 and N100 24-h concentrations for the year 2000 and 2003. ASL and Associates. 111.

Lewis, R.L. 1998. Transforming the Appalachian countryside: railroads, deforestation, and social change in West Virginia, 1880-1920. University of North Carolina, Chapel Hill. 368 p.

Levins, R., 1966. The strategy of model building in population ecology. American Scientist. 54 (4): 421-431.Lin, H., 2011. Three principles of soil change and pedogenesis in time and space. Soil Sci. Soc. Am. J. 75.6, 2049-2070. 
Lindstrom, M.J., R.I. Papendick, and F.E. Koehler. 1975. A model to predict winter wheat emergence as affected by soil temperature, water potential and depth of planting. Agronomy Journal. 68 (1): 137-141.

Losche, C.K. and W.W. Beverage. 1967. Soil survey of Tucker County and part of Northern Randolph County, West Virginia. USDA. 83 p.

Lundström, U.S., N. van Breemen, and D. Bain, 2000a. The podzolization process. A review. Geoderma. 94(2): 91-107.

Lundström, U.S., N. van Breemen, D.C. Bain, P.A.W. van Hees, R. Giesler, J.P. Gustafsson, H. Ilvesniemi, E. Karltun, P.A. Melkerud, M. Olsson, G. Riise, O. Wahlberg, A. Bergelin, K. Bishop, R. Finlay, A.G. Jongmans, T. Magnusson, H. Mannerkoski, A. Nordgren, L. Nyberg, M. Starr, and L. Tau Strand. 2000b. Advances in understanding the podsolization process resulting from a multidisciplinary study of three coniferous forest soils in the Nordic Countries. Geoderma. 94(2): 335-353.

McBratney, A.B., Odeh, I.O.A., Bishop, T.F.A., Dunbar, M.S., and T.M. Shatar. 2000. An overview of pedometric techniques for use in soil survey. Geoderma. 97. 293-327.

McDowell, W.H., Wood, T., 1984. Podzolization: soil processes control dissolved organic carbon concentrations in stream water. Soil Sci. 137(1), 23-32.

McLaughlin, S.B., Downing, D.J., Blasing, T.J., Cook, E.R., and H.S. Adams. 1987. Oecologia. 72:487-501.

Merow, C., Smith, M.J., Silander, J.A., 2013. A practical guide to MaxEnt for modeling species' distributions: what it does and why inputs and settings matter. Ecogr. 36(10), 1058-1069.

Mitas, L., and H. Mitasova. 1999. Spatial interpolation: geographic information systems: principles techniques, management and applications. 1. 481-492. 
Mohlenbrock, R. 1995. Red spruce. U.S. Department of Agriculture, NRCS: Plant Materials Program.USDA NRCS. http://plants.usda.gov/factsheet/pdf/fs_piru.pdf. 2 p.

Monger, C., Rachal, D.M., 2013. Soil and landscape memory of climate change-how sensitive, how connected? Soc. Sediment. Geol. 104, 63-70.

Monson, R.K., D.L. Lipson, S.P. Burns, A.A. Turnipseed, A.C. Delany, M.W. Williams, and S.K. Schmidt. 2005. Winter forest respiration controlled by climate and microbial community composition. Nature. 439(7077): 711-714.

Murphy, L., 1917. The red spruce: its growth and management. USDA USFS Bulletin No. 544. Washington, D.C. Washington Government Printing Office. 116 p.

Nauman, T.W., J.A. Thompson, S.J. Teets, T.A. Dilliplane, J.W. Bell, S.J. Connolly, H.J. Liebermann, and K.M. Yoast. 2015a. Ghosts of the forest: mapping pedomemory to guide restoration. Geoderma 247:51-64.

Nauman, T.W., Thompson, J.A., Teets, J., Dilliplane, T., Bell, J.W., Connolly, S.J., Liebermann, H.J., K. Yoast. 2015b. Pedoecological modeling to guide forest restoration using ecological site descriptions. Soil Sci. Soc. Am. J.. 79.5, 1406-1419.

Noss, R. F., E. T. LaRoe, and J. M. Scott. 1995. Endangered ecosystems of the United States: a preliminary assessment of loss and degradation. Biological Report 28, National Biological Service, Washington, D.C. 95 p.

Odeh, I.O.A., McBratney, A.B., and D.J. Chittleborough.1995. Further results on prediction of soil properties from terrain attributes: heterotropic cokriging and regression kriging. Geoderma. 623.4: 215-226. 
Oliver, M.A., and R. Webster. 2007. Kriging a method of interpolation for geographical information systems. International Journal of Geographical Information Systems. 4(3): 313-332.

Oosting, H.J., Billings, W.D., 1951. A comparison of virgin spruce-fir forest in the northern and southern Appalachian system. Ecol. 36(1), 82-103.

Pearson, R.G. 2007. Species distribution modeling for conservation educators and practitioners. American Museum of Natural History. http://biodiversityinformatics.amnh.org. Accessed 03/01/2016.

Pearson, R.G. 2010. Species' distribution modeling for conservation educators and practitioners. Lessons in conservation 3: 54-89

Pielke, R. A. 1981. The distribution of spruce in west-central Virginia before lumbering. Castanea. 46:201-216.

Phillips, S.J., Dudik, M., and R.E. Schapire. 2004. A maximum entropy approach to species distribution modeling. IN Proceedings of the $21^{\text {st }}$ International Conference on Machine Learning. ACM Press. New York. p 655-662.

Phillips, S.J., Anderson, R.P., and R.E. Schapire. 2006. Maximum entropy modeling of species geographic distributions. Ecological Modelling. 190(3): 231-259.

Phillips, S.J., and M. Dudik. 2008. Modeling of species distributions with MaxEnt: new extensions and a comprehensive evaluation. Ecography. 31(2):161-175.

Phillips, S.J. 2013. A brief tutorial on Maxent, versions: 3.3.1. http://www.cs.princeton.edu/ schapire/maxent. 
Rentch, J.S., T.M. Schuler, M.W. Ford, and G.J. Nowacki. 2007. Red spruce stand dynamics, simulations and restoration opportunities in the central Applachians. Restoration Ecology. 15(3): 440-452.

Rodriguez, R. 2015. Interation of topographic and bathymetric digital elevation models using ArcGIS interpolation methods. Diss. University of Southern California.

Sauer, D., H. Sponagel, M. Sommer, L. Giani, J. Reinhold, and K. Stahr. 2007. Podzol: Soil of the Year 2007: A review on genesis, occurrence, and functions. Journal of Plant Nutrition and Soil Science. 170(5): 581-597.

Schaetzl, R.J., Isard, S.A., 1996. Regional-scale relationships between climate and strength of podzolization in the Great Lakes Region, North America. Catena. 28, 47-69.

Schwarz, P.A., T.J. Fahey, and T.E. Dawson. 1997. Seasonal air and soil temperature effects on photosynthesis in red spruce (Picea rubens) saplings. Tree Physiology. 17(3): 197-194.

Siccama, T.G., M. Bliss, and H.W. Vogelmann. 1982. Decline of red spruce in the Green Mountains of Vermont. Bulletin of the Torrey Botanical Club. 109 (2):162-168.

Soil Survey Staff. 1999. Soil Taxonomy: A basic system of soil classification for making and interpreting soil surveys. $2^{\text {nd }}$ edition. USDA NRCS. http://www.nrcs.usda.gov/Internet/ FSE_DOCUMENTS/nrcs142p2_051232.pdf. Accessed 01/28/2016.

Stanely, S.R., and E.J. Ciolkosz. 1981. Classification and genesis of spodosols in the central Appalachians. Soil Science Society of America Journal. 45(5):912-917.

Stephenson, N.L., 1990. Climatic controls on vegetation distribution: the role of the water balance. American Naturalist. 135(1): 649-670. 
Strimbeck, G.R., DeHayes, D.H., Shane, J.B., Hawley, G.J., Schaberg, P.G. 1995. Midwinter dehardening of montane red spruce during a natural thaw. Canadian Journal of Forest Research. 25(12): 2040-2044.

Sullivan, J. 1993. Picea rubens. U.S. Department of Agriculture, USFS. http://www.fs.fed.us/database/feis/. Accessed 02/15/2016.

Targulian, V.O. and S.V. Goryachkin. 2010. Soil Memory and Environmental Reconstructions. Eurasian Soil Science 44(4):464-465.

Vann, D.R., Johnson, A.H., Casper, B.B. 1994. Effect of elevated temperatures on carbon dioxide exchange in Picea rubens. Tree Physiol. 14:1339-1349.

Voltz, M., and R. Webster. 1990. A comparison of kriging, cubic splines and classification for predicting soil properties from sample information. European journal of soil science. 41.3: $473-490$.

Waldrop, M.P. and M.K. Firestone. 2006. Response of microbial community composition and function to soil climate change. Microbial Ecology. 52(4): 716-724.

Ward, J.S., M.E. Montgomery, C.A. Chea, B.P. Onken, and R.S. Cowles. 2004. Eastern hemlock forests: guidelines to minimize the impacts of hemlock wooly adelgid. USDA USFS. http://na.fs.fed.us/pubs/tps/eastern_hemlock/eastern_hemlock.pdf $32 \mathrm{p}$.

Whittaker, R.H., 1967. Gradient analysis of vegetation. Biol. Rev. 42(2): 207-264.

Willis, K.J., M. Braun, P. Sumegi, and A. Toth, 1997. Does soil change cause vegetation change or vice versa? A temporal perspective from Hungary. Ecology. 78(3): 740-750.

Yli-Halla, M. and D.L. Mokma. 1998. Soil temperature regimes in Finland. Agricultural and Food Science in Finland. 7(4): 507-512. 
Young, N., L. Carter, and P. A. Evangelista. 2011. A MaxEnt Model v3.3.3e Tutorial (ArcGIS v10). Colorado, USA: Natural Resource Ecology Laboratory at Colorado State University and the National Institute of Invasive Species Science.

Zheng, D., E.R. Hunt, and S.W. Running. 1993. A daily soil temperature model based on air temperature and precipitation for continental applications. Climate Research. 2(3):183191. 


\subsection{Mapping Pedomemory of Spodic Morphology Using a Species}

\section{Distribution Model}

\subsection{Abstract}

Red spruce (Picea rubens) ecosystems in the high elevations of the central Appalachians of the eastern United States are the focus of ongoing restoration efforts due to the valuable ecosystem services these forests provide. Persistent pedoecological linkages exist between historic red spruce cover and underlying soils, and recent research has shown that spodic materials still present in the soil offer evidence of the historic extent of red spruce forests. A dataset containing 221 points with varying spodic intensities and 29 environmental variables collected from a portion of the Monongahela National Forest in West Virginia, USA, was used to evaluate the utility of a species distribution model, Maximum Entropy (MaxEnt), for predicting the presence of spodic properties. Model outputs that employed three different spodic intensity class inputs - very weak to strong expression, weak to strong expression, and strong expression-resulted in similar spodic probability predictions, though there was less area mapped as transitional probabilities than the two models that included weaker spodic intensity input data. Permutation importance indicated that no one or two variables were the drivers of the model. Rather, permutation importance was distributed relatively evenly across all environmental covariates used. The environmental covariates may have been too coarse and not strongly enough associated with podzolization processes to be very important. The two models resulted in only approximately 62 percent agreement. The interest in mapping spodic expression is tied to restoration of the red spruce forest type, which currently occupies only about 10 percent of its original range in West Virginia, but serves as habitat for a number of threatened and endangered species. 


\subsection{Introduction and Background}

Soils form as the result of five interacting environmental factors: climate, organisms, relief, parent material and time (Dokuchaev, 1999; Jenny, 1941). The concept of using environmental factors to predict soil characteristics is accepted and provides the basis for traditional soil mapping and contemporary digital soil mapping (McBratney et al., 2003; Boettinger, et al., 2010). Nauman et al. (2015a,b) demonstrated that the inverse also may be possible; that is, current soil properties might be useful for predicting previous environmental conditions because certain soil characteristics can persist even after some environmental factors change — a concept termed pedomemory (Targuilian and Goryachkin, 2010; Lin, 2011; Monger and Rachal, 2013; Nauman et al., 2015a,b).

In the central Appalachians of the eastern United States, red spruce (Picea rubens) ecosystems and the Spodosols that form beneath them serve as a prime example of the pedomemory concept (Nauman et al., 2015a,b). Historically, red spruce was the dominant forest type at high elevations in the central Appalachians (Clarkson, 1964; Lewis, 1998; Adams et al., 2010) and is estimated to have occupied 242,811 ha in West Virginia alone (Rentch et al., 2007). From 1880 to 1930 , extensive logging and subsequent wildfires eliminated red spruce from much of the landscape (Clarkson, 1964; Lewis, 1998). Disturbed areas typically regenerated to mixed hardwood ecosystems (Clarkson, 1964; Lewis, 1998). Today red spruce ecosystems (defined as forests with at least $15 \%$ red spruce) are estimated to occupy only $10 \%$ of their historic range in West Virginia, or approximately 24,000 ha (Adams et al., 2010).

Spodosols form through the process of podzolization (Schaetzl and Isard, 1996;

Lundstrom et al., 2000a,b; Sauer, et al., 2007). In central Appalachia, podzolization is largely driven by three factors: organisms (conifer vegetation) climate (cool, moist) and parent material (base-poor geologies) (Oosting and Billings, 1951; Stanley and Ciolkosz, 1981). However, in 
some instances spodic materials can degrade, a process referred to as depodzolization (Barrett and Schaetzl, 1998). Consequently, the degree to which spodic characteristics are expressed (i.e., spodic intensity) depends upon the state and pathways of progressive or regressive pedogenesis (Barret and Schaetzl 1998). The time required for depodzolization is variable and ultimately depends upon site-specific environmental characteristics (Barret and Schatezl, 1998), but it has been shown to require as few as 30 and as many as 200 years (Hole, 1975; Nornberg et al., 1993).

Based on the knowledge that both podzolization and depodzolization are soil forming processes, some assumptions regarding spodic properties and historic red spruce cover in central Appalachia can be made. First, if spodic soil properties are observed today, one can reasonably assume that red spruce was present at that site in the past. Conversely, if spodic soil properties are not present at a site today, one cannot assume that red spruce was not historically present due to the potential for depodzolization.

This paper describes the results of pedomemory modeling using MaxEnt, which uses presence-only data (i.e., locations where spodic properties are present and observed). The first objective of this study was to determine how employing three different spodic intensity ranges affects the mapped extent of Spodosols using MaxEnt, which is a presence-only species distribution model. The second objective of this study was to compare model outputs of spodic intensity obtained from MaxEnt to those obtained by Nauman et al. (2015a) using a random forests model that employed both presence and absence data for the same area.

The dataset we employed was the same one used by Nauman et al. (2015a), except that the absence data were excluded for the MaxEnt analyses. Studies have documented the potential negative effects of including absence data, mainly due to the possibility of including of 'false 
absences' (locations incorrectly found to be absent of attribute of interest) in the model (Svenning and Skov, 2004; Jimenez-Valverde et al., 2008). The inclusion of absence data may introduce confusion in the random forests model due to the potential for depodzolization (Nauman et al., 2015a,b); in other words, the random forests model treats locations where spodic properties were not observed as if they are true absence locations (i.e., they do not have and never had spodic properties). A presence-only modeling approach may be a better tool for identifying the extent of spodic soils. By excluding absence data, this approach avoids the assumption that the lack of current spodic soil properties means podzolization never occurred at that location. In turn, a presence-only model eliminates the opportunity for false absences (locations where spodic morphology is not currently present, but was present historically). Consequently, the resulting mapped extent of spodic properties may be more representative of the 'fundamental niche' (Phillips et al., 2006) of spodic properties, which represents all places on a landscape which are conducive to Spodosol formation (and, therefore, likely within the historic extent of red spruce forests).

\subsection{Materials and Methods}

\subsubsection{Study Area}

This study involves approximately 124,687 ha of the Monongahela National Forest (MNF) in eastern West Virginia, USA (Fig. 1). It includes areas underlain by Chemung Group, Hampshire Formation (Devonian-age acidic shales and siltstones), and Pottsville Formation (Pennsylvanian-age acid sandstone) geologies (West Virginia Geological and Economic Survey, 1968). The majority of the MNF has a moist climate (1184-1524 mm of precipitation per year) with cool mean annual temperatures (ranging from 6- $8^{\circ} \mathrm{C}$ ) (NOAA-NCDC, 2016). Much of the area considered in this study is among the wettest and coolest in the MNF and West Virginia. The elevation ranges from approximately 800 to $1300 \mathrm{~m}$; associated soil temperature regimes 
span the bounds between mesic and frigid soil temperatures (Stanley and Ciolkosz, 1981; Lietzke and McGuire, 1987), with the colder soil temperatures generally present at higher elevations. On the MNF, such areas are typically transition zones between areas dominated by mixed hardwood species (Acer rubrum, A. pennsylvanicum, Prunus serotina, and Fagus grandifolia) and those dominated by red spruce and hemlock (Tsuga canadensis) (Shigo, 1972; Nauman et al., 2015a).

The presence-only data (i.e., spodic presence) for this study are part of a dataset collected from 2010-2012 in an effort to understand the extent of podzolization across the MNF (Nauman, 2015). Point observations were collected from soil pits and soil transects across a variety of geology types and soil series (Dekalb, Berks, Mandy and Wildell), and under varying forest compositions (sub-dominant red spruce, co-dominant red spruce, and dominant red spruce forests). A total of 332 point observations obtained from Nauman (2015) were compiled (Fig. 2). Spodic intensities were assigned at the time of soil sampling to each of the 332 points using the spodic-intensity scale developed by the USDA-NRCS, which has discrete values ranging from 0 to 2 (Table 1) (Nauman et al., 2015a). Spodic properties occur in varying intensities (Schaetzl and Isard, 1996; Lundstrom et al., 2000a,b; Nauman et al., 2015a) depending on the degree of influence of each environmental factor at the specific location. Spodic properties include a lighter colored $\mathrm{E}$ horizon and subsoil accumulations of aluminum and iron sesquioxides that are darker and redder in color (Soil Survey Staff, 2003). A spodic intensity of 0 indicates that the soil has no spodic properties, while a spodic intensity of 2 indicates the soil has the strongest spodic expression.

\subsection{MaxEnt Modeling Approach and Settings}

MaxEnt requires two sets of data: presence-only data (in this case, point locations where spodic soil properties were observed) and environmental variables believed to be important for the attribute of interest (Pearson, 2007, 2010). Environmental variables can be continuous (e.g., 
elevation) or categorical (e.g., geologic formations), although MaxEnt works best when the number of categorical variables is limited (Pearson, 2007, 2010). The 332 data points originally compiled included locations spanning the entire range of spodic intensities (Table 2). The MaxEnt model required locations that had evidence (i.e., presence) of podzolization, so only locations with a spodic intensity of at least 0.5 were utilized in this study. Consequently, 221 presence points were included. These data were further assembled into three presence-only data sets for use in MaxEnt based on three spodic intensity ranges: 0.5-2.0, 1.0-2.0, and 2.0 (Table 2).

Environmental variables believed to be important to the development of spodic soil properties and presence of red spruce were used to generate the background sample (a userspecified number of samples taken from all possible locations considered to be equally likely to be a presence locality) in the MaxEnt models (Merow et al., 2013b). To allow comparison to the result from Nauman et al. (2015a), we employed 29 of the same 32 environmental variables, derived from digital elevation models and Landsat Geocover data (Table 3). The three calculated ratios of Landsat Geocover data used by Nauman et al. (2015a) were excluded because their use resulted in too much missing data due to division by zero.

Coefficients of correlation (r) were calculated among all 29 variables and, as expected, many showed high correlation (which we defined as $r>0.80$ or $<-0.80$ ). Undesired outcomes, such as increased model complexity and decreased confidence in interpretations, may result when correlated variables are used in MaxEnt (Baldwin, 2009; Phillips, 2005). Therefore, model runs using all 29 variables first were compared to runs without correlated variables to determine how model gain was affected by including and excluding the correlated variables. Area under the curve (AUC) (i.e., under the receiver operating characteristic (ROC) curve) values (Beane et al., 2013; Elith et al., 2011; Merow et al., 2013a), described later, revealed the two types of runs 
resulted in only minor differences in AUC values (measures of model performance). Because the differences were minor and one of our objectives was to compare MaxEnt and the random forests results obtained by Nauman et al. (2015a), which employed the correlated variables, all 29 of the variables were utilized in the MaxEnt model runs described herein.

MaxEnt has numerous model settings that influence the outputs. For most settings, the model defaults were utilized in all runs (Pearson, 2007, 2010). Only those settings for which the defaults were not utilized are discussed further (Table 4).

MaxEnt has three methods of replication (used to quantify the variation in model results), bootstrapping was used in this analysis. Bootstrapping selects the user-specified number of points from the environmental variables across the study area to create the background sample. For each bootstrap analysis the background sample is randomly selected from the selected environmental variables, and then each point is returned back to the sample pool (Beane et al., 2013; Pearson, 2007, 2010) so the same record may be included in more than one replicate run (Pearson, 2007, 2010). We also used the random seed option in bootstrapping to ensure that each replicate data set was independent from all others (Pearson, 2007, 2010). Prior to running the replications, bootstrapping also randomly withholds a percentage of the available presence-only data to test model validation, and these random test data are not included in the replicate runs. We used 40 percent of data as random test data because this a percentage commonly used in MaxEnt modeling (Beane et al., 2013; Elith et al., 2006; Phillips et al., 2008). The random test percentage of 40 percent equates to 89,80 and 35 withheld test sample sizes, respectively, for spodic intensity classes $0.5-2.0,1.0-2.0$ and 2 . Ten replicates for each spodic intensity range were run. 
MaxEnt has three output types: raw and two transformed outputs derived from the raw data (Merow et al., 2013a; Pearson, 2007, 2010). For this analysis, logistic output, one of the transformed outputs, was used because it is useful for comparing model results (Merow et al., 2013a) and both study objectives involve comparisons of model runs. Some explanation of logistic outputs is warranted for understanding the results described later; a more detailed explanation of the logistic and other outputs is provided in Merow et al. (2013a).

As noted, the logistic output is a transformation of the raw output. For the raw output, MaxEnt initially assumes that all cells in the study area are equally likely to contain the species or attribute of interest, so the initial probability value for each cell is calculated by the inverse of the total number of cells. For this analysis, there are approximately 1.6 million cells, so the probability of spodic presence for each cell in the study area would have be approximately 1/1.6 million. Probabilities of each cell then are adjusted based upon environmental variable values at presence-only locations and the background sample such that the sum of the final probabilities for all cells in the raw output must sum to 1 . Consequently, the cells in a raw output are not independent from one another. The transformation applied to the raw data for obtaining the logistic output amplifies higher probabilities while linearly scaling lower probability values. Therefore, the cell probability values for logistic output also are not independent, but they do not sum to 1 (Merow et al., 2013a).

\subsection{Model Comparison Techniques}

Comparison of spatial maps and modeling outputs often is necessary — and indeed was needed for this study, but no widely accepted protocols exist for such comparisons (Kuhnert et al., 2005; Visser and Nijs, 2005). Consequently, we used a combination of model-generated statistics, visual assessment, and model comparison tools for this paper (Kuhnert et al., 2005; Visser and Nijs, 2005). 
To address the first study objective of comparing the MaxEnt model outputs of the three different spodic intensities, the three possible two-way comparisons were examined (i.e., 0.5-2.0 vs. $1.0-2.0,1.0-2.0$ vs. 2.0 , and $0.5-2.0$ vs. 2.0 ). However, because the probability data are continuous, and model agreement would result only for cells in which the probabilities were exactly equal (an almost impossible result), a more useful and interpretable procedure was used. Frequency distributions of the average probabilities were developed for each of the spodic intensity class model outputs. All three had similar distributions and there was a break in the distributions at the 0.6 probability level. Using that break, the MaxEnt modeled outputs were converted to binary outputs, where cells $\geq 0.6$ and $<0.6$ were assigned unique integer values and compared mathematically.

The AUC value was used to assess MaxEnt model performance. This value is the area underneath a ROC curve (Beane et al., 2013; Elith et al., 2011; Merow et al., 2013a; Pearson, 2007, 2010) (Fig. 3). A ROC curve is a plot of true positive vs. false positive rates (Pearson, 2007, 2010). The curve is a plot of sensitivity (number of presences correctly predicted) versus 1 specificity (number of absences incorrectly predicted) (Pearson, 2007, 2010). An AUC value of 0.5 suggests that the model performed no better than a random model, while an AUC value of $>0.9$ suggests the model excelled (Pearson, 2007, 2010; Young et al., 2011).

The importance of environmental variables was evaluated using permutation importance, normalized to percentages. The larger the permutation importance value, the more influence that variable has on the model outcome, particularly when it is followed by a marked decline in the permutation importance value for the next most important permutation value (in descending order) (Kalle et al., 2013). Permutation importance is not influenced by the paths that MaxEnt uses to generate the individual runs and final results (Phillips, 2006). 
To evaluate the second objective of this paper, the MaxEnt model results were compared to the Nauman et al. (2015a) random forests model results. Because the random forests model employed presence and absence data (i.e., the entire 0-2.0 spodic intensity range), only the MaxEnt model results using the most similar spodic intensity range (0.5-2.0) was employed in the comparison (i.e., 0 spodic intensity observations were not used because MaxEnt is a presence-only model). This comparison presents some challenges due to the inherent differences between the two models. Recall that cell values are not independent for MaxEnt, which often results in many cells with small predicted probability values (Merow et al., 2013b). By contrast, random forests output for each run is binary - after the model runs, each cell within the project area is classified as spodic or non-spodic. The cell probabilities reported by Nauman et al. (2015a) were based on the outcomes of 100 replicate runs: the value of each cell is equal to the number of times out of 100 that the cell was predicted to be spodic. For example, a cell with a value of 0.80 , was classified as spodic (having some level of spodic expression) in 80 out of 100 model runs. Consequently, in random forests output, each cell is independent of all other cells (Nauman et al., 2015a).

Due to the differences between MaxEnt and random forests, we focused on the general rank of cells for comparing the two model outputs. An agreement/disagreement analysis, similar to that for the three MaxEnt comparisons described previously, was performed. In this case the upper $40 \%$ of cells (in terms of predicted probability) were considered to be high probability (of spodic presence), and lower $60 \%$ of cells were considered low probability.

We also were interested in examining the environmental conditions present at locations where both models agreed (predicted high probability of spodic presence) and disagreement (low probability of spodic presence) to get some idea of model drivers, as well as the degree of 
overlap in the environmental covariates where the models did not agree. Because the data were not normally distributed, the nonparametric Wilcoxon rank-sum test was used for the latter analysis to determine if environmental conditions were significantly different between the two models where their outcomes disagreed.

\subsection{Results}

\subsubsection{MaxEnt Comparisons}

The modeled outputs for each of the three spodic intensity classes are shown in Figure 4. Note that each of these maps shows the averaged probability of occurrence from 10 replicate runs for the modeled spodic intensity class, not the probability of intensity of spodic expression (except for the model for spodic intensity class 2.0 since it is developed from only the most wellexpressed spodic samples). In other words, red and orange cells in Figure 4A indicate a high probability that some degree of spodic expression are present because the $0.5-2.0$ range includes the entire range of spodic intensity expression from very weak to strong (Table 1). By comparison, red and orange cells in figure 4B indicate a high probability of the presence of weak to strong spodic intensities since the 1.0-2.0 class data are employed.

The distributions of all the MaxEnt probability data are heavily tailed, and follow a second order decay function. This is due to the fact that in a MaxEnt output cells are not independent (Merow et al., 2013b). Approximately 80 percent of the cells have probability of presence values $\leq 0.2$ for all three models (Fig. 5). Because no cells are modeled as 0 probability in MaxEnt, probability values between the smallest value and 0.01 were used to approximate 0 probability. Using that approach, 25, 24, and 30 percent of the entire area had approximately 0 probability of presence for the $0.5-2.0,1.0-2.0$, and 2.0 spodic intensity class models, respectively. Those areas are concentrated primarily in the four corners of the area, particularly in the northwest and southeast corners (Fig. 4). 
Mean AUC values for the outputs of three spodic intensity classes $(0.5-2.0,1.0-2.0,2.0)$ were identical at $0.96(96 \%)$, and the standard deviations were all quite small, respectively, 0.003, 0.003, and 0.007. That the largest standard deviation was associated with the spodic intensity 2.0 class is not surprising given that it contained less than half the number of presence points than the other two classes (Table 2). Overall, the high AUC values and low standard deviations indicate excellent model performance (Pearson, 2007, 2010).

The results of the binary agreement/disagreement analysis of the MaxEnt model outputs indicate very high agreement (98-99 percent) among the three MaxEnt models (Table 5). The greatest amount of disagreement (cells predicted by one model as high probability, and predicted by another model as low probability) occurred for the spodic intensity class comparison of 0.5 2.0 vs. 2.0, which was due at least in part to those two models, respectively, having the greatest and fewest numbers of initial presence points (Table 2). However, it should be noted that only a small number of the cells had probabilities $\geq 0.6$ (Table 6 ), so the agreement/disagreement results are reflective of only a small percentage of the entire area that was originally modeled in Figure 4.

Interestingly, there are fewer cells with $\geq 0.6$ probability in the $1.0-2.0$ spodic intensity class than in the 2.0 spodic intensity class (or the 0.5 to 2.0 class) (Table 6), even though the 2.0 class had less than half the number of original presence sites than the 1.0-2.0 class (Table 2). This result suggests that for the original data there was a much narrower range of conditions for the environmental covariates for the 1.0 and 1.5 spodic intensity classes than for the 2.0 class, or the covariates were most strongly associated with the strongest spodic characteristics (i.e., the 2.0 intensity class model). There were marked drops in permutation importance values in the 1.02.0 and 2.0 models, such that that there were three variables for each of those two models that 
were more important than the other environmental covariates (Table 7). For the 0.5-2.0 class model, all the permutation importance values were relatively small and there were no distinct breaks across the 29 environmental variables (Table 7). Rather, according to the permutation importance metric, all covariates had similarly important influence. In all three models, an elevation-associated covariate was most important; dem for 0.5-2.0 and 1.0-2.0, and baselevel for 2.0. This is not surprising given that spodic characteristics are primarily associated with red spruce in this region, and red spruce is known to compete best at high elevations (Rentch et al., 2007; Adams et al., 2010)

\subsubsection{MaxEnt and Random Forests Output Comparisons}

The MaxEnt and random forests outputs are shown in Figure 6. The highest probabilities in random forests output are distributed relatively evenly over the entire study area, compared to MaxEnt, which as noted previously, are primarily concentrated in the area where most of the original soil samples were collected. This is likely due to MaxEnt's tendency to overfit to the supplied presence-only data (Pearson, 2007). The agreement/disagreement comparison of $40 \%$ highest probability cells for the MaxEnt and random forests output showed approximately $62 \%$ agreement and 38\% disagreement between the models (Table 8). Much of the concentration of cells where the models disagreed were again in the corners of the study area (Fig. 7).

The mean, minimum, and maximum values for each of the environmental covariates for the top 40 percent of highest probabilities of spodic occurrence in which there was agreement between the MaxEnt and random forests model are shown in Table 9. The same statistics are presented for each model for the top 40 percent of cells in which they did not agree in Table 10. The Wilcoxon rank sum test indicate that there was a significant difference $(p<0.0001)$ between the two models for every covariate. 


\subsection{Discussion}

All three of the MaxEnt models yielded relatively similar estimates of spodic expression. The environmental covariates had only minor influence on contributing to the spodic intensity class MaxEnt models. The highest permutation importance value was $15.6 \%$ for the spodic intensity 1.0-2.0 class model. This is a fairly low value compared to permutation importance values typically obtained for many of the more traditional species distribution applications described in the literature (e.g., Adhikari et al., 2012; Brambilla and Ficetol, 2012; Smart et al., 2012). It is likely that the environmental covariates are too coarse and not sufficiently uniquely related to conditions that favor podzolization. Comparison of the permutation importance values for the spodic intensity 2.0 class to the $0.5-2.0$ class values provide support for this conclusion. The decreases in permutation importance values for the 2.0 intensity class (i.e., that included only strong spodic expression) had three variables (baselevel, relht50, and mir) that were useful for model prediction (Table 7). By contrast, based on the low permutation importance values and especially the lack of marked drop between any of the values for the 0.5-2.0 class (Table 7), none of the environmental variables were particularly revealing of Spodosol presence. This latter class included observations that spanned the entire range of spodic expression (very weak to strong), so for an important covariate to be identified it would have to be uniquely associated with Spodosol formation or presence, including weak expression, while simultaneously not associated with locations where spodic expression is absent.

The highest probabilities for all three of the MaxEnt outputs (Fig. 4) tend to be concentrated near the locations of the original model input presence points (Fig. 2). Farther from those points, such as toward the northwest and southeastern corners of the areas, the probabilities were predominantly approximately 0 . This is likely due to the fact that these areas have the lowest elevations. These latter areas also correspond to much of the area where the two models 
disagreed and random forests predicted a high probability of presence (Fig. 7). MaxEnt is known to be constrained by sampling bias, so it performs poorly when predicting outside of the range of conditions from which the original presence data were collected (Elith et al., 2011; Hernandez et al., 2011; Kramer-Schadt et al., 2013). Consequently, it follows that even if environmental conditions in those locations were conducive to spodic presence, no observations were made there, so the full range of conditions that promote spodic presence were not sampled, limiting the modeled probability of presence of red spruce in those areas.

One visually apparent difference in the MaxEnt modeled outputs between the spodic intensity class that contained only a single rating (2.0) and the other two classes that included ranges of spodic intensities is the amount of area mapped as transitional areas (i.e., yellow shades) (Fig. 4). The output for the single spodic rating 2.0 (Fig. 4C) has very little transitional area; instead red shades tend to transition directly to green shades. By comparison, the $0.5-2.0$ and 1.0-2.0 modeled outputs have substantially more area in those transitional yellow shades (Figs. 4a and 4b). The frequency distributions of the three models (Fig. 5) show this response more quantitatively - the number of cells in the 2.0 class for the low probabilities $(\leq 0.1)$ are greater than the other two classes, and there are more cells for the mid-range values (i.e., yellows) of the 2.0 intensity class than for the two other classes.

Presence-only modeling approaches are known to have drawbacks for species distribution modeling compared to models in which both presence and absence data are employed (Elith et al., 2006; Hastie and Fithian, 2013; Phillips et al., 2009). However, MaxEnt was used in this study because it was believed to be advantageous due to the exclusion of potential false absences (areas that historically had spodic properties but have since undergone depodzolization). Even though metrics for both MaxEnt output generated here and random forests output generated by 
Nauman et al. (2015a) indicated good to excellent model performance for predicting spodic expression, there was still substantial amount of area in disagreement between the two models.

Where the high probability cells for the two model were in disagreement, all of the values of the environmental covariates were significantly different between models. The analysis was performed on ranks rather than the actual values, which is why there is a substantial amount of overlap in the range of individual covariate values for the two models even though there are differences for every covariate (Table 10). In terms of magnitude, the contributing area (contribare) was the environmental variable that was most different for cells that were not in agreement between the two models. The mean and maximum contributing area (in $\left.\mathrm{m}^{2}\right)$ for MaxEnt cells were both a magnitude smaller than the mean and maximum contributing areas for random forests (Table 10). Coupled with the higher dem mean and maximum values for MaxEnt (Table 10), these results suggest that when the two models do not agree, MaxEnt tends to predict the highest probabilities for spodic characteristics occur higher up in watersheds. Another striking difference between the two models for high probability predictions pertains to slope aspect. The mean values for eastness, nwness, southness, and neness from MaxEnt were associated with the opposing aspect than that for random forests, as denoted by the opposite signs of each between models (Table 10).

The two models clearly resulted in different extent and location of spodic presence, and which most accurately describes current presence cannot be determined without field verification. However, a primary research need is to understand where podzolization could possibly occur in today's climate and biogeochemical conditions to inform red spruce restoration—-specifically, to identify landscape locations that have the greatest potential for successful expansion of red spruce. There are many reason for encouraging its expansion; in 
addition to providing greater forest diversity and highly-valued recreational opportunities, this forest type is intimately tied to and essential for the survival of threatened and endangered wildlife species (Dillard et al., 2008; Menzel and Ford, 2004; Pauley, 2008).

The potential for depodzolization creates more difficulty for modeling spodic potential than many typical modeling applications in which presence of a specific modeled feature or attribute can be verified by field validation. As such, success in modeling spodic potential, and thus, conditions conducive to red spruce survival, may require the use of environmental variables that include fine-scale microclimate metrics as these may be more discerning for identifying conditions associated with spodic formation, and for differentiating between weak spodic presence and spodic absence. Inclusion of microclimate variables may yield models that are more robust and effective at predicting the occurrence of Spodosols. In addition, rather than relying solely on physical attributes, other local biological or chemical soil characteristics may be more robust and effective for informing MaxEnt about spodic prediction. It should be noted that although there are many known drivers of podzolization (parent material, vegetation, microbiological activity, climate), there is no consensus regarding which of these drivers is the primary pathway (Lundstrom et al., 2000a,b). Spodic properties are found in a variety of environments, and consequently the model covariates are likely regionally dependent. Given that Spodosols are considered to have among the most distinct ecological niches of all soil orders, if covariates cannot be identified at a scale useful for explaining spodic presence or covariate data are not easily obtainable, it is unlikely that modeling will be effective in the foreseeable future for other less distinctive types of soils, such as Ultisols or Inceptisols.

\subsection{Conclusion}

The probability of occurrence of spodic expression was modeled in a portion of the Monongahela National Forest, in eastern West Virginia using the presence-only species 
distribution model MaxEnt. Three different spodic intensity classes were modeled, but the results were relatively similar. However, the model employing only the strongest spodic intensity values tended to have more abrupt transitions between cells with high probability of occurrence and those with low probability compared to the models that employed wider ranges of spodic intensity.

Individually, the 29 environmental covariates did not contribute substantially to any of the MaxEnt the modeled outputs, though the two models that excluded the very weak spodic intensity class distinguish a few variables with some influence. Most of these were related in one way or another to elevation, which was expected because podzolization in this region is associated historically with red spruce presence, and red spruce is primarily found at high elevations.

The MaxEnt output determined from the widest spodic intensity class was compared to results from random forests, which employed presence and absence data from the same data set. Outputs using the 40 percent of cells with the highest probability of occurrence from both models were compared. Approximately 60 percent of those cells were in agreement between the two models. Areas of disagreement were primarily concentrated in areas that were located far from the original soil sampling points, and these areas also corresponded to locations where MaxEnt did not predict a high probability of presence whereas random forests did predict a high probability.

Covariates probably were not unique enough to the conditions that control spodic formation, which may have caused the prediction of low probabilities with distance from the original soil sampling locations. However, variables that control podzolization are not well defined in the literature, which increases the difficulty in such modeling. It is possible that more 
important environmental variables might include site-specific biological and chemical soil characteristics, rather than just coarse physical characteristics alone. The overall interest in predicting spodic potential is to apply this information to identify areas for red spruce restoration. Because this forest type is highly valued for many reasons, including as providing habitat for several threatened and endangered species, further investigation into model improvement will likely continue.

\section{Acknowledgements and Disclaimer}

I would like to acknowledge the Monongahela National Forest for their support of this research and the NRCS for providing soils data from the study area. The use of trade or firm names in this publication is for reader information and does not imply endorsement by the U.S. Department of Agriculture of any product or service.

\subsection{References}

Adams, H.S., Stephenson, S.L., Rollins, A.W., Adams, M.B., 2010. The isolated red spruce communities of Virginia and West Virginia, in: Rentch, J.S., Schuler, T.M. (Eds.), Proceedings from the Conference on the Ecology and Management of High-Elevation Forests in the Central and Southern Appalachian Mountains. GTR-NRS-P-64. USDA Forest Service, Northern Research Station, Newtown Square, PA, pp. 1-12.

Adhikari, D., Barik, S.K., Upadhaya, K., 2012. Habitat distribution modeling for reintroduction of Ilex khasiana Purk., a critically endangered tree species for northeastern India. Ecol. Eng. 40, 37-43

Baldwin, R.A., 2009. Use of Maximum entropy modeling in wildlife research. Entropy. 11.4, 854-866.

Barrett, L.R., Schaetzl, R.J., 1998. Regressive pedogenesis following a century of deforestation: evidence for depodzolization. Soil Sci. 163 (6), 482-497. 
Beane, N.R., Rentch, J.S., Schuler, T.M., 2013. Using maximum entropy modeling to identify and prioritize red spruce forest habitat in West Virginia. RP-NRS-23. USDA Forest Service, Northern Research Station, Newtown Square, PA.

Boettinger, J.L., Howell, D.W., Moore, A.C., Hartemink, A.E., Kienast-Brown, S., 2010. Current state of digital soil mapping and what is next, in: Hartemink, A.E., McBratney, A.B. (Eds.), Progress in Soil Science, Digital Soil Mapping: Bridging Research, Environmental Application And Operation. Springer, New York, pp 4-10.

Brambilla, M., Ficetola, G.F., 2012. Species distribution models as a tool to estimate reproductive parameters: a case study with a passerine bird species. J. Anim. Ecol. 81, $781-787$.

Byers, E.A., Love, K.C., Haider, K.R., Burks, E.J., Rowan, J.E., 2013. Red spruce (Picea rubens) cover in West Virginia 2013, Version 1.0. West Virginia Division of Natural Resources, Central Appalachian Spruce Restoration Initiative, Appalachian Forest Heritage Area Americorps, Monongahela National Forest, and US Fish and Wildlife Service. http://wvgis.wvu.edu/data/dataset.php?ID=455. Accessed 04/03/2017.

Clarkson, R.B. 1964. Tumult on the Mountains: Lumbering in West Virginia, 1770-1920. McClain Printing Co., Parsons, WV.

Dillard, L.O., Russell, K.R., Ford, W.M., 2008. Macrohabitat models of occurrence for the threatened cheat mountain salamander, Plethodon nettingi. Appl. Herpetol. 5(3), 201224.

Dokuchaev, V.V., 1999. On the concept of natural zones - St. Petersburg, 1899. Eur. Soil Sci. $32,726-727$. 
Elith, J., Graham, C.H., Anderson, R.P., Dudik, M., Ferrier, S., Guisan, A., Hijmans, R.J., Huettmann, F., Leathwick, J.R., Lehmann, A., Li, J., Lohmann, L.G., Loiselle, B.A., Manion, G., Moritz, C., Nakamura, M., Nakazawa, Y., Overton, J.McC., Peterson, A.T., Phillips, S.J., Richardson, K.S., Scachetti-Pereira, R., Schapire, R.E., Soberon, J., Williams, S., Wisz, M.S., Zimmermann, N. E., 2006. Novel methods improve prediction of species' distributions from occurrence data. Ecogr. 29, 129-151.

Elith, J., Phillips, S.J., Hastie, T., Dudik, M., Chee, Y.E., Yates, C.J., 2011. A statistical explanation of MaxEnt for ecologists. Divers. and Distrib. 17(1), 43-57.

Hastie, T., Fithian, W., 2013. Inference form presence-only data; the ongoing controversy. Ecogr. 36, 864-867.

Hatfield, D.C. 1996. TopoTools - a collection of topographic modeling tools for ArcINFO: slope position. US Forest Service, ESRI.

Hernandez, P.A., Graham, C.H., Master, L.L., Albert, D.L., 2006. The effect of sample size and species characteristics on performance of different species distribution modeling methods. Ecogr. 29(5), 773-785.

Hole, F.D., 1975. Some relationships between forest vegetation and podzol B horizons in soils of Menominee tribal lands, Wisconsin, USA. Sov. Soil Sci. 7, 714-723.

Jenny, H., 1941. Factors of Soil Formation. McGraw-Hill, New York.

Jimenez-Valverde, A., Lobo, J.M., Hortal, J., 2008. Not as good as they seem: the importance of concepts in species distribution modeling. Divers. and Distrib.. 14, 1372-1381.

Kalle, R., Ramesh, T., Qureshi, Q., Sankar, K., 2013. Predicting the distribution pattern of small carnivores in response to environmental factors in the western Ghats. PLoS ONE 8(11), e79295. doi:10.1371/journal.pone.0079295 
Kramer-Schadt, S., Niedballa, J., Pilgrim, J.D., Schroder, B., Lindenborn, J., Reinfelder, V., Stillfried, M., Heckmann, I., Scharf, A.K., Augeri, D.M., Cheyne, Sm>, Hearn, A.J., Ross, J., Macdonald, D.W., Mathai, J., Eaton, J., Marshall, a.J., Semiadi, G., Rustam, R., Bernard, H., Alfred, R., Samejima, H., Duckworth, J.W., Breitenmoser-Wuersten C., Belant, J.L., Hofer, H., Wilting, A., 2013. The importance of correcting for sampling bias in MaxEnt species distribution models. Biodivers. Res. 19, 1366-1379.

Kuhnert, M., Voinov, A., Seppelt, R., 2005. Comparing raster map comparison algorithms for spatial modeling and analysis. Photogramm. Eng. and Remote Sens. 71, 975-894.

Lietzke, D.A., McGuire, G.A., 1987. Characterization and classification of soils with spodic morphology in the southern Appalachians. Soil Sci. Soc. Am. J. 51, 165-170.

Lin, H., 2011. Three principles of soil change and pedogenesis in time and space. Soil Sci. Soc. Am. J. 75.6, 2049-2070.

Lewis, R.L., 1998. Transforming the Appalachian Countryside: Railroads, Deforestation, and Social Change in West Virginia, 1880-1920. University of North Carolina, Chapel Hill, NC.

Lundström, U.S., van Breemen, N., Bain, D., 2000a. The podzolization process. a review. Geoderma 94, 91-107.

Lundström, U.S., van Breemen, N., Bain, D.C., van Hees, P.A.W., Giesler, R., Gustafsson, J.P., Ilvesniemi, H., Karltun, E., Melkerud, P.A., Olsson, M., Riise, G.,Wahlberg, O., Bergelin, A., Bishop, K., Finlay, R., Jongmans, A.G.,Magnusson, T., Mannerkoski, H., Nordgren, A., Nyberg, L., Starr, M., Tau Strand, L., 2000b. Advances in understanding the podsolization process resulting from a multidisciplinary study of three coniferous forest soils in the Nordic Countries. Geoderma 94, 335-353. 
McBratney, A.B., Santos Mendoca, M.L., Minasny, B., 2003. On digital soil mapping. Geoderma. 117, 3-52.

McDowell, W.H., Wood, T., 1984. Podzolization: soil processes control dissolved organic carbon concentrations in stream water. Soil Sci. 137(1), 23-32.

Menzel, J.M., Ford, W.M., 2004. Nest tree use by the endangered Virginia northern flying squirrel in the central Appalachian Mountains. Am. Midl. Nat. 151(2), 355-368.

Merow, C., Smith, M.J., Silander, J.A., 2013a. A practical guide to MaxEnt for modeling species' distributions: what it does and why inputs and settings matter. Ecogr. 36(10), 1058-1069.

Merow, C., Smith, M.J., Silander, J.A., 2013b. A practical guide to MaxEnt for modeling species' distributions: what it does and why inputs and settings matter. Appendix ECOG07872, Appendix 1-6. http://ww.oikosoffice.lu.se/appendix. Accessed 04/03/2017.

Monger, C., Rachal, D.M., 2013. Soil and landscape memory of climate change- how sensitive, how connected? Soc. Sediment. Geol. 104, 63-70.

Nauman , T.W., 2015. Spatializing the soil-ecological factorial: data driven integrated land management tools. PhD Diss. West Virginia University, Morgantown, WV.

Nauman, T.W., Thompson, J.A., Teets, S.J., Dilliplane, T.A., Bell, J.W., Connolly, S.J., Liebermann, H.J., Yoast, K.M., 2015a. Ghosts of the forest: mapping pedomemory to guide restoration. Geoderma. 247, 51-64.

Nauman, T.W., Thompson, J.A., Teets, J., Dilliplane, T., Bell, J.W., Connolly, S.J., Liebermann, H.J., K. Yoast. 2015b. Pedoecological modeling to guide forest restoration using ecological site descriptions. Soil Sci. Soc. Am. Jo.. 79.5, 1406-1419. 
NOAA NCDC, 2016. Northeast regional climate center. https://www.ncdc.noaa.gov/climateinformation/regional. Accessed 12/05/2016.

Nornberg, P., Sloth, L., Neilson, K.E., 1993. Rapid changes of sandy soils caused by vegetation changes. Can. J. Soil Sci. 73(4), 459-468.

Oosting, H.J., Billings, W.D., 1951. A comparison of virgin spruce-fir forest in the northern and southern Appalachian system. Ecol. 36(1), 82-103.

Pauley, T.K., 2008. The Appalachian inferno: historical causes for the disjunct distribution of plethodon nettingi (Cheat Mountain Salamander). Northeast. Nat. 15(4), 595-606.

Pearson, R.G., 2007. Species' distribution modeling for conservation educators and practitioners. American Museum of Natural History, New York.

Pearson, R.G., 2010. Species' distribution modeling for conservation educators and practitioners. Lessons Conserv. 3, 54-89.

Phillips, S.J., 2006. A brief tutorial on Maxent. AT\&T Research. https://www.cs.princeton.edu/ sschapire/maxent/tutorial/tutorial.doc. Accessed 04/03/2017.

Phillips, S.J., Anderson, R.P., Schapire, R.E., 2006. Maximum entropy modeling of species geographic distributions. Ecol. Model. 190, 231-259.

Phillips, S.J., Dudik, M., 2008. Modeling of species distributions with MaxEnt: new extensions and a comprehensive evaluation. Ecogr. 31(2), 161-175

Phillips, S.J., Dudik, M., Elith, J., Graham, C.H., Lehmann, A., Leathwick, J., Ferrier, S., 2009. Sample selection bias and presence-only distribution models: implications for background and pseudo-absence data. Ecol. Appl. 19(1, 181-197. 
Rentch, J.S., Schuler, T.M., Ford, M.W., Nowacki, G.J., 2007. Red spruce stand dynamics, simulations and restoration opportunities in the central Appalachians. Restor. Ecol. 15(3), 440-452.

Sauer, D., Sponagel, H., Sommer, M., Giani, L., Jahn, R., Strahr, K., 2007. Podzol: soil of the year 2007. A review on its genesis, occurrence and functions. J. Plant Nutr. Soil Sci. 170, $581-597$.

Schaetzl, R.J., Isard, S.A., 1996. Regional-scale relationships between climate and strength of podzolization in the Great Lakes Region, North America. Catena. 28, 47-69.

Shigo, A.L., 1972. The beech bark disease today in the northeastern US. J. For. 70, 286-289. Schoeneberger, P.J., Wysocki,D.A., Benham, E.C., Soil Survey Staff., 2012. Field Book for Describing and Sampling Soils, Version 3.0. Natural Resources Conservation Service, National Soil Survey Center, Lincoln, NE.

Smart, L.S., Swenson, J.J., Christensen, N.L., Sexton, J.O., 2012. Three-dimensional characterization of pine forest type and red-cockaded woodpecker habitat by smallfootprint, discrete-return lidar. For. Ecol. Manag. 281, 100-110.

Soil Survey Staff, 2003. Soil Taxonomy - A Basis System of Soil Classification for Making and Interpreting Soil Surveys. US Government Printing Office, Washington, DC.

Stanley, S.R., Ciolkosz, E.J., 1981. Classification and genesis of Spodosols in the central Appalachians. Soil Sci. Soc. Am. J. 45, 912-917.

Svenning, J.C., Skov, F., 2004. Limited filling of the potential range in European tree species. Ecol. Lett. 7, 565-573.

Targulian, V.O., Goryachkin, S.V., 2010. Soil memory and environmental reconstructions. Eurasian Soil Sci. 44(4), 464-465. 
Visser, H., de Nijs, T., 2005. The map comparison kit. Environ. Model. Softw. 21.3, 346-358.

West Virginia Geological and Economic Survey, 1968. Surface geology - rock units. Digitized map. http://wvgis.wvu.edu/. Accessed 04/03/2017.

Young, N., Carter, L., Evangelista, P., 2011. A MaxEnt model v3.3.3e tutorial (ArcGIS v10). Natural Resource Ecology Laboratory, Colorado State University. http://ibis.colostate.edu/webcontent/ws/coloradoview/tutorialsdownloads/a_maxent_mod el_v7.pdf. Accessed 04/03/2017. 


\subsection{Tables and Figures}

Table 1. Spodic intensity classes and respective characteristics (adapted from Nauman et al., 2015a)

\begin{tabular}{lll}
\hline Rating & Level of Podzolization & \multicolumn{1}{c}{ Soil Properties Associated with Podzolization } \\
\hline $0.0 \quad$ No evidence & Not applicable \\
& Only slight physical evidence of podsolization; \\
& slightly redder hue and higher value is present at the \\
& top of the B horizon, but the hue is less than one \\
& Munsell hue redder than an underlying horizon; soil is \\
& non-smeary* \\
& Weak expression of podzolization; spodic \\
& materials are present, but do not meet the criteria for a \\
& spodic horizon; a weakly expressed Bs horizon is \\
& present, and is one Munsell hue redder than an \\
& underlying horizon. Bhs material is usually absent; no \\
& albic E horizon; spodic materials are \\
& sometimes weakly smeary \\
& Moderate expression of podzolization; spodic \\
& materials present as a spodic horizon; moderately \\
& expressed Bs horizon present, often with pockets of \\
& Bhs material; no albic E horizon; spodic materials are \\
& often weakly smeary
\end{tabular}




\begin{tabular}{clc}
\hline Rating & Level of Podzolization & Soil Properties Associated with Podzolization \\
\hline 2.0 & Strong, Spodosol & Strong expression of podzolization; spodic horizon is \\
& present usually underlying an albic E horizon; Bhs or \\
& Bh horizon is continuous across at least 85 \\
& percent of the pedon; spodic materials are often \\
& moderately smeary. \\
\hline
\end{tabular}

* See Schoeneberger et al., 2012 page 2-65 for a description of this metric.

** Spodic integrades are soils that may have some spodic properties or materials but do not fully meet the requirements of a Spodosol (Soil Survey Staff, 2003). 
Table 2.. Number of samples by spodic intensity (left), and number of samples by MaxEnt modeling classes. Points with a spodic intensity of 0.0 represent spodic absences, so they were not used for MaxEnt modeling because it employs presence-only data.

\begin{tabular}{cccr}
\hline Spodic Intensity & $\begin{array}{c}\text { Number of } \\
\text { Observations }\end{array}$ & Class & Number in Class \\
\hline 0.0 & 111 & $0.5-2.0$ & 221 \\
0.5 & 22 & $1.0-2.0$ & 88 \\
1.0 & 103 & 2.0 & \\
1.5 & 8 & & \\
2.0 & 88 & & \\
\hline
\end{tabular}


Table 3. Digital elevation model-derived and Landsat Geocover environmental variables used to map spodic properties in MaxEnt (taken from Nauman et al., 2015b).

\begin{tabular}{|c|c|}
\hline Variable Name & Description \\
\hline & National Elevation Dataset (27.5 m resolution) \\
\hline nwness & Index from 1 to -1 of how northwest (1) or southeast (-1) a site faces \\
\hline eastness & Index from 1 to -1 of how east (1) or west $(-1)$ a site faces \\
\hline southness & Index from 1 to -1 of how south (1) or north (-1) a site faces \\
\hline neness & Index from 1 to -1 of how northeast (1) or southwest (-1) a site faces \\
\hline dem & Elevation in meters \\
\hline plan_curv & Curvature perpendicular to the slope direction \\
\hline prof_curv & Curvature parallel to slope direction \\
\hline 1s_factor & Slope-length factor from USLE as calculated in SAGA GIS \\
\hline convergence & Overall measure of concavity \\
\hline slopepos & $\begin{array}{l}\text { Index from } 0 \text { (valley floor) to } 100 \text { (ridgetop) of slope position } \\
\text { (Hatfield, 1996) }\end{array}$ \\
\hline slope & Slope gradient (rise/run) in fraction units \\
\hline mrrtf & Multiple resolution ridgetop flatness index \\
\hline mrvbf & Multiple resolution valley bottom flatness index \\
\hline twi & Topographic wetness index \\
\hline aacn2 & Altitude above local stream channel \\
\hline baselevel & Elevation of nearest channel point to each cell in its given watershed \\
\hline contribarea & Upstream contributing area \\
\hline relht1 & Height of cell above the local minimum elevation in 1-cell radius \\
\hline relht2 & Height of cell above the local minimum elevation in 2-cell radius \\
\hline
\end{tabular}




\begin{tabular}{|c|c|}
\hline Variable Name & Description \\
\hline \multicolumn{2}{|r|}{ National Elevation Dataset (27.5 m resolution) } \\
\hline relht3 & Height of cell above the local minimum elevation in 3-cell radius \\
\hline relh_5 & Height of cell above the local minimum elevation in 5-cell radius \\
\hline relht10 & Height of cell above the local minimum elevation in 10 -cell radius \\
\hline relht 20 & Height of cell above the local minimum elevation in 20 -cell radius \\
\hline relht30 & Height of cell above the local minimum elevation in 30 -cell radius \\
\hline relht50 & Height of cell above the local minimum elevation in 50-cell radius \\
\hline relht70 & Height of cell above the local minimum elevation in 70 -cell radius \\
\hline \multicolumn{2}{|c|}{ Landsat Geocover 2000 (14.5-m resolution, resampled to $27.5 \mathrm{~m})$} \\
\hline NIR & Near infrared band in 8-bit digital number units \\
\hline MIR & Middle infrared band in 8-bit digital number units \\
\hline Green & Green visible band in 8-bit digital number units \\
\hline
\end{tabular}


Table 4. MaxEnt settings used in this analysis and the justification for the setting choice. Model defaults were used for settings not listed in this table.

\begin{tabular}{|c|c|c|c|}
\hline Setting & Setting utilized & Justification & References \\
\hline Output Format & Logistic & $\begin{array}{l}\text { Recommended for } \\
\text { comparing models }\end{array}$ & (Merow et al., 2013a) \\
\hline Replication Type & Bootstrapping & $\begin{array}{l}\text { Bootstrapping samples } \\
\text { with replacement; } \\
\text { commonly used in the } \\
\text { literature }\end{array}$ & $\begin{array}{l}\text { (Elith et al., 2011; } \\
\text { Merow et al., 2013a) }\end{array}$ \\
\hline Random Test & $40 \%$ & Commonly used in & (Phillips, 2005; \\
\hline Percentage & & MaxEnt analyses & $\begin{array}{l}\text { Phillips and Dudik, } \\
\text { 2008) }\end{array}$ \\
\hline Replicates & 10 & $\begin{array}{l}\text { Chosen due to } \\
\text { computing restraints }\end{array}$ & $\begin{array}{l}\text { (Merow et al., 2013a; } \\
\text { Pearson, 2010) }\end{array}$ \\
\hline
\end{tabular}


Table 5. Percentages of agreement and disagreement probability of presence for the pairwise comparisons produced by the three spodic intensity classes (0.5-2.0, 1.0-2.0 and 2.0) using MaxEnt.

\section{Pairwise Comparisons}

Modeled Probability of Presence $\quad 0.5-2.0$ vs. $1.0-2.0 \quad 1.0-2.0$ vs $2.0 \quad 0.5-2.0$ vs 2.0

(Agreement or Disagreement)

$\%$ Agreement or Disagreement

Both models predict low probability or

both models predict high probability

(Agreement)

One model predicts high probability,

0.65

1.04

1.24

one model predicts low probability

(Disagreement) 
Table 6. Number of cells and percent of cells (or area) in the high probability $(\geq 0.60)$ and low probability $(<0.6)$ classes for the MaxEnt models for each spodic intensity class.

Probability range Spodic intensity range

\begin{tabular}{lll}
\hline $0.5-2.0$ & $1.0-2.0$ & 2.0
\end{tabular}

number of cells

Less than 60

$1,601,664$

$1,605,569$

$1,601,847$

Greater than or equal to 60

13,623

9,718

13,440

percent of cells

Less than 60

99.16

99.40

99.17

Greater than or equal to 60

0.84

0.60

0.83 
Table 7. Permutation importance values for each of the 29 environmental covariates for the three MaxEnt spodic intensity class outputs. Variable definitions are provided in Table 3.

\begin{tabular}{|c|c|c|c|c|c|}
\hline \multicolumn{6}{|c|}{ Spodic intensity range } \\
\hline \multicolumn{2}{|c|}{$0.5-2.0$} & \multicolumn{2}{|c|}{$1.0-2.0$} & \multicolumn{2}{|c|}{2.0} \\
\hline Variable & Permutation & Variable & Permutation & Variable & Permutation \\
\hline & Importance & & Importance & & Importance \\
\hline dem & 9.4 & dem & 15.6 & baselevel & 13.2 \\
\hline relht70 & 7.7 & mrvbf & 8.8 & relht50 & 12.9 \\
\hline slpos & 6.6 & relht70 & 8.3 & mir & 11.2 \\
\hline baselevel & 5.5 & relht 20 & 4.5 & eastness & 5.4 \\
\hline mir & 5.2 & baselevel & 4.4 & southness & 5.1 \\
\hline relht 20 & 5.1 & green & 3.8 & nwness & 4.9 \\
\hline relht 1 & 4.6 & relht5 & 3.8 & relht70 & 4.9 \\
\hline lsfactor & 4.5 & eastness & 3.6 & mrvbf & 3.3 \\
\hline relht50 & 4.4 & nwness & 3.5 & green & 3.2 \\
\hline eastness & 4.3 & $\operatorname{mir}$ & 3.5 & slope2 & 3.0 \\
\hline nir & 3.9 & nir & 3.2 & relht5 & 3.0 \\
\hline green & 3.4 & slpos & 3.2 & contribare & 2.8 \\
\hline relht5 & 3.2 & relht10 & 2.8 & neness & 2.7 \\
\hline nwness & 3.1 & mrrtf & 2.8 & relht3 & 2.6 \\
\hline mrvbf & 3.1 & relht50 & 2.7 & relht1 & 2.5 \\
\hline relht 10 & 2.5 & relht3 & 2.6 & $\operatorname{aacn} 2$ & 2.5 \\
\hline slope2 & 2.5 & $\operatorname{aacn} 2$ & 2.6 & relht 20 & 2.4 \\
\hline
\end{tabular}




\begin{tabular}{rrrrrr}
\hline aacn2 & 2.4 & relht30 & 2.2 & relht2 & 2.2 \\
plan_curv & 2.3 & southness & 2.2 & relht30 & 2.2 \\
southness & 2.3 & convergenc & 2.2 & slpos & 2.1 \\
convergenc & 2.1 & relht1 & 2.0 & relht10 & 2.1 \\
relht3 & 1.8 & plan_curv & 1.9 & dem & 1.5 \\
relht30 & 1.7 & prof_curv & 1.8 & mrrtf & 1.1 \\
mrrtf & 1.7 & relht2 & 1.8 & plan_curv & 0.9 \\
contribare & 1.6 & slope2 & 1.6 & prof_curv & 0.7 \\
twi & 1.5 & contribare & 1.4 & convergenc & 0.5 \\
prof_curv & 1.3 & lsfactor & 1.4 & nir & 0.4 \\
neness & 1.1 & neness & 1.0 & lsfactor & 0.4 \\
relht2 & 1.0 & twi & 0.7 & twi & 0.3 \\
\hline & & & & &
\end{tabular}


Table 8. Percentages of agreement and disagreement probability of presence for the MaxEntrandom forests comparison.

\begin{tabular}{rcc}
\hline & Agreement & Disagreement \\
\hline \% Agreement & 61.85 & 38.15 \\
\# of Cells & 403,901 & 249,152 \\
\hline
\end{tabular}


Table 9. Mean, minimum, and maximum environmental variable values for the top 40 percent of highest probability cells where MaxEnt and random forests models were in agreement.

\begin{tabular}{|c|c|c|c|}
\hline Variable & Mean & Minimum & Maximum \\
\hline aacn2 & 64.56 & 0 & 463.18 \\
\hline baselevel & 998.22 & 633.88 & 1263.65 \\
\hline contribare & 5515 & 772 & 29312400 \\
\hline convergenc & 3.87 & -61.21 & 93.73 \\
\hline dem & 1062.78 & 645.22 & 1461.23 \\
\hline eastness & -0.49 & -1.00 & 1.00 \\
\hline green & 43.44 & 0 & 247.30 \\
\hline lsfactor & 3.74 & 0 & 17.81 \\
\hline mir & 56.20 & 0 & 255.00 \\
\hline mrrtf & 0.11 & 0 & 3.90 \\
\hline mrvbf & 0.05 & 0 & 3.96 \\
\hline neness & -0.21 & -1.00 & 1.00 \\
\hline nir & 134.61 & 0 & 255.00 \\
\hline nwness & 0.48 & -1.00 & 1.00 \\
\hline plan_curv & 0.00055 & -0.0055 & 0.0082 \\
\hline prof_curv & 0.00007 & -0.0088 & 0.0085 \\
\hline relht1 & 6.75 & 0 & 24.56 \\
\hline relht10 & 53.68 & 0 & 165.69 \\
\hline relht2 & 13.33 & 0 & 45.86 \\
\hline relht20 & 77.38 & 0 & 275.95 \\
\hline relht3 & 20.51 & 0 & 70.22 \\
\hline
\end{tabular}




\begin{tabular}{lccc}
\hline Variable & Mean & Minimum & Maximum \\
\hline relht30 & 93.12 & 0.17 & 360.40 \\
relht5 & 32.84 & 0 & 94.59 \\
relht50 & 116.26 & 0.96 & 491.42 \\
relht70 & 135.74 & 0.96 & 576.65 \\
slope2 & 0.248 & 0.000 & 0.759 \\
slpos & 50.04 & 0 & 102.00 \\
southness & -0.20 & -1.00 & 1.00 \\
twi & 5.77 & 3.18 & 21.82 \\
\hline
\end{tabular}


Table 10. Mean, minimum, and maximum environmental variable values for the top 40 percent of highest probability cells where MaxEnt and random forests models did not agree. All means were significantly different, with Wilcoxon rank-sum test probability values $<0.0001$.

$$
\text { MaxEnt Random Forests }
$$

\begin{tabular}{|c|c|c|c|c|c|c|}
\hline Variable & Mean & Minimum & Maximum & Mean & Minimum & Maximum \\
\hline aacn2 & 65.33 & 0 & 409.02 & 100.23 & 0 & 463.89 \\
\hline baselevel & 993.85 & 633.45 & 1265.19 & 903.76 & 616.07 & 1224.17 \\
\hline contribare & 14380 & 772 & 65630600 & 130037 & 772 & 177626000 \\
\hline convergenc & 2.02 & -99.41 & 97.37 & 2.07 & -90.71 & 96.04 \\
\hline dem & 1059.18 & 646.94 & 1465.21 & 1003.99 & 616.07 & 1458.14 \\
\hline eastness & 0.28 & -1.00 & 1.00 & -0.59 & -1.00 & 1.00 \\
\hline green & 55.41 & 0 & 255.00 & 59.34 & 0 & 255.00 \\
\hline 1sfactor & 4.19 & 0 & 18.59 & 3.71 & 0 & 23.09 \\
\hline mir & 79.00 & 0 & 255.00 & 71.17 & 0 & 255.00 \\
\hline mrrtf & 0.12 & 0 & 4.60 & 0.12 & 0 & 4.16 \\
\hline mrvbf & 0.07 & 0 & 3.98 & 0.18 & 0 & 4.98 \\
\hline neness & 0.11 & -1.00 & 1.00 & -0.25 & -1.00 & 1.00 \\
\hline nir & 153.86 & 0 & 255.00 & 141.65 & 0 & 255.00 \\
\hline nwness & -0.29 & -1.00 & 1.00 & 0.59 & -1.00 & 1.00 \\
\hline plan_curv & 0.00 & -0.01 & 0.01 & 0.00040 & -0.01 & 0.01 \\
\hline prof_curv & 0.00 & -0.01 & 0.01 & -0.00001 & -0.01 & 0.01 \\
\hline relht1 & 7.01 & 0 & 28.86 & 6.27 & 0 & 28.13 \\
\hline relht10 & 51.59 & 0 & 160.91 & 62.47 & 0 & 198.02 \\
\hline relht2 & 13.53 & 0 & 50.05 & 12.47 & 0 & 47.15 \\
\hline
\end{tabular}




\begin{tabular}{|c|c|c|c|c|c|c|}
\hline \multirow[b]{2}{*}{ Variable } & \multicolumn{3}{|c|}{ MaxEnt } & \multicolumn{3}{|c|}{ Random Forests } \\
\hline & Mean & Minimum & Maximum & Mean & Minimum & Maximum \\
\hline relht20 & 75.35 & 0 & 263.75 & 106.41 & 0 & 335.43 \\
\hline relht3 & 20.50 & 0 & 66.52 & 19.66 & 0 & 66.28 \\
\hline relht 30 & 91.62 & 0 & 358.32 & 135.89 & 0 & 431.26 \\
\hline relht5 & 32.04 & 0 & 101.19 & 33.29 & 0 & 98.31 \\
\hline relht50 & 114.58 & 0 & 492.49 & 173.77 & 0 & 502.49 \\
\hline relht70 & 132.80 & 0 & 578.24 & 196.40 & 0 & 574.64 \\
\hline slope2 & 0.264 & 0.000 & 0.751 & 0.234 & 0.000 & 0.815 \\
\hline slpos & 49.72 & 0 & 103.00 & 51.04 & -1.00 & 102.00 \\
\hline southness & 0.13 & -1.00 & 1.00 & -0.24 & -1.00 & 1.00 \\
\hline twi & 5.93 & 3.31 & 21.33 & 6.26 & 0 & 22.78 \\
\hline
\end{tabular}



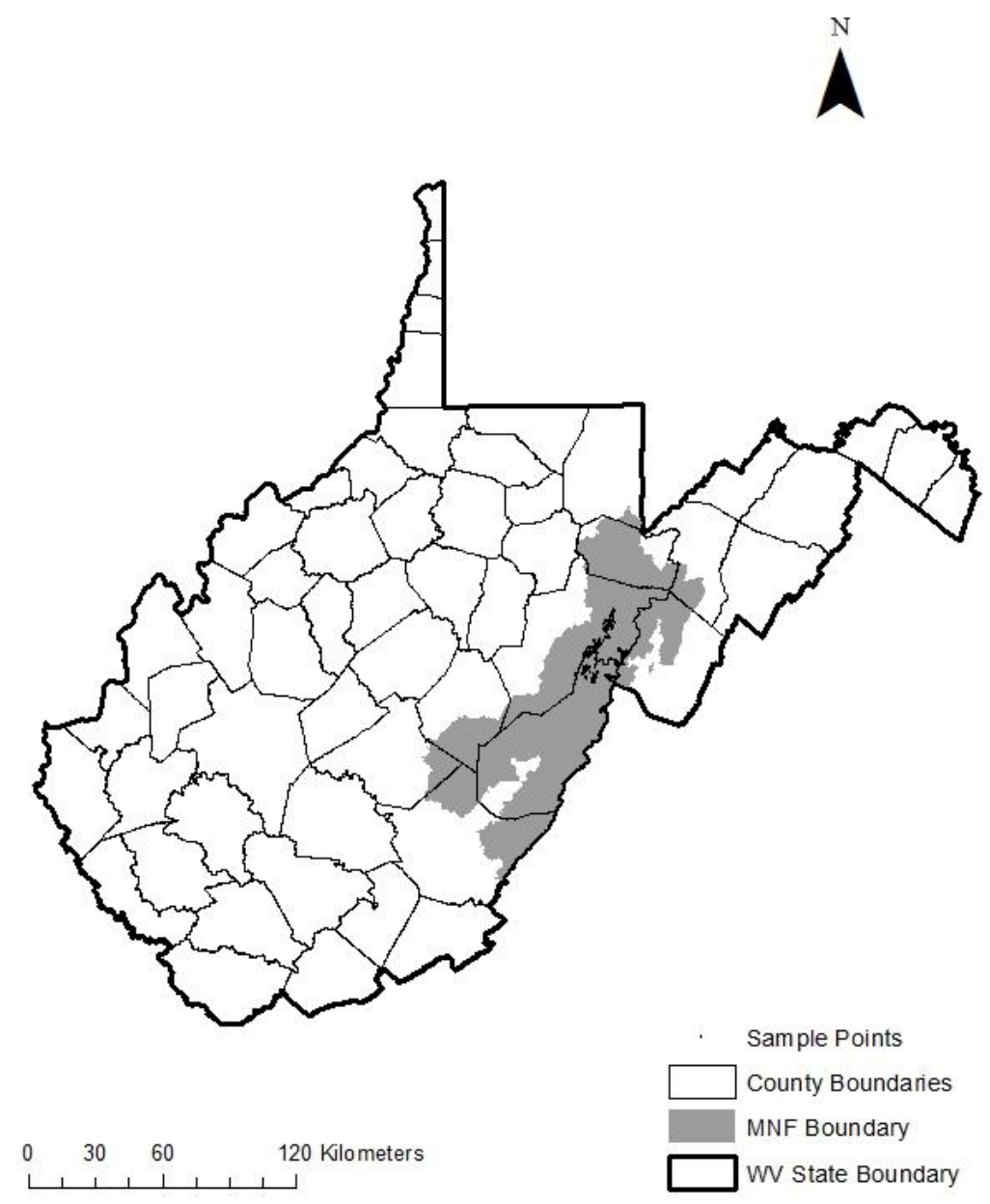

Figure 1. Location of sample points across the Monongahela National Forest in eastern West Virginia. 


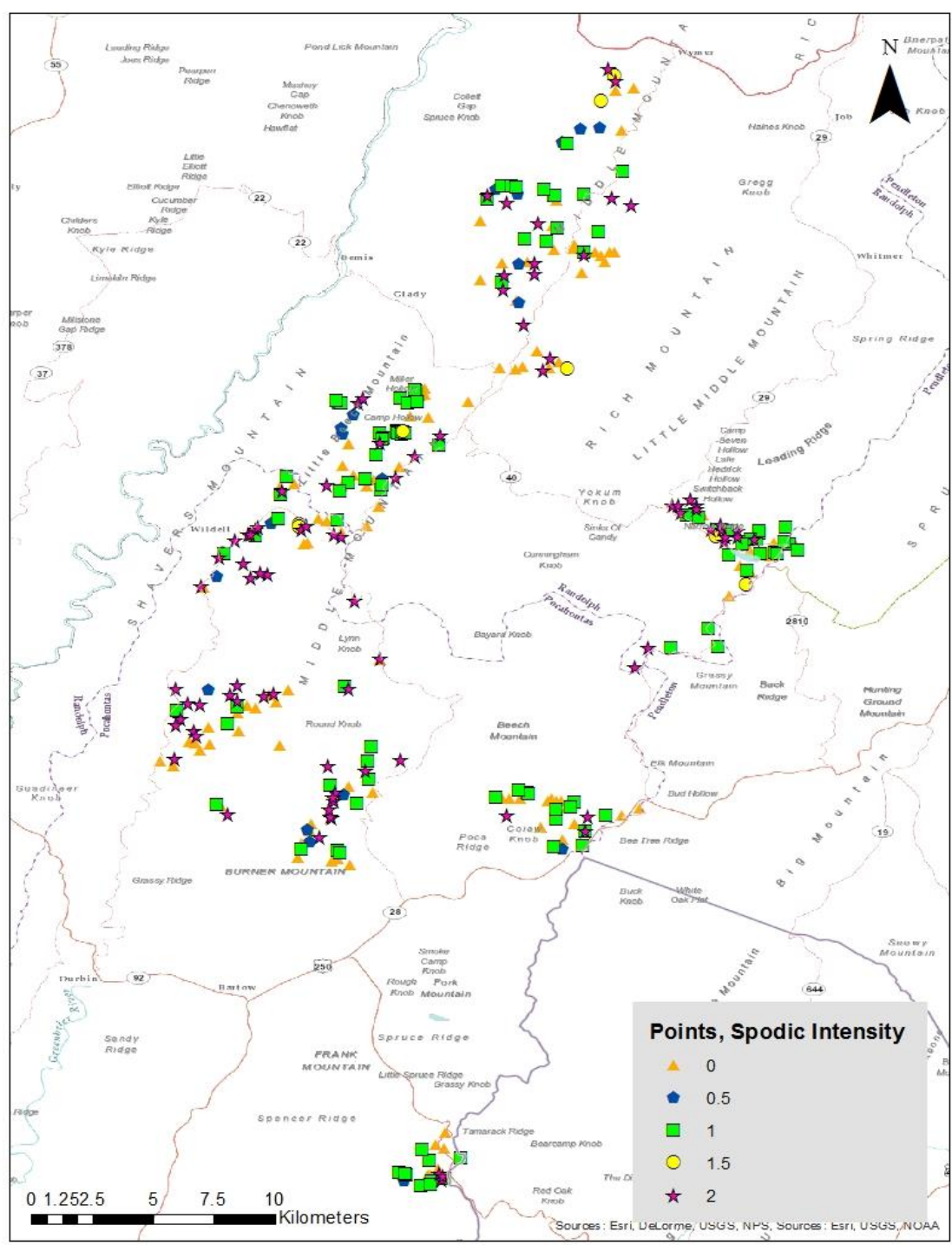

Figure 2. Soil sampling and description points within the study area. Symbols denote the spodic intensity recorded at each point. 


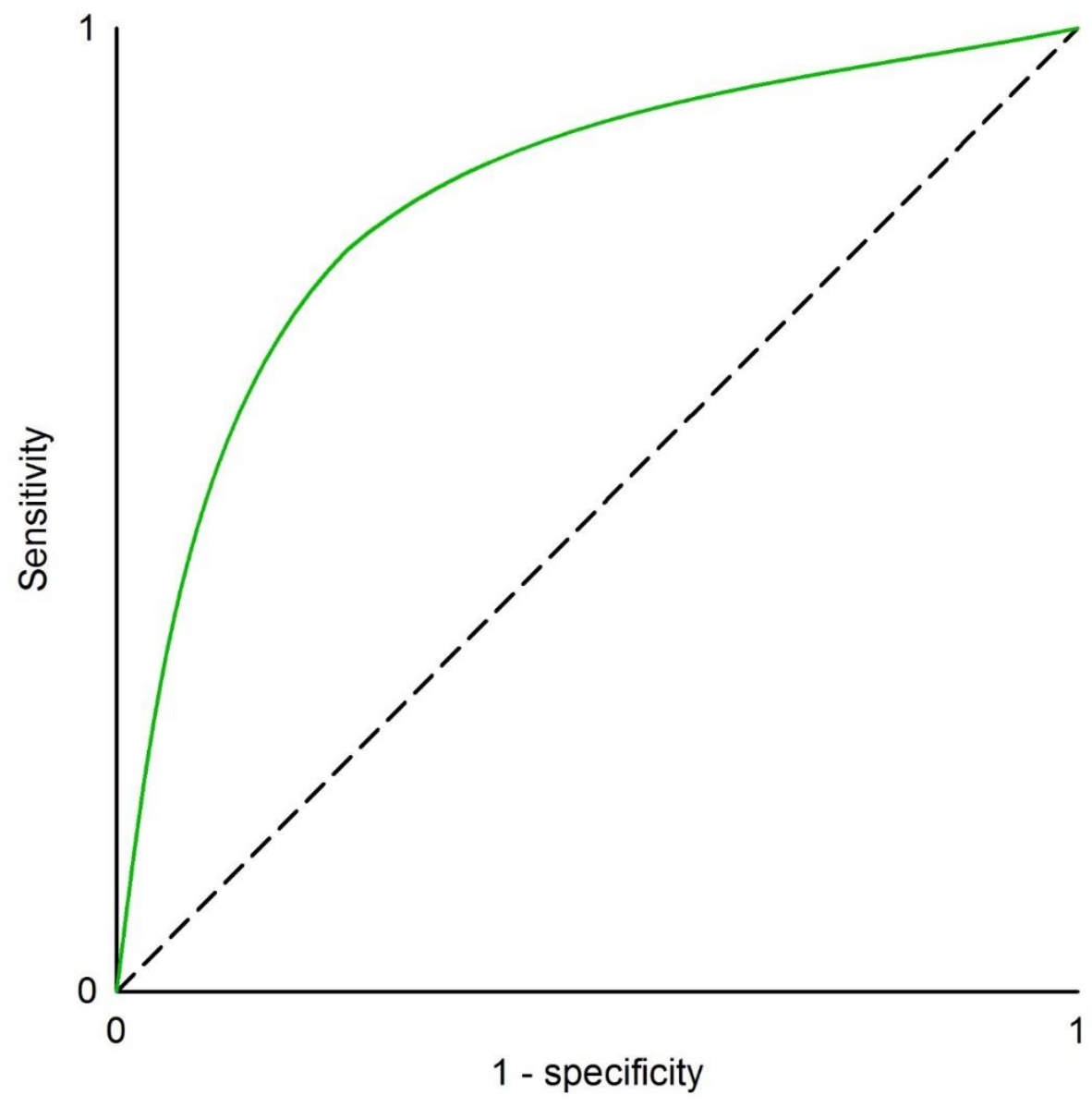

Figure 3. A generalized example of an area under the receiver operating characteristic (ROC) curve value. The dashed line is included in all generated AUC values and is not reflective of data used in the model; it indicates an AUC value of 0.5, and represents a model that performs no better than one with random output. A model that performs perfectly would have an AUC value of 1 . The red and blue lines represent actual model runs (from Pearson, 2010). 


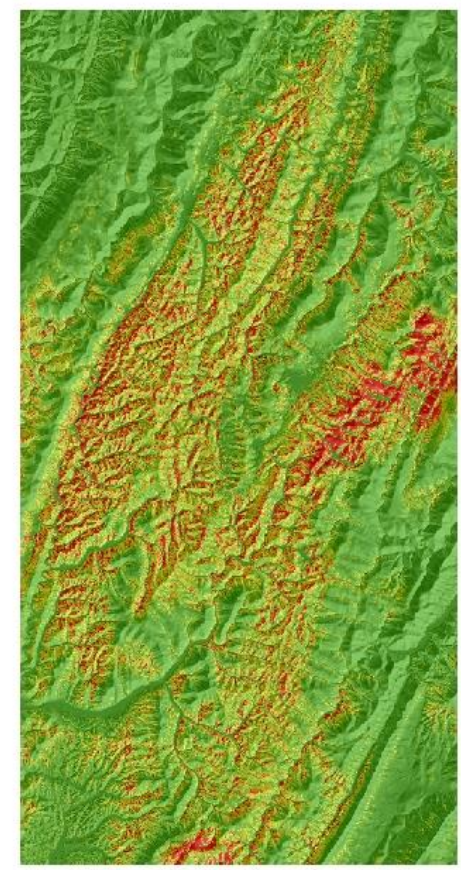

A

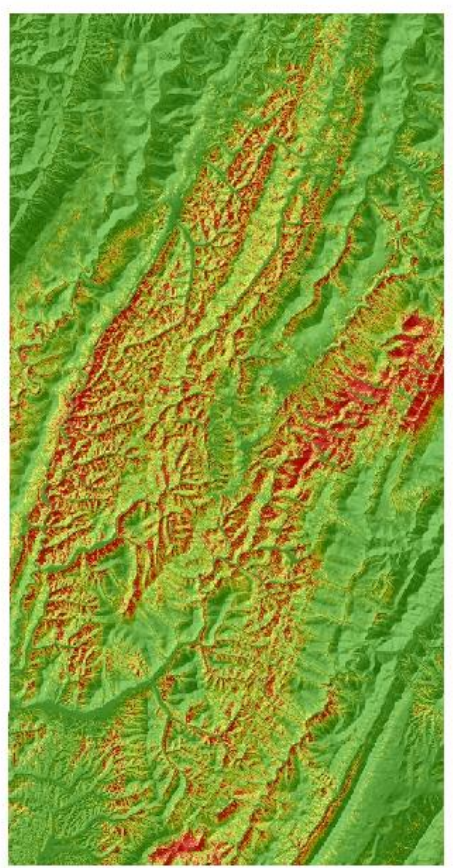

B

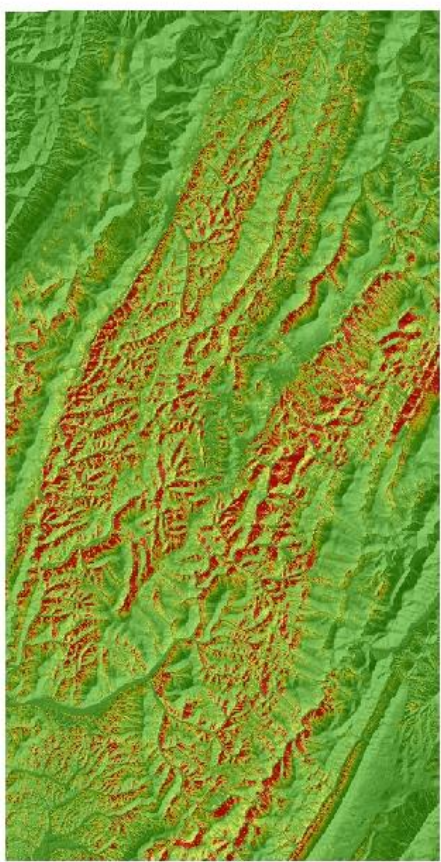

C

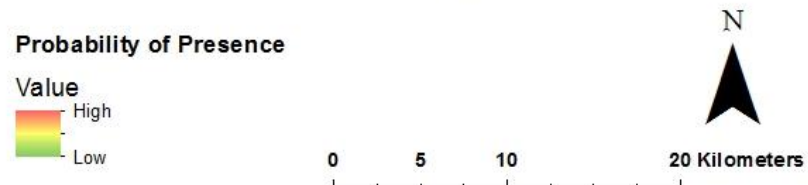

Figure 4. The three MaxEnt spodic intensity model outputs: (A) spodic intensity class $=0.5-2.0$, (B) spodic intensity class $=1.0-2.0$, and (C) spodic intensity class $=2.0$. 


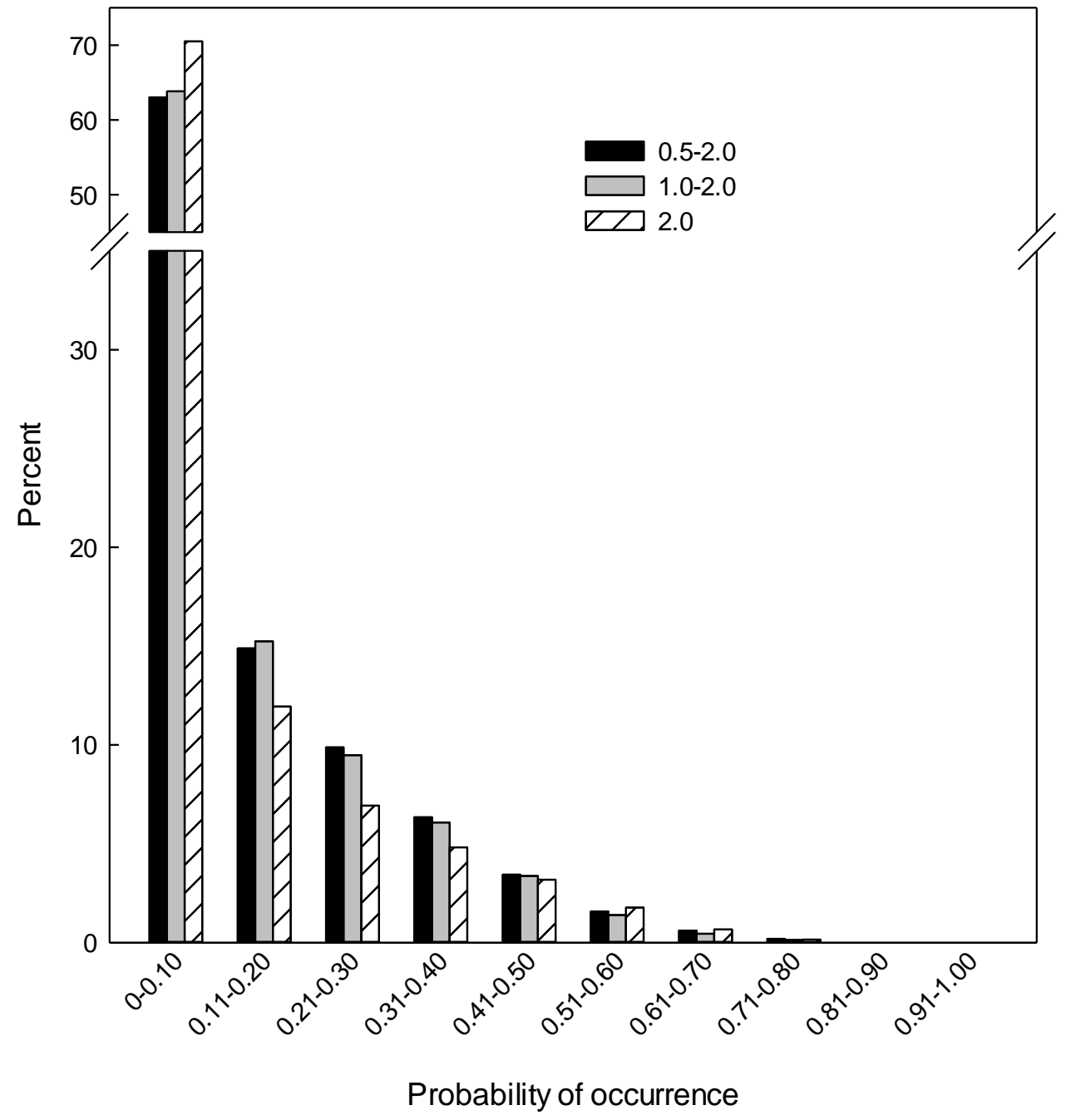

Figure 5. Frequency distributions of MaxEnt probability of presence of spodic expression for the $0.5-2.0,1.0-2.0$, and 2.0 spodic intensity classes. 


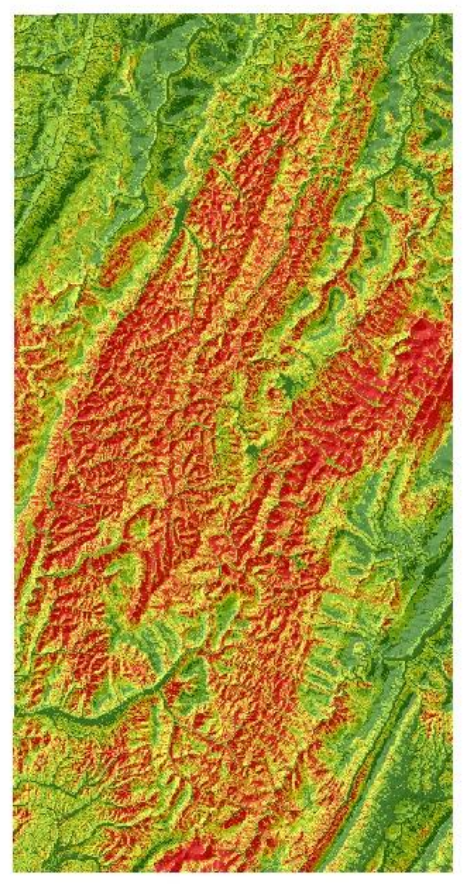

MaxEnt Spodic Probability of Presence $\leq 0.0036$ $0.0037-0.0293$ $0.0294-0.0992$ $0.0993-0.2351$ $0.2352-0.9372$

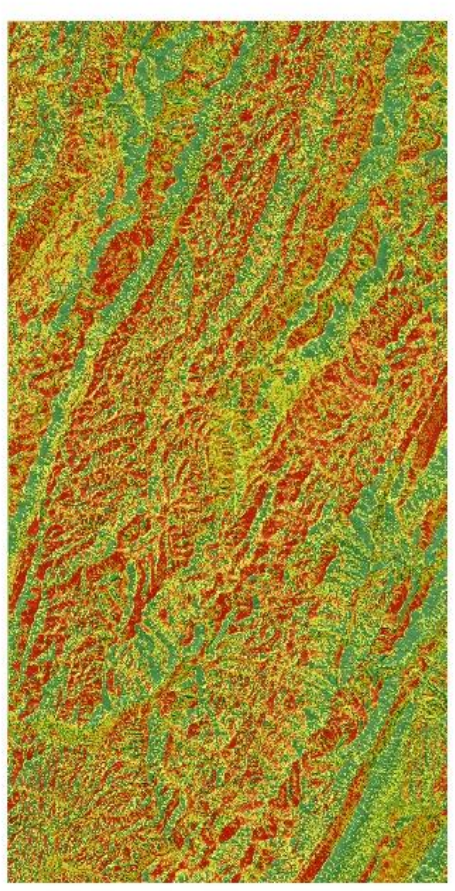

Random Forest Spodic Probabilty

$0.1040-0.4250$

$0.4251-0.5157$

$0.5158-0.6100$

$0.6101-0.7252$

$0.7253-0.9940$

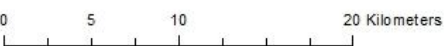

Figure 6. Comparison of MaxEnt (A) and random forests (B) outputs. The MaxEnt model employed presence data using the range of 0.5-2.0 spodic intensity, while random forests used 02.0 spodic intensity data, since random forests includes absence data. Cells were separated into five equal cell quantiles to compare these outputs by rank. Colors represent probability that spodic properties exist, not intensity of spodic expression. 


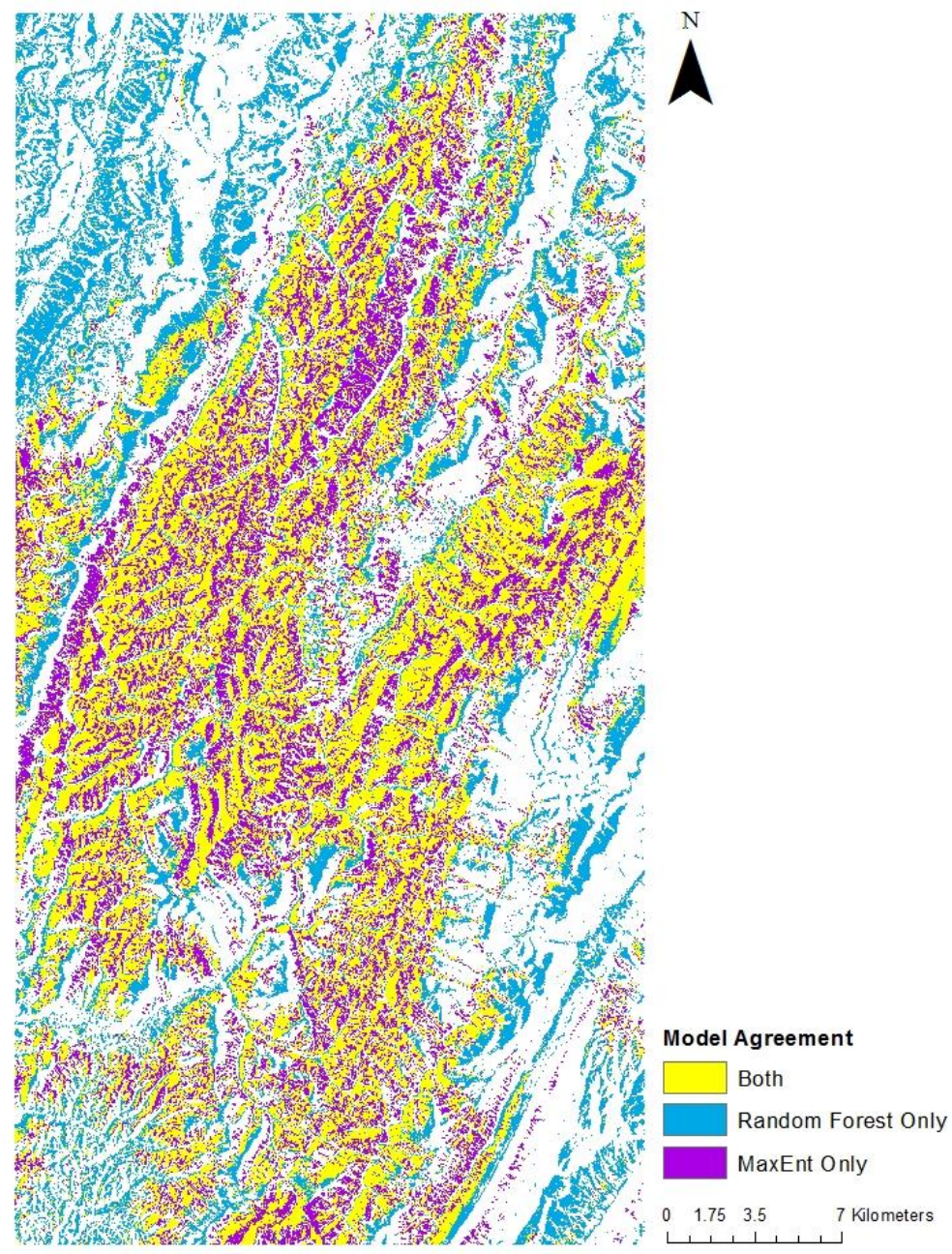

Figure 7. Spatial comparison of the MaxEnt and random forests agreement and disagreement, using the top 40 percent of probabilities for each model. White areas are cells in the lower $60 \%$ of probabilities for both the MaxEnt and random forests outputs, so they were not included in this comparison. 


\subsection{The Effects of Soil Moisture, Soil Temperature, and Air Temperature on Red Spruce Distribution: Maximum Entropy Modeling in a Small Forested Catchment}

\subsection{Abstract}

High elevation red spruce (Picea rubens) ecosystems of the central Appalachians are the focus of many restoration efforts due to the valuable ecosystem services these forests provide. Studies have attempted to model the best locations to focus red spruce restoration efforts, but often microclimatic data are not utilized, or low-resolution modeled climatic surfaces are used. Microclimate data may provide better model results given that microclimate is known to affect both species composition and distribution. In this study, local air temperature, soil temperature, and soil moisture data were collected at 20 randomly-located plots in a small $\left(5.4 \mathrm{~km}^{2}\right)$, high elevation (>700 meters above sea level) watershed for approximately one year. Microclimatic data were then summarized into variables that might affect red spruce presence. These variables, in conjunction with topographic data and a red spruce presence-only data set were used in a species distribution model, Maximum Entropy, to model the spatial distribution of red spruce. The objectives of this research are twofold: determine microclimatic variable importance to red spruce presence, and evaluate the effect that microclimatic variables have on the relative occurrence rate (ROR) of red spruce presence in comparison to ROR generated using only topographic variables. Area under the receiver operating characteristic curve (AUC) values for the models using only topographic variables, only air temperature variables, only soil temperature variables, and only soil moisture variables were $0.80,0.79,0.78$ and 0.69 respectively. The most important topographic and microclimatic variables from the preliminary model runs were combined in the final model. The AUC value of the final model was 0.82 , only slightly better than the best AUC value from the preliminary runs. The final model, which 
utilized topographic and microclimatic variables was compared to the model that only used topographic variables with the two outputs having agreement in 82 percent of cells, with only 18 percent disagreement. Interestingly, the highest relative occurrence rate of red spruce within the watershed (for both models) was predicted at the lower elevations in cold air drainage ways rather than on higher elevation ridgetops.

\subsection{Introduction}

High elevation red spruce (Picea rubens) ecosystems of the central Appalachians are the focus of many restoration efforts due to the valuable ecosystem services these forests provide including water storage (Sauer et al., 2007), soil carbon sequestration (Herbauts and Buyl, 1981; Miles, 1985; Sohet et al., 1988; Tarnocai et al., 2009; Averill et al., 2014) and habitat for sensitive, threatened, or endangered species, such as the Virginia northern flying squirrel (Glaucomys sabrinus fuscus) and Cheat Mountain salamander (Plethodon nettingi) (Menzel and Ford, 2004; Dillard et al., 2008; Pauley, 2008). Historic documentation suggests that much of the central Appalachians were covered with red spruce forests, but extensive logging and wildfires decimated the population (Allard and Leonard, 1952; Clarkson, 1964; Lewis, 1998; Rentch et al., 2007; Adams et al, 2010). Both governmental and non-governmental agencies are attempting to restore red spruce ecosystems in the central Appalachians (CASRI, 2017), so information on where these ecosystems existed historically, and where they are most likely to succeed today is needed (Rentch et al., 2016).

Environmental conditions conducive to red spruce establishment and growth have been used in a variety of models to predict historic red spruce extent and guide restoration efforts (Iverson et al., 2008; Beane et al., 2013; Madron, 2013; Koo et al., 2014; Nauman et al., 2015a). In some studies, macroclimatic variables were found to have the most influence on model outputs, ranking higher than some topographic variables such as elevation (Iverson et al., 2008; 
Beane et al., 2013; Madron, 2013). However, research has noted the importance of microclimatic factors, including local air temperature, soil temperature, and soil moisture on plant growth, species diversity, nutrient cycling, and biotic activity (Flucker, 1958; Munn et al., 1978;

Tajchman et al., 1986; Chen et al., 1993; Perry, 1994; Chen, 1999; Dobrowski, 2011; Yao et al., 2013). Furthermore, forests dominated by conifer cover can have unique microclimates due to protection from direct solar radiation, precipitation, and winds (Chen et al., 1993; Boggs and McNulty, 2010). Consequently, mapped outputs from modeling efforts that have employed only coarse climatic data inputs, which includes most reported species distribution model results, may not provide the degree of sensitivity that microclimate could for identifying red spruce potential.

While the most-general climate preferences of red spruce in this region (central Appalachians) are well known (i.e., cool, moist climates) (Piekle, 1981; Blum, 1990; Gordon, 1994; Flegel, 1999), information regarding specific microclimatic requirements is limited (Baldwin, 1934; McLaughlin et al., 1987; Johnson et al., 1988; Blum, 1990; Hadley et al., 1991; Fincher and Alscher, 1992; Gordon, 1994; Day, 2000; Dumais and Prevost, 2007). The literature states that red spruce prefers mild temperatures in early winter (November and December) (McLaughlin et al., 1987), cool, wet late summers (July-August) (McLaughlin et al., 1987; Johnson et al., 1988), and responds poorly to air temperatures above $34^{\circ} \mathrm{C}$ (Dumais and Prevost, 2007; Baldwin, 1934; Piekle, 1981) and rapid temperature changes, which have been linked to winter damage and desiccation (McLaughlin et al., 1987; Johnson et al., 1988; Hadley et al., 1991).

There is limited information about specific microclimatic conditions that affect red spruce. Optimal air temperatures for red spruce photosynthesis fall between 15 and $20^{\circ} \mathrm{C}$ (Dumais and Prevost, 2007). However, as air temperature increases to $25^{\circ} \mathrm{C}$ and then $30^{\circ} \mathrm{C}$, there 
are $20 \%$ and $40 \%$ declines in photosynthesis, respectively (Fincher and Alscher, 1992). Once air temperature reaches 32 to $40^{\circ} \mathrm{C}$, red spruce seedlings may be permanently damaged (Fincher and Alscher, 1992). Piekle (1981) and Baldwin (1934) also observed irreversible damage to red spruce seedlings at air or surface-soil temperatures of $34^{\circ} \mathrm{C}$.

There were two objectives of this study: determine microclimatic variable importance when modeling red spruce presence, and compare model results generated using only topographic variables to model results generated using both topographic and microclimatic variables. Determining if microclimatic variables are important to red spruce presence, and if so which variables are important, will be useful to researchers and land managers for conducting future red spruce studies or modeling efforts, as well as for choosing locations on the landscape for red spruce restoration. The second objective of this study will provide insight into the differences between traditional red spruce models, which primarily have used only topographic variables and occasionally coarse climatic data, and the output of this modeling effort which utilized topographic variables and site-specific microclimatic variables.

\subsection{Materials and Methods}

For this study, a species distribution model, Maximum Entropy (MaxEnt) was used to model red spruce presence using topographic and site-specific, fine-resolution climatic data (air temperature, soil temperature, and soil moisture) from a small watershed. MaxEnt is a presenceonly model, meaning that it uses point locations where an attribute of concern (in this case, red spruce) is known to exist in conjunction with other environmental variables believed to be important to the attribute of concern (Fleishman et al., 2001; Phillips et al., 2004; Elith et al., 2006; Pearson, 2010; Merow et al., 2013a). 


\subsubsection{Field Methods}

This study was conducted in Snorting Lick Run watershed (SLR). The watershed is 5.4 $\mathrm{km}^{2}$ and located in Pocahontas County, West Virginia, USA, and lies entirely within the boundary of the Monongahela National Forest (MNF). Elevation within SLR ranges from 781 to $1424 \mathrm{~m}$. Approximately 90 percent of the watershed is mapped as currently-supporting deciduous forest $\left(4.71 \mathrm{~km}^{2}\right)$ (Fry et al., 2011). The remainder of the watershed is currently mapped as supporting nearly equal areas of coniferous forest $\left(0.18 \mathrm{~km}^{2}\right)$, mixed forests $(0.19$ $\left.\mathrm{km}^{2}\right)$, and unknown or open areas $\left(0.19 \mathrm{~km}^{2}\right)$ (Fry et al., 2011).

Geologies within the watershed are limited to Hampshire (dominated by shale, siltstone and sandstone) and Chemung (dominated by sandstone and shales) formations (Reger and Price, 1929; Flegel, 1999). Soils in the watershed (and surrounding areas) were recently remapped to reflect a greater extent of Spodosols and Spodic Dystrudepts in the area than previously believed to occur (Teets and Nowacki, 2012; Nauman et al., 2015a). Soil series within the watershed consist of Snowdog (Fine-loamy, siliceous, active, frigid Typic Fragiudepts), Mandy (Loamyskeletal, mixed, active, frigid, Spodic Dystrudepts), and Wildell (loamy-skeletal, mixed, superactive, frigid Typic Haplorthods) (Soil Survey Staff, NRCS USDA, 2017).

In this area, cold winters with snow as the dominant form of precipitation are common at both high and low elevations. However, continuous winter-long snow packs occur only at the highest elevations of the landscape (Flegel, 1999). Precipitation is relatively evenly distributed throughout the year (Flegel, 1999). Although long term local temperature data are not available for this watershed, Snowshoe Mountain which is approximately $65 \mathrm{~km}$ south-west (elevation $1478 \mathrm{~m}$; about $50 \mathrm{~m}$ higher than the highest elevation within SLR) experiences average temperatures of $-5^{\circ} \mathrm{C}$ in the winter and $17^{\circ} \mathrm{C}$ during the summer (Flegel, 1999). 
Microclimatic monitoring and soil characterization within SLR occurred at 20 sites. Eighteen of the 20 sites have a red spruce component (at least $10 \%$ by ocular estimate) in the mid- or overstory for use as presence-only data in MaxEnt (described later). Sites were required to be random, but spatially distributed across the watershed because MaxEnt performs best with well-distributed samples (Phillips and Dudik, 2008). Consequently, the 20 sites were chosen using the 'Create Spatially Balanced Points' tool in ArcGIS (Reverse Randomized QuadrantRecursive Raster algorithm) (Theobald et al., 2007).

Soil pits were dug to $50 \mathrm{~cm}$ and in situ Decagon 5TE soil moisture and temperature sensors were installed in combination with Decagon EM50 data loggers. The sensors were not field-calibrated for this study. Prior to sensor installation, a fresh pit face was exposed across the entirety of the upslope pit face. Sensors were installed at three depths: $0 \mathrm{~cm}, 25 \mathrm{~cm}$, and $50 \mathrm{~cm}$. The upslope pit face was used so that water moving downslope would contact the sensors before reaching the disturbed, backfilled soil (Beck, 2011). Each sensor was inserted vertically to the end of the probe (Decagon Devices, 2015). The data loggers were programmed to record a soil moisture and temperature measurement hourly at each depth. Data collected from December 2015 through September 2016 are used in this analysis.

Air temperature data were collected with Onset HOBO temperature sensors with integrated data loggers. One Onset HOBO data logger was installed at each of the 20 sites and recorded air temperature every 30 minutes. To reduce the effects of direct solar radiation on air temperature measurements, each air temperature logger was installed at $1.8 \mathrm{~m}$ height on the north side of a tree (Whiteman et al., 1999; Lookingbill, 2003). Air temperature data were collected from November 2015 through September 2016. 


\subsubsection{Data Management and Analysis}

Air temperature, soil moisture, and soil temperature data were reviewed for completeness and development of descriptive statistics using SAS software (SAS Institute Inc., 2013). Air temperature data were missing from plot 9 from November 2015 through mid-March 2016, and from plot 17 in November 2015. Data gaps were due to technical errors (electrical shorts in cables) and battery depletion. The soil moisture and soil temperature data had more frequent sensor issues that resulted in more frequent and longer data gaps across most plots. Missing data in the soil temperature and moisture data sets were due to electrical shorts in the equipment and disturbance of the sensors by animals. A summary of the number of days of missing data by variable and plot are given in Table 1. Three plots had complete data records while data gaps for 7 of the other 17 plots were negligible as they were missing only 2 days of data as the result of timing of data collection.

Descriptive statistics for each variable indicated the data were highly correlated among plots (Table 2) and positively serially correlated across time (Table 2). Because of these relationships, the missing data were estimated from only plots that were most strongly related to the plot in question and had full data records. Stepwise regression was used to select which plots with full data sets were most strongly related to those with missing data. Linear regressions with first-order autoregressive error models were fit to each data set using the SAS AUTOREG procedure (Hipel and McLeod, 1994; SAS Institute Inc., 2013). Predicted values were calculated within the AUTOREG procedure and substituted for missing values. Regression results are given in detail in Appendix A.

SAS software also was used to calculate the by-plot climate summary variables. Climate variables considered for use in the MaxEnt modeling were selected based on a review of the literature for factors affecting red spruce germination, growth, and survival (Baldwin, 1934; 
Johnson et al., 1988; McLaughlin et al., 1987; Blum, 1990; Hadley et al., 1991; Fincher and Alscher, 1992; Gordon, 1994; Day, 2000; Dumais and Prevost, 2007). The variables developed from the field data consisted primarily of minimums, maximums, ranges, and extremes in temperature or moisture. A total of 242 air temperature, soil temperature, and soil moisture variables were created. A complete list of climate variables developed for this study is included in Appendix B. Some the variables differed only slightly from one another; consequently, many of the initial variables were strongly correlated (see Appendices C, D and E). Many of the original 241 variables differ only temporally (e.g., instantaneous measurements vs. daily averages, or the hottest air temperature value from the hottest overall day vs. the hottest instantaneous air temperature regardless of day). Finally, some of the variables created were developed from data ranges, or the number of days above or below a given temperature.

In an effort to capture extremes and worst-case scenarios, the variables selected for use in the final model were those that were developed from instantaneous measurements that did not necessarily occur on the same day (variables ending in '-oneday' were omitted). One exception to this was the dry 24 hour, 7 day, and 30 day soil moisture measurements, which were selected for use in preliminary runs given the importance of soil moisture to red spruce. Ranges and day count variables also were excluded because interpretation of surfaces created from these variables was difficult. In the end, a total of 107 microclimatic variables were utilized in preliminary runs (Table 3). Ten topographic variables derived from the National Elevation Dataset 30-m resolution digital elevation model (USGS, 2015) known to be important to red spruce presence (Murphy, 1917; Sullivan, 1993; Mohlenbrock, 1995; Oosting and Billings, 1951; Flegel, 1998; Rentch, 2007; Adams et al., 2010; Nowacki and Wendt, 2010; Thomas-Van Gundy, et al., 2012; Byers et al., 2013) were used in model runs (Table 3). 
MaxEnt requires gridded environmental covariates (Young et al., 2011; Phillips et al., 2013), so the point-based microclimatic data collected in the field were summarized into variables and interpolated into surfaces covering the entire watershed area using kriging and cokriging. Kriging is a geostatistical interpolation method which has been used for soil and climate surface creation in many other studies (e.g., Odeh et al., 1995; Voltz and Webster, 1990; Hengl et al., 2004), and provides statistical measures of accuracy and error which are useful when evaluating the kriging results (Mitas and Mitasova, 1999; Bodnar, 2010). Cokriging is a type of kriging which uses covariates to improve interpolation. Prior to kriging, all data were evaluated for normality and trends to determine the most appropriate kriging type and settings for the data sets. Most of the variables in the data sets were not normally distributed, and frequently exhibited weak second-order polynomial trends (Mitas and Mitasova, 1999; Hengl et al., 2004). Universal kriging, which is recommended when trends are present in data (Mitas and Mitasova, 1999), did not result in better fit statistics than ordinary kriging, so ordinary kriging and cokriging were used to create all final air temperature, soil temperature, and soil moisture surfaces. All air temperature surfaces were created using cokriging with elevation as the covariate. The air temperature variables were strongly correlated to elevation $(r>0.70$ or $<-0.70)$, and cokriging resulted in better fit statistics than kriging alone. The soil temperature and moisture data were not correlated strongly enough with any topographical variables for cokriging to be considered for surface creation. Kriging and cokriging accuracy metrics including standardized root mean square prediction error, root mean square prediction error and standardized average prediction error are presented for each microclimatic variable in Appendix C. 


\subsubsection{MaxEnt Modeling}

MaxEnt requires a presence-only data and gridded environmental layers believed to be important to the species of interest (Phillips, 2005; Pearson, 2007; 2010; Phillips and Dudik, 2008; Elith et al., 2011; Warren and Seifert, 2011; Merow et al., 2013a). The presence data consisted of 18 locations where red spruce was observed (at least $10 \%$ in the midstory and overstory) within SLR. Four sets of continuous environmental variables were assembled: topographic, air temperature, soil temperature, and soil moisture variables. Models were run utilizing only topographic variables, only air temperature variables, only soil temperature variables, and only soil moisture variables. From each of these models the most important variables were determined (using permutation importance, described later) and used in the final model that incorporated both topographic and microclimatic variables.

There are numerous options available for all phases of model fitting and testing in MaxEnt. Those options that were chosen for this study were based upon overall objectives as well as the characteristics of data sets used in modeling (Phillips and Dudik, 2008; Elith et al., 2011; Merow et al., 2013a), and are discussed below. MaxEnt has three output types: raw, and two transformed outputs derived from the raw data (Pearson, 2007, 2010; Merow et al., 2013a, b). Only the raw output, which has been termed the relative occurrence rate (ROR), was utilized because it has less assumptions (Phillips and Dudik, 2008; Elith et al., 2011; Merow et al., 2013a).

For the input covariate data, six features classes can be selected automatically or in any combination manually. Feature classes are types of data transformations or constraints used to improve overall model fit (Phillips and Dudik, 2008; Merow et al., 2013a); they are linear, quadratic, product, threshold, hinge and categorical feature types. Generally, linear features are considered most useful for continuous variables, while quadratic features are preferred for 
nonlinear data sets (Phillips and Dudik, 2008; Merow et al., 2013a). Threshold and hinge features are useful when a specific value of an environmental variable is known to have a positive or negative effect on a species' distribution (e.g., in general, red spruce is not believed to be dominant below 900 m elevation) (Phillips and Dudik, 2008; Merow et al., 2014a). The more features types that are utilized within a data set, the more complex the model becomes, which often results in overfitting (Phillips and Dudik, 2008; Merow et al., 2013a).

For each environmental covariate, MaxEnt determines the feature type that best fits the data and generates a response curve and a "lambdas" output file which documents the feature type selected (Merow et al., 2013a). Response curves serve as a graphical representation of the relationship between the variable and species presence (Merow et al., 2013a). After preliminary model runs, response curves of each variable were reviewed in combination with the lambdas files to determine which feature types should be used in final model runs. Response curves and lambdas files indicated that only linear and quadratic feature types were utilized; consequently only linear and quadratic feature classes were selected for use in final model runs.

MaxEnt has three methods of replication used to quantify the variation in model results: cross-validation, bootstrapping, and subsampling. Bootstrapping was selected for this analysis and is defined as sampling with replacement (Pearson, 2007, 2010; Merow et al., 2013). Bootstrapping withholds a user-specified percentage of the supplied presence data (called a random test percentage) for testing, and uses the remaining presence data to train the model (Beane et al., 2013; Pearson, 2007, 2010). The random seed option, which ensures that each replicate data set is independent from all others (Pearson, 2007, 2010), also was used. Although no literature recommends a specific random test percentage, many have used either 25 or 40 percent (Beane et al., 2013; Elith et al., 2006; Elith et al., 2011; Phillips et al., 2008). A random 
test percentage of 25 percent was utilized for this study because the presence-only data set is relatively small (18 presence-only locations). The random test percentage of 25 percent equates to 4 presence-only locations withheld for testing. MaxEnt also has the option to run any number of replicates of the same model; ten replicates of each model were run in this study.

The regularization parameter is a user-editable setting which prevents MaxEnt from overfitting (Phillips and Dudik, 2008; Elith et al., 2011; Merow et al., 2013a). To reduce overfitting, regularization decreases model complexity by fitting models to the data more generally (Phillips and Dudik, 2008; Elith et al., 2011; Merow et al., 2013a). MaxEnt reduces model complexity by regulating how closely a model fits the data set as well (Merow et al., 2013). The amount of regularization is altered by choosing a regularization coefficient (the default is 1). If the regularization coefficient is increased, model complexity is decreased, and vice versa (Merow et al., 2013a). The default regularization is known to perform well (Hastie et al., 2009) and to reduce the risk of selecting an arbitrary regularization coefficient the default regularization coefficient was utilized for all model runs.

MaxEnt generates model validation metrics which are used to evaluate overall model results and the importance of environmental covariates. One metric is the area under the receiver operator characteristic (ROC) curve which is generally referred to as the AUC value (Elith, 2002; Pearson, 2007, 2010; Phillips and Dudik, 2008; Young et al., 2011). A ROC curve is a plot of true positive vs. false positive rates (Pearson, 2007, 2010). The AUC value measures the quality of ranking sites (Fielding and Bell, 1997), and is the probability that a random site modeled as having the species of interest, is ranked above a randomly chosen background site. When no independent test file (a set of locations where the species is present or absent) is supplied to MaxEnt, the AUC curve is generated using a randomly chosen set of background 
points which serve as 'pseudo absences' (Phillips and Dudik, 2008). In this study, the background sample (default of 10,000 points) was used to create the AUC value since no independent test data were available. This situation is common but changes the interpretation of results (Phillips and Dudik, 2008); consequently AUC values are reported only to provide a general sense of model performance among the five model outputs.

Due to the lack of literature regarding how specific microclimatic conditions affect spruce presence, a secondary objective of this study was to identify important microclimatic variables, as indicated by permutation importance and jackknife analyses. Permutation importance is not influenced by the paths that MaxEnt uses to generate the individual replicates and final results (Phillips, 2006), but rather is based on the final model output. The larger the permutation importance value, the more influence that variable has on the model outcome, particularly when it is followed by a marked decline in the permutation importance value for the next most important variable (in descending order of permutation importance values) (Kalle et al., 2013). Jackknife analyses also evaluate variable importance. During the jackknife analysis, the model runs with one variable excluded and then runs the model with only that variable for all possible combinations. The result is represented graphically by a bar graphthat displays regularized training gain, test gain, and AUC values when a variable is omitted and then used alone (Phillips, 2005; Pearson, 2007, 2010). Jackknife tests are useful for determining the variables that provide the most unique information, which variables contribute positively, and which contribute negatively (Phillips, 2005; Pearson, 2007, 2010).

To address the second objective of this study, model results that employed only topographic variables were compared to results that employed the most important topographic variables and microclimatic variables. However, because the probability data are continuous, true 
model agreement would result only for cells in which the probabilities were exactly equal (an almost impossible result). Consequently, the model outputs were converted to binary outputs: high and low red spruce ROR. Because no natural breaks were observed in the frequency distributions of either model's results and the median ROR of the model that used only topographic variables and the model that used topographic and microclimatic variables were nearly equal ( 0.000075 and 0.000077 , respectively), all cells with values greater than the median ROR were classified as having high red spruce ROR. All cells equal to or less than median ROR values were classified as having low ROR. The reclassification tool in ArcGIS was used to convert the two model results to binary where cells greater than the median ROR and less than or equal to the median ROR were assigned unique integer values for both models (4 total unique values) (Table 4). The raster calculator in ArcGIS was then used to add the model that used only topographic variables and the model that used topographic and microclimatic variables together in order to find areas of agreement and disagreement between the two models. Wilcoxon twosample tests were used to determine if the environmental covariates (topographic and microclimatic variables) were significantly different between the two models for the areas of disagreement.

\subsection{Results}

Four preliminary models - one model with 10 topographic variables, one with 20 air temperature variables, one with 54 soil temperature variables, and one with 33 soil moisture variables (Table 3) — were evaluated to identify variables that were most important to red spruce ROR. AUC values for the four preliminary models ranged from 0.690 to 0.800 (Table 5); however, the AUC values presented here can only be interpreted in a general sense to compare models because a small, non-independent test data set was used to develop them (Phillips and Dudik, 2008). Of the four preliminary models, the highest AUC value was from the model that 
utilized only topographic variables, while the lowest AUC value was from the model that utilized only soil moisture variables. For the intermediate AUC values the model using only air temperature values was slightly better than the model that employed only soil temperature variables (Table 5).

Permutation importance (PI) values (normalized as percentages) for the variables in the topographic model ranged from 0.7 to 70.0 percent (Table 6). Altitude above channel network (aacn) had the highest PI of 70.0 percent, while the next highest PI, for topographic wetness index (twi), was lower by a factor of 10 . The PI ranges for the three microclimatic models (which used only air temperature, only soil temperature, and only soil moisture) were much lower than the ranges displayed in the model that utilized only topographic variables (Table 6). Of all the soil temperature and soil moisture variables utilized, the most important ones pertained to maximum and minimum conditions during the summer season (Table 6). Interestingly, these variables included both minimum and maximum temperature metrics within the same months and maximum soil moisture metrics within the same months.

A large decrease in permutation importance between one variable and the next variable, (when listed in descending order) indicates that the model relies heavily on the former variable (Kalle et al., 2013). Consequently, of the 115 variables that were used in preliminary models, only five were considered to be important and were included in the final model. These were aacn, augabsmaxanyday, augabsmaxanyday $0 \mathrm{~cm}$, juldailymaxanyday $50 \mathrm{~cm}$ and $\mathrm{dry} 25 \mathrm{hr} 0 \mathrm{~cm}$ (Table 6). Correlation analyses between the important variables from each preliminary model indicated only weakly correlation, except for juldailymaxanyday50cm and $d r y 24 \mathrm{hr} 0 \mathrm{~cm}$ (Table 7).

The final model employing the five variables had an AUC value of 0.821 , only slightly higher than the best AUC of the preliminary model employing only topographic variables. Given 
the importance of aacn in the preliminary topographic model, it is not surprising that it was again the most important variable $(\mathrm{PI}=36.7)$ in the final model that employed both topographic and microclimatic variables (Table 8). The variable with the second highest PI was augabsmaxanyday (air temperature) at 24.3 percent. The soil variables included in the final model contributed the least to the model (Table 8). The largest drop in PI was between aacn and augabsmaxanyday (air temperature), so the model relied heavily on aacn. Even though the largest drop in PI occurred at augabsmaxanyday, the PI value of 24.3 percent indicates it was still important in the model. While augabsmaxanyday $0 \mathrm{~cm}$ had a PI value of only 18.3 percent, it was still considered to be important in this analysis. The variable response curves from the final model indicate that as aacn, augabsmaxanyday and augabsmaxanyday0cm increase, the red spruce ROR decreases (Figs. 1-3).

The jackknife test generated during the final model supports the conclusions about variable importance drawn from the PI values (Figure 4). Specifically, it supports the previous finding that aacn and augabsmaxanyday were the most important variables used in the final model. AUC values when aacn was used alone were highest (approximately 0.74). Conversely, omitting aacn from the model decreased AUC the most of all variables tested (approximately 0.65), This indicates that aacn had the most unique (uncorrelated) information of all variables included in the final model (Phillips et al., 2006; Young et al., 2011). Similar results were seen with augabsmaxanyday, which was the second-most important variable. The two soil moisture variables, dry24hrOcm and juldailymaxanyday50cm, had little effect on the AUC values when they were used alone or omitted, indicating that they contained the least unique information and contributed the least to the final model output. 
The second objective of this study was to evaluate the differences in outputs between the model that employed only topographic variables and the final model that used the five most important topographic and microclimatic variables (Fig. 5). Agreement/disagreement analyses indicate that the classified model results agreed (both predicted high ROR or both predicted low ROR) for 82 percent of the cells in the watershed (Table 9). Interestingly, within areas of model agreement, predicted high and low ROR were almost equal at approximately 41 percent (Table 9). Disagreement (where one model predicted high red spruce ROR and one predicted low red spruce ROR) was limited to the remaining approximate 18 percent of the cells in the watershed. Areas where the topographic model predicted high ROR and the topographic and microclimatic variable predicted low ROR and vice versa were almost equal at approximately 8 percent (Table 9). Disagreement between the two models does not occur at the summits, ridges and shoulders where both models ubiquitously predict low red spruce ROR. Notably, both models predicted the highest red spruce RORs at the lower elevations along the stream and in coves within this watershed (Fig. 6).

To compare the environmental conditions in areas where the two models disagreed, descriptive statistics (minimums, maximums, and means) for variables used in both models were calculated (Table 10). The average aacn values were higher for areas where the topographic model predicted high red spruce ROR than areas where the model that utilized topographic and microclimatic variables predicted high red spruce ROR. Interestingly, areas of model disagreement had similar mean values for all four microclimatic variables which suggests that areas of disagreement were largely controlled by aacn. The Wilcoxon two-sample test was performed for each of the environmental covariates used in each respective model in areas 
where the two models disagreed, all variables were significantly different $(\mathrm{p}<0.0001)$ between model, except baselevel $(\mathrm{p}=0.1827)($ Table 10).

\subsection{Discussion}

It is not entirely surprising that the model that utilized topographic variables had the highest AUC value of all four preliminary models because the relationship between red spruce presence and topographic conditions is well known (Piekle, 1981; Flegel, 1999; Rentch et al., 2007; Adams et al., 2010). However, only select topographic variables in the preliminary run were important. Altitude above channel network was the most important variable by a factor of ten, which indicates that red spruce presence in SLR is largely associated with concave topography, which promotes cool air and soil temperatures and accumulation of soil moisture (Dobrowski, 2011).

The AUC values declined in this order: topographic variable model > air temperature variable model > soil temperature variable model > soil moisture variable model (Tables 5 and 6). The smallest AUC values for the models employing only soil variables might be attributable to the increasingly larger amounts of missing data in the soil temperature and soil moisture data sets. By definition, microclimatic variables describe conditions at localized points in space (Geiger, 1965; Chen et al., 1999), and soil temperature and moisture are known to vary over short distances (Ma et al., 2014; Seyfried et al., 2016). The number of soil temperature and soil moisture sampling locations may have been too sparse to adequately characterize spatial variability of the respective variables within the study area (20 sites over $5.4 \mathrm{~km}^{2}$ ). Additionally, while others have used cokriging with topographic variables to improve interpolation results (e.g., Bàrdossy and Lehmann, 1998; Kang et al. 2000; Zhu and Lin 2010), no topographic variables in this watershed were found to have a strong enough relationship with soil temperature or soil moisture to improve surface creation. Consequently, the soil temperature and moisture 
surfaces may not represent field conditions since they are relatively coarse mathematical interpolations based on neighboring values with no supplementary information to improve the kriged surfaces. The sampling density required to capture a spatially-sufficient amount of microclimatic observations to produce an accurate surface, particularly without covariates to help inform the modeled surface, may make inclusion of microclimate variables prohibitive from both cost and complexity of sampling.

The most important variables in the preliminary models are consistent with the known general site and climate preferences of red spruce, which include cool, moist conditions (Piekle, 1981; Blum, 1990; Gordon, 1994; Flegel, 1999). However, based on the literature, other variables also were expected to be important to red spruce presence. Slope aspect, which influences microclimate, and therefore influences red spruce presence at the local level, has been important in previous modeling efforts (Nauman et al., 2015a), but it was not important in the preliminary model. Mean annual air temperature, along with minimum and maximum air temperatures are variables commonly available from online data sets, such as BioClim (http://www.worldclim.org/bioclim), that have been identified as important covariates in various studies involving large-scale modeling (Iverson et al., 2008; Beane et al., 2013; Madron, 2013). None of these variables were important during preliminary model runs, which suggests that commonly available climate variables may have little utility for small-scale watershed modeling.

It also is surprising that maximum and minimum winter air temperatures were not more important, given the number of studies which have reported that extremely cold temperatures and large fluctuations in daily temperatures during winter months can result in injury and/or death to red spruce (McLaughlin et al., 1987; Johnson et al., 1988; Hadley et al., 1991; DeHayes et al., 2001). Variables related to minimum and maximum soil temperatures during July and August 
also were expected to be important based on literature indicating that high soil temperatures late in the summer could be detrimental to red spruce presence (Piekle, 1981; Blum, 1990; Gordon, 1994; Flegel, 1999; Dumais and Prevost, 2007). Other literature also suggests that minimum soil temperatures during winter months may be important because they can result in frozen soil and prevent water uptake by red spruce (DeHayes et al., 2001); however, minimum soil temperatures during winter months were not found to be important in the preliminary model. Minimum soil temperatures probably were not important in SLR in this watershed as the occurrence of freezing soil temperatures at the surface was sporadic, and freezing soil temperatures were never reached at $25-$ and $50-\mathrm{cm}$ soil depths. Soil temperature regimes for the soils in this watershed all classified as being mesic (Soil Survey Staff, 2015). Thus, winter damage to red spruce may be a concern only at higher elevations where colder temperatures persist for a longer duration during the winter.

While no literature was located that explicitly discusses soil moisture requirements of red spruce, research does state red spruce prefers moist conditions (Piekle, 1981; Blum, 1990; Gordon, 1994; Flegel, 1999). Consequently, it follows that extensive periods of low soil moisture likely would be stressful to red spruce. While the preliminary soil moisture model did show the driest 24-hour period at the surface and wettest soil moisture at 50-cm depth in July were somewhat important to red spruce presence, the driest 7 or 30 days were not important. The potential inaccuracy of the soil moisture surfaces (described previously) and the frequency of missing soil moisture data during field collection (soil moisture was the most frequently missing data) may have influenced the outcome of the lack of importance of these variables in the model. Consequently, there may be utility in collecting soil moisture data for small-scale watershed modeling if the occurrence of missing data is not extensive. 
In the preliminary model that utilized only topographic variables and the final model that used the five most important topographic and microclimatic variables, aacn and augabsmaxanyday (air temperature), respectively, were the two most important variables in the final model. Red spruce presence was inversely related to increased distance from stream channels and increased August air temperatures (Fig. 2). Landscape positions closer to stream channels in this landscape are concave and include coves and swales. These micro-topographic features promote soil moisture accumulation and cool air temperatures-conditions known to be conducive to red spruce presence (Piekle, 1981; Blum, 1990; Gordon, 1994; Flegel, 1999).

AUC and PI values each were similar for the model that only used topographic variables and the model that used both topographic and microclimatic variables. This result suggests that topographic variables alone may be suitable for modeling red spruce presence. The 241 microclimate variables initially developed for this study were based on best-available information in the literature; however, there may be other, more useful permutations of data that were not anticipated or examined due to the lack of information about red spruce responses to microclimatic conditions. Air temperature was the most important microclimatic variable in the final model. Because it is generally easier to collect air temperature measurements (and maintain the equipment) than soil temperature and moisture measurements, in future modeling efforts that employ microclimate data it may be more efficient simply to use only air temperature data. This is particularly true if a denser network of microclimate sensors are used to develop a more accurate picture of spatial temperature variations. Furthermore, the variables created for this study were based on relatively short climatic data set (approximately 1 year), which also happened to be the third warmest year on record in WV (NOAA, 2017). More climatic data is always desirable but this data set was the only available data to utilize in this study. 
Visual comparison of the topographic model to the model using both topographic and microclimatic variables (Fig. 5) showed an unexpected result—-both predicted the highest red spruce ROR at the lowest elevations in the watershed (approximately $700 \mathrm{~m}$ ) and the lowest red spruce ROR at the highest elevations in the watershed. These model outputs contradict that idea that the highest elevations are universally preferable (Rentch et al., 2007; Nowacki and Wendt, 2010); instead they suggest that at elevations above $700 \mathrm{~m}$ (the lowest elevation in the SLR), red spruce restoration efforts should be targeted to concave areas that serve as cold-air drainages and promote lower air and soil temperatures and increased soil moisture (Butler et al., 2015). Since extensive red spruce stands currently exist on ridges and shoulders at the highest elevations in the central Appalachians (which are likely cooler and moister than conditions in SLR), these findings and recommendations may be applicable only to similar, marginal elevations. It should be noted that during random site selection, few sites at ridgetop or shoulder landscape positions with red spruce cover were identified and consequently, a limited number of microclimatic measurements and presence only points were taken at these landscape positions. Red spruce restoration efforts within marginal elevations in lower backslopes, toeslopes and stream channels may provide an opportunity to improve habitat connectivity, which is particularly desirable given the sensitive, threatened and endangered species that are endemic to this ecosystem.

The findings described here are based on a relatively short-term data set (approximately 1 year), but still offer valuable insight into potential future climate conditions. The year 2016 was the third warmest year on record for West Virginia (NOAA National Centers for Environmental Information, 2017). Maximum air and soil temperatures reported to be detrimental to red spruce (Baldwin, 1934; Piekle, 1981) were observed in only one plot within SLR even at the lowest elevation of $700 \mathrm{~m}$. Detrimental minimum air and soil temperatures also were rarely observed. 
However, given the projected climatic warming in this region coupled with predictions that red spruce habitat will continue to decrease (Butler et al., 2015), red spruce restoration planning should first focus on the highest elevations on the landscape, and then during finer-scale implementation target previously discussed near-stream and other concave landscape positions that accumulate surface and subsurface moisture and that act as microrefugia (Dowbrowski, 2011).

\subsection{Conclusion}

This study was conducted in a Snorting Lick Run watershed (SLR), which is a small (5.4 $\mathrm{km}^{2}$ ) high elevation (approximately 700-900 m) watershed in the central Appalachians. This research was conducted to obtain information to help prioritize areas for red spruce restoration. Historically, red spruce forests had a larger extent in the central Appalachians, but were reduced via logging during the early $19^{\text {th }}$ century. Red spruce forests offer numerous ecosystem services and are habitat to sensitive, threatened and endangered species. Consequently, red spruce restoration is an objective of many land managers.

Air temperature, soil temperature, and soil moisture were measured in situ in SLR at 20 sites for approximately one year. While longer climatic data sets are always preferred, none were available for this study. The raw data were summarized into 107 variables believed to be important to red spruce presence. These variables, along with ten topographic variables were used to model red spruce presence. MaxEnt, a species distribution model, was used to model red spruce presence using the aforementioned topographic and microclimatic variables.

The most important variable in both preliminary (runs that used only topographic, only air temperature, only soil temperature, and only soil moisture variables) and the final model run (which included the most important topographic and microclimatic variables) was altitude above channel network (aacn), which showed that higher red spruce relative occurrence rate occurred 
in locations that were close to streams or coves (i.e., concave landforms that accumulate moisture and are cooler). August absolute maximum air temperature was the second most important variable in the final model. Soil temperature and soil moisture variables contributed relatively little to the final model, which was likely due to a combination of reliance on a single year of data, poor interpolated surfaces (as only weak correlation between topographic covariates and microclimatic variables was observed which made cokriging unfeasible) and missing data. Area-under-the-curve and permutation importance values were not that different between the model that utilized only topographic variables, and the final model that utilized the most important topographic and microclimate variables, which indicates it may be appropriate for red spruce restoration modelers to continue using only topographic variables. However, if a microclimatic component is desired, air temperature was shown to be important and is easier to measure.

It is accepted knowledge that red spruce historically, currently, and in the future is likely to exist on the highest elevations in the central Appalachians due to climatic conditions present there. Consequently, in general red spruce restoration should be focused at the highest elevations. In SLR, the highest red spruce ROR occurred at the lower elevations in the watershed. This research indicates that lower elevations can also be the focus of red spruce restoration, but will require that concave landscape positions that promote cool air and soil temperatures, and increased soil moisture be targeted. Restoration locations should be located in areas that could provide the microrefugia that red spruce may require in a changing climate. Focusing restoration efforts in coves adjacent to ridgetops and shoulders where red spruce is already present could also lead to improved ecosystem connectivity, which is especially important for species endemic to the red spruce ecosystem (Menzel and Ford, 2004; Dillard et al., 2008; Pauley, 2008). 


\section{Acknowledgments and Disclaimer}

Thanks to the Monongahela National Forest for financial support and providing access to the research sites. Sincere thanks also go to Stephanie Connolly and Steffany Scagline for their assistance and advice with this study. The use of trade or firm names in this publication is for reader information and does not imply endorsement by the U.S. Department of Agriculture of any product or service.

\subsection{References}

Adams, H.S., Stephenson, S.L., Rollins, A.W., Adams, M.B., 2010. The isolated red spruce communities of Virginia and West Virginia, in: Rentch, J.S., Schuler, T.M. (Eds.), Proceedings from the Conference on the Ecology and Management of High-Elevation Forests in the Central and Southern Appalachian Mountains. GTR-NRS-P-64. USDA Forest Service, Northern Research Station, Newtown Square, PA, pp. 1-12.

Allard, H.A., Leonard, E.C. 1952. The Canaan and Stony River Valleys of West Virginia, their former magnificent spruce forests, their vegetation and floristics today. Journal of the South. Appalachian Botanical Club. 17(1): 2-59.

Averill, C., Turner, B.L., Finzi, C. 2014. Mycorrhiza-mediated competition between plants and decomposers drives soil carbon storage. Nature. 505(7484): 543-545.

Bàrdossy, A., Lehmann, W. 1998. Spatial distribution of soil moisture in a small catchment: Part 1. Geostatistical analysis. Journal of hydrology. 206(1998): 1-15.

Baldwin, H.I. 1934. Germination of the red spruce. Plant physiology. 9(3): 491-524.

Beane, N.R., J.S. Rentch, and T.M. Schuler. 2013. Using maximum entropy modeling to identify and prioritize red spruce forest habitat in West Virginia. Research Paper NRS-23. Newton Square, PA: U.S. Department of Agriculture, Forest Service, Northern Research Station. 16. 
Beck, J.F. 2011. Fragipan influence on hydropedological properties of benchmark soilscapes in West Virginia. Ph.D. Dissertation. West Virginia University. Morgantown, WV.

Blum, B.M. 1990. Red spruce. In Burns, R.M., Honkala, B.H: Silvics of North America. Agriculture Handbook No 654: USDA Forest Service. Washington, DC. 1: 250-259.

Bodnar, Lacey. 2010. The use of ArcGIS geostatistical analyst exploratory spatial data analysis and integrated regionalization of Colorado precipitation and elevation data. Thesis. Texas A\&M University.

Boggs, Johnny L.; McNulty, Steven G. 2010. Changes in canopy cover alter surface air and forest floor temperature in a high-elevation red spruce (Picea rubens Sarg.) forest. In: Rentch, James S.; Schuler, Thomas M., eds. 2010. Proceedings from the conference on the ecology and management of high-elevation forests in the central and southern Appalachian Mountains; 2009 May 14-15; Slatyfork, WV. Gen. Tech. Rep. NRS-P-64. Newtown Square, PA: U.S. Department of Agriculture, Forest Service, Northern Research Station: 13-21.Byers, E.A., Vanderhorst, J.P. and B.P. Streets. 2010. Classification and conservation assessment of upland red spruce communities in West Virginia. WV DNR. http://www.wvdnr.org/publications/PDFFiles/RedSpruceUplands$\underline{\text { web.pdf }}$

CASRI. 2017. Central Appalachian Spruce Restoration Initiative. http://www.restoreredspruce.org/index.php. Accessed 06/05/2017.

Chen, J., Franklin, J.F., and T.A. Spies. 1993. Contrasting microclimates among clearcut edge and interior of old-growth Douglas-fir forest. Agricultural and forest meteorology. 63(34): 219-237. 
Chen, J., Saunders, S.C., Crow, T.R., Naiman, R.J., Brosofske, K.D., Mroz, G.D., Brookshire, B.L., and J.F. Franklin. 1999. Microclimate in forest ecosystem and landscape ecology: variations in local climate can be used to monitor and compare the effects of different management regimes. Bioscience: 49(4): 288-297.

Clarkson, R.B. 1964. Tumult on the mountains: Lumbering in West Virginia, 1770-1920. Parsons, WV: McClain Printing Company. 410 p.

Day, M.E. 2000. Influence of temperature and leaf to air vapor pressure deficit on net photosynthesis and stomatal conductance in red spruce (Picea rubens). Tree Physiology. 20: 57-63.

Decagon Devices, Inc. 2015. 5TE Water content, EC and temperature sensor. Pullman, WA. http://manuals.decagon.com/Manuals/13509_5TE_Web.pdf. Accessed 02/15/2015.

Dillard, L.O., K.R. Russel and W.M. Ford. 2008. Macrohabitat models of occurrence for the threatened cheat mountain salamander, Plethodon nettingi . Applied Herpetology. 5(3):201-224 .

Dumais, D., and M. Prevost. 2007. Management for red spruce conservation in Quebec: the importance of some physiological and ecological characteristics- a review. The Forestry Chronicle. 83. 378-391.

Elith, J., C.H. Graham, R.P. Anderson, M. Dudik, S. Ferrier, Al. Guisan, R.J. Hijmans, F. Huettman, J.R. Leathwick, A. Lehmann, J. Li, L.G. Lohmann, B.A. Loiselle, G. Manion, C. Moritz, M. Nakamura, Y. Nakazawa, J. Overton, A.T. Peterson, S.J. Phillips, K.S. Richardson, R. Scachetti-Pereira, R.E. Schapire, J. Soberon, S. Williams, M.S. Wisz, and N.E. Zimmermann. 2006. Novel methods improve prediction of species' distributions from occurrence data. Ecography. 29(2):129-151. 
Elith, J., Phillips, S.J., Hastie, T., Dudik, M., Chee, Y.E. and C.J. Yates. 2011. A statistical explanation of MaxEnt for ecologists. Diversity and Distribtuions. 17(1): 43-57.

Evans, J.S., Oakleaf, J., Cushman, S.A., Theobald, D. 2014. An ArcGIS toolbox for surface gradient and geomorphometric modeling, version 2.0-0. http://evansmurphy.wix.com/evansspatial. Accessed 04/10/2017.

Fincher, J., and R.G. Alscher. 1992. The effect of long-term ozone exposure on injury in seedlings of red spruce (Picea rubens sarg.). New Phytology. 120: 49-59.

Flegel, D.G. 1999. Soil Survey of Pocahontas County, West Virginia. USDA-NRCS. U.S. Gov. Print. Office, Washington, DC. 301 p.

Fleishman, E., R.M. Nally, J.P. Fay, and D.D. Murphy. 2001. Modeling and predicting species occurrence using broad scale environmental variables: An example with butterflies of the Great Basin. Conservation Biology. 15(6):1674-1685.

Flucker, B.J., 1958. Soil temperatures. Soil Science. 86: 35-46.

Fry, J., G. Xian, S. Jin, J. Dewitz, C. Homer, L. Yang, C. Barnes, N. Herold, and J. Wickham. 2011. Completion of the 2006 National Land Cover Database for the Conterminous United States. Photogrammetric Engineering and Remote Sensing. 77(9): 858-864.

Geiger, R. 1965. The climate near the ground. Cambridge, MA. Harvard University Press. Gordon, A.G. 1994. The red spruce option: red spruce and the hemlock connection. In H.W. Anderson and A.G. Gordon. The tolerant conifers: eastern hemlock and red spruce, their ecology and management. For. Res. Inform. Pap. 113:99-114.

Hadley, J.L., Friedland, A.J., Herrick, G.T., and R.G. Amednson. 1991. Winter desiccation and solar radiation in relation to red spruce decline in the norther Appalachians. Canadian Journal of Forest Restoration. 21: 269-272. 
Hatfield, D.C. 1996. TopoTools- A collection of topographic modeling tools for ArcINFO: SlopePosition. US Forest Service. http://proceedings.esri.com/library/userconf/proc00/ professional/papers/pap560/p560.htm

Hengl, T., Heuvelink, G.B.M., Stein, A. 2004. A generic framework for spatial prediction of soil variables based on regression-kriging. Geoderma. 120, 75-93.

Herbauts, J. and E. Buyl. 1981. The relation between spruce monoculture and incipient podzolization in ochreous brown earths of the Belgian Ardennes. Plant and Soil. 59 (1): $33-49$.

Hipel, K.W., and A.I. McLeod. 1994. Time series modelling of water resources and environmental systems. Amsterdam: Elsevier Science. 1013.

Iverson, L.R., A.M. Prasad, S.N. Matthews and M. Peters. 2008. Estimating potential habitat for 134 eastern US tree species under six climate scenarios. Forest Ecology and Management. 254 (3):390-406.

Johnson, A.H., Cook, E.R., and T.G. Siccama. 1988. Climate and red spruce growth and decline in the northern Appalachians. Proc. Natl. Acad. Sci. 85: 5369-5373.

Kalle, R., Ramesh, T., Qureshi, Q., Sankar, K., 2013. Predicting the distribution pattern of small carnivores in response to environmental factors in the western Ghats. PLoS ONE 8(11), e79295. doi:10.1371/journal.pone.0079295Koo, K.A., M. Marguerite and C.P Bernard. 2014. Projection of red spruce (Picea rubens Sargent) habitat suitability and distribution in the southern Appalachian Mountains, USA. Ecological Modelling. 293:91-101.

Kang, S., Kim, S., Oh, S., Lee, D. 2000. Predicting spatial and temporal patterns of soil temperature based on topography, surface cover and air temperature. Forest ecology and management. 136(2000): 173-184. 
Lewis, R.L. 1998. Transforming the Appalachian countryside: railroads, deforestation, and social change in West Virginia, 1880-1920. University of North Carolina, Chapel Hill. 368 p.

Lookingbill T.R., and D.L. Urban. 2003. Spatial estimation of air temperature differences for landscape scale studies in montane environments. Agricultural and Forest Meteorology. 114(3): 141-151.

Ma, Y., Van Dam, R.L., Jayawickreme, D.H. 2014. Soil moisture variability in a temperate deciduous forest: insights from electrical resistivity and throughfall data. Environmental Earth Sciences. 72: 1367-1381.

Madron, Justin.2013. Reforestation of red spruce (Picea rubens) on the Cheat Mountain range, West Virginia. M.S. Thesis. Virginia Commonwealth University. Richmond, VA. 86 p.

McLaughlin, S.B., Downing, D.J., Blasing, T.J., Cook, E.R., and H.S. Adams. 1987. Oecologia. $72: 487-501$

Menzel, J.M., and W.M Ford. 2004. Nest tree use by the endangered Virginia northern flying squirrel in the central Appalachian Mountains. American Midland Naturalist. 355 p.

Merow, C., Smith, M.J., Silander, J.A., 2013a. A practical guide to MaxEnt for modeling species' distributions: what it does and why inputs and settings matter. Ecogr. 36(10), 1058-1069.

Merow, C., Smith, M.J., Silander, J.A., 2013b. A practical guide to MaxEnt for modeling species' distributions: what it does and why inputs and settings matter. Appendix ECOG07872, Appendix 1-6. http://ww.oikosoffice.lu.se/appendix. Accessed 04/03/2017.

Miles, J. 1985. The pedogenic effects of different species and vegetation types and the implications of succession. Journal of Soil Science. 36(4): 571-584. 
Mitas, L., and Mitasova, H. 1999. Spatial interpolation. Geographical information systems: principles, techniques, management and applications. 1, 481-492.

Munn. L.C., Buchanan, B.A., and G.A., Nielsen. 178. Soil temperature in adjacent high elevation forest and meadows of Montana. Soil Science Society of America Journal. 42: 982-983.

Nauman, T.W., 2015. Spatializing the soil-ecological factorial: data driven integrated land management tools. PhD Diss. West Virginia University, Morgantown, WV.

Nauman, T.W., J.A. Thompson, S.J. Teets, T.A. Dilliplane, J.W. Bell, S.J. Connolly, H.J. Liebermann, and K.M. Yoast. 2015a. Ghosts of the forest: mapping pedomemory to guide restoration. Geoderma 247:51-64.

Nauman, T.W., Thompson, J.A., Teets, S.J., Dilliplane, T., Bell, J.W., Connolly, S.J., Liebermann, H.J., and K. Yoast. 2015b. Pedoecological modeling to guide forest restoration using ecological site descriptions. Soil Science Society of America Journal. 79.5: 1406-1419.

NOAA National Centers for Environmental Information, State of the Climate: National Climate Report for Annual 2016, published online January 2017, retrieved on May 14, 2017 from https://www.ncdc.noaa.gov/sotc/national/201613.

Odeh, I.O., McBratney, A.B., and Chittleborough, D.J. 1995. Further results on prediction of soil properties from terrain attributes: heterotropic cokriging and regression-kriging. Geoderma. 67(3-4), 215-226.

Pauley, T.K. 2008. The Appalachian inferno: historical causes for the disjunct distribution of plethodon nettingi (Cheat Mountain Salamander). Northeastern Naturalist. 15(4): 595.

Pearson, R.G., 2007. Species' distribution modeling for conservation educators and practitioners. American Museum of Natural History, New York. Pearson, R.G. 2010. Species' 
distribution modeling for conservation educators and practitioners. Lessons in conservation 3: 54-89

Pearson, R.G., 2010. Species' distribution modeling for conservation educators and practitioners. Lessons Conserv. 3, 54-89.

Perry, D.A. 1994. Forest ecosystems. Baltimore: John Hopkins University Press.

Phillips, S.J., Dudik, M., and R.E. Schapire. 2004. A maximum entropy approach to species distribution modeling. IN Proceedings of the $21^{\text {st }}$ International Conference on Machine Learning. ACM Press. New York. p 655-662.

Phillips, S.J., 2006. A brief tutorial on Maxent. AT\&T Research. https://www.cs.princeton.edu/ schapire/maxent/tutorial/tutorial.doc. Accessed 04/03/2017.

Phillips, J.D., and M. Dudik. 2008. Modeling of species distributions with MaxEnt: new extensions and a comprehensive evaluation. Ecography. 31(2):161-175.

Phillips, S.J., Anderson, R.P., Schapire, R.E., 2006. Maximum entropy modeling of species geographic distributions. Ecol. Model. 190, 231-259.

Phillips, S.J., Dudik, M., Elith, J., Graham, C.H., Lehmann, A., Leathwick, J., Ferrier, S., 2009. Sample selection bias and presence-only distribution models: implications for background and pseudo-absence data. Ecol. Appl.. 19(1, 181-197.

Pielke, R. A. 1981. The distribution of spruce in west-central Virginia before lumbering. Castanea. 46:201-216.

Reger, D.B., and P.H. Price. 1929. West Virginia geologic survey: Pocahontas County. United States Geologic Survey.Wheeling News Litho Company. Wheeling, WV. 521 p. 
Rentch, J.S., T.M. Schuler, M.W. Ford, and G.J. Nowacki. 2007. Red spruce stand dynamics, simulations and restoration opportunities in the central Applachians. Restoration Ecology. 15(3): 440-452.

Rentch, J.S., Ford, W.M., Schuler, T.S., Palmer, J., and C.A. Diggins. 2016. Release of suppressed red spruce using canopy gap creation- Ecological restoration in the central Appalachians. Natural Areas Journal. 36(1): 29-37.

Rodriguez, R. 2015. Interation of topographic and bathymetric digital elevation models using ArcGIS interpolation methods. Diss. University of Southern California.

SAS Institute, Inc. 2013. SAS/ETS ${ }^{1} 12.3$ User’s Guide. Cary, NC: SAS Institute, Inc.

Sauer, D., H. Sponagel, M. Sommer, L. Giani, J. Reinhold, and K. Stahr. 2007. Podzol: Soil of the Year 2007: A review on genesis, occurrence, and functions. Journal of Plant Nutrition and Soil Science. 170(5): 581-597.

Seyfried, M., Link, t., Marks, D., Murdock, M. 2016. Soil temperature variability in complex terrain measured using fiber-optic distributed temperature sensing. Vadose Zone Journal. 15(6): 1539-1663.

Sohet, K., J. Herbauts, and W. Gruber. 1988. Changes caused by Norway spruce in an ochreous brown earth, assessed by the isoquartz method. Journal of Soil Science. 39(4): 549-561.

Soil Survey Staff. 2015. Kellogg Soil Survey Laboratory Methods Manual. Soil Survey Investigations Report No. 42, Version 5.0. R. Burt and Soil Survey Staff (ed.). U.S. Department of Agriculture, Natural Resources Conservation Service. http://www.nrcs.usda.gov/wps/portal/nrcs/detail/soils/ref/?cid=nrcs142p2_054247. Accessed 02/10/2016. 
Soil Survey Staff, Natural Resources Conservation Service, United States Department of Agriculture. Official Soil Series Descriptions. Available online. Accessed 06/05/2017. Tajchman, S.J., and H.V., Wiant. 1983. Topography and biomass characteristics of a forested catchment in the northern Appalachians. Forest Ecology and Management. 5: 55-69.

Tarnocai, C. et al. 2009. Soil organic carbon pools in the northern circumpolar permafrost region. Global Biogeochemical Cycles. 23(2):1-11.

Teets, J.G. and Nowacki, G. 2012. Conservation and restoration of America's great outdoors: soil science adds additional restoration tools. http://www.nrcs.usda.gov/wps/portal/nrcs/ detail/wv/newsroom/factsheets/?cid=nrcs144p2_074439

Theobald, D.M., D.L. Stevens, D. White, N.S. Urquhart, A.R. Olsen, and J.B. Norman. 2007. Using GIS to Generate Spatially Balanced Random Survey Designs for Natural Resource Applications. Environmental Management. 40(1): 134-146.

Thomas-Van Gundy, Melissa, Michael Strager, and James Rentch. "Site characteristics of red spruce witness tree locations in the uplands of West Virginia, USA." The Journal of the Torrey Botanical Society 139.4 (2012): 391-405.

University of Connecticut. 2011. Introduction to MaxEnt. http://web2.uconn.edu/cyberinfra/ module3/Downloads/Day\%204\%20-\%20Maxent.pdf. Accessed 04/28/2017.

Voltz, M., and Webster, R. 1990. A comparison of kriging, cubic splines and classification for predicting soil properties from sample information. European Journal of Soil Science. 41(3), 473-490.

Warren, D.L., and Seifert, S.N. 2011. Ecological niche modeling in Maxent: the importance of model complexity and the performance of model selection criteria. Ecological Applications. 21(2), 335-342. 
Whiteman, C.D., J.M. Hubbe, and W.J. Shaw. 1999. Evaluation of inexpensive temperature data logger for meteorological applications. American Meteorological Society. 17(1):77-81.

WV DNR, CASRI, USFS MNF. 2013. Red spruce (Picea rubens) cover in West Virginia 2013. http://wvgis.wvu.edu/data/dataset.php?ID=455. Accessed 01/15/2016.

Yao, X., Fu, B., Lu, Y, Sun, F., Wang, S., and L. Min. 2013. Comparison of four spatial interpolation methods for estimating soil moisture in a complex terrain catchment. PLoS ONE. 8(1): e54660.

Young, N., Carter, L., Evangelista, P., 2011. A MaxEnt model v3.3.3e tutorial (ArcGIS v10). Natural Resource Ecology Laboratory, Colorado State University. http://ibis.colostate.edu/webcontent/ws/coloradoview/tutorialsdownloads/a_maxent_mod el_v7.pdf. Accessed 04/03/2017.

Zhu, Q., Lin, H.S. 2010. Comparing ordinary kriging and regression kriging for soil properties in contrasting landscapes. Pedosphere. 20(5): 594-606. 


\subsection{Tables and Figures}

Table 1. Summary of missing soil moisture and soil temperature data for the period December 2015 through September 2016.

\begin{tabular}{|c|c|c|c|c|c|c|c|}
\hline \multirow[t]{2}{*}{ Plot } & \multicolumn{3}{|c|}{ Soil Moisture } & \multicolumn{3}{|c|}{ Soil Temperature } & \multirow[t]{2}{*}{ Dates } \\
\hline & $0 \mathrm{~cm}$ & $25 \mathrm{~cm}$ & $50 \mathrm{~cm}$ & $0 \mathrm{~cm}$ & $25 \mathrm{~cm}$ & $50 \mathrm{~cm}$ & \\
\hline & \multicolumn{6}{|c|}{ Number of days of missing data - } & \multirow{4}{*}{ Aug, Sept 2016} \\
\hline 0 & 38 & 38 & 38 & 38 & 38 & 38 & \\
\hline 1 & $2^{\mathrm{a}}$ & 2 & 2 & 2 & 2 & 2 & \\
\hline 2 & 0 & 0 & 0 & 0 & 0 & 0 & \\
\hline \multirow[t]{2}{*}{3} & 78 & 56 & 31 & 78 & 56 & 31 & Dec 2015; Jan, Aug, Sept \\
\hline & & & & & & & 2016 \\
\hline 4 & 12 & 12 & 2 & 12 & 12 & 2 & Sept 2016 \\
\hline 5 & 2 & 2 & 2 & 2 & 2 & 2 & \\
\hline 6 & 57 & 2 & 2 & 57 & 2 & 2 & Jul, Aug, Sept 2016 \\
\hline 9 & 25 & 2 & 2 & 2 & 2 & 2 & Sept 2016 \\
\hline 10 & 2 & 2 & 2 & 2 & 2 & 2 & \\
\hline 11 & 2 & 2 & 96 & 2 & 2 & 96 & Dec 2015 to Mar 2016 \\
\hline 12 & 2 & 2 & 2 & 2 & 2 & 2 & \\
\hline 13 & 2 & 2 & 2 & 2 & 2 & 2 & \\
\hline \multirow[t]{2}{*}{14} & 67 & 67 & 32 & 67 & 67 & 32 & Dec 2015; Jan, Aug, Sept \\
\hline & & & & & & & 2016 \\
\hline 16 & 30 & 30 & 30 & 30 & 30 & 30 & Sept 2016 \\
\hline 17 & 80 & 80 & 80 & 80 & 80 & 80 & May to Aug 2016 \\
\hline 19 & 28 & 28 & 28 & 28 & 28 & 28 & Sept 2016 \\
\hline
\end{tabular}




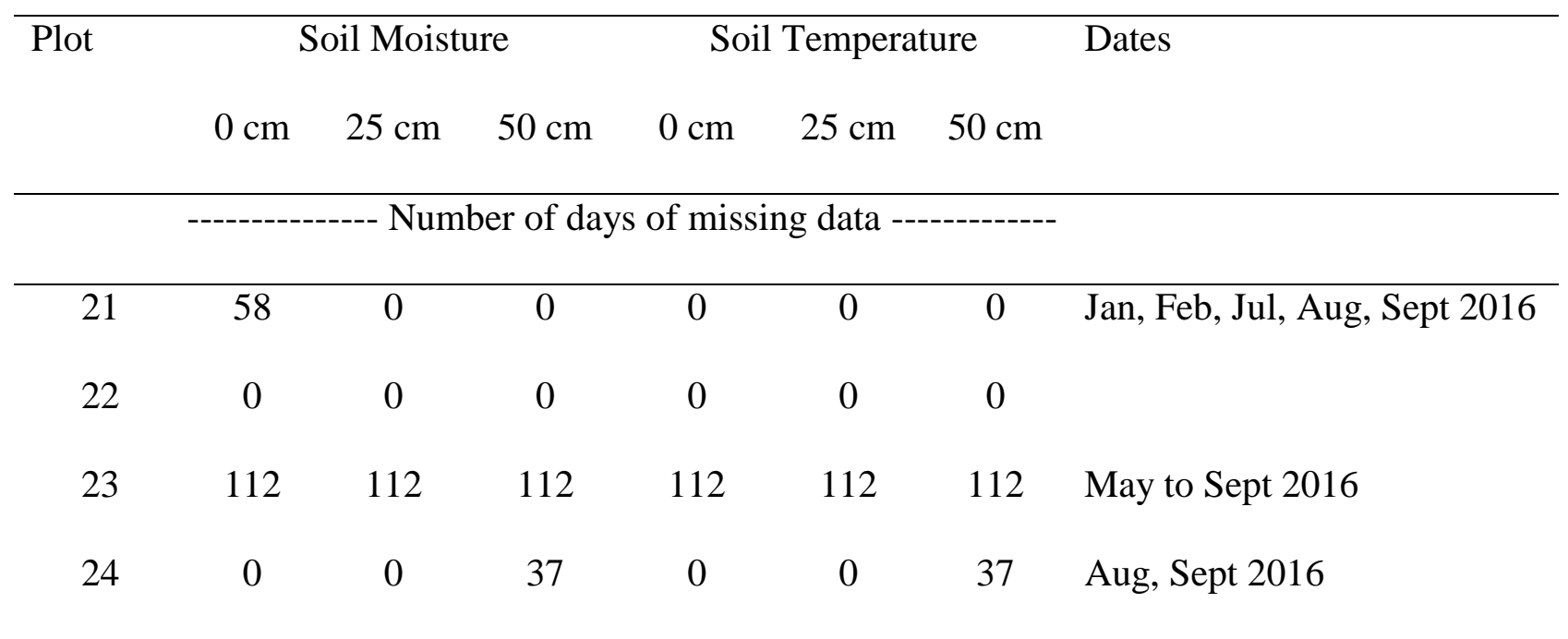

${ }^{\mathrm{a}}$ For all plots with 2 days of missing data, data collection was terminated on September 29, 2016. 
Table 2. Correlation statistics for correlation among plots (Pearson) and serial correlation (Durbin-Watson).

Durbin-Watson

Variable

Pearson Correlation Coefficient

Statistic

$$
(\text { minimum })^{\mathrm{a}}
$$

${\text { (maximum })^{\mathrm{a}}}$

(mean)

(mean)

Air temperature

0.9827

0.9986

0.9932

0.0043

Soil moisture at $0 \mathrm{~cm}$

0.0100

0.9461

0.6449

0.0146

Soil moisture at $25 \mathrm{~cm}$

0.0144

0.9671

0.7308

0.0259

Soil moisture at $50 \mathrm{~cm}$

0.0077

0.9768

0.6362

0.0424

Soil temperature at $0 \mathrm{~cm}$

0.9563

0.9984

0.9891

0.0030

Soil temperature at $25 \mathrm{~cm}$

0.9722

0.9996

0.9955

0.0011

Soil temperature at $50 \mathrm{~cm}$

0.9960

0.9996

0.9949

0.0013

${ }^{a}$ absolute values. 
Table 3. All topographic and microclimatic variables used in preliminary model runs.

\begin{tabular}{ll}
\hline Variable & Description \\
\hline Air Temperature & average July daytime air temperature for each plot \\
\hline julavgdaytime & average August daytime air temperature for each plot \\
augavgdaytime & coldest January 30-min air temperature for each plot - any date \\
janabsminanyday & coldest February 30-min air temperature for each plot - any date \\
febabsminanyday & coolest July 30-min air temperature for each plot - any date \\
julabsminanyday & coolest August 30-min air temperature for each plot - any date \\
augabsminanyday & coldest November 30-min air temperature for each plot - any date \\
novabsminanyday & coldest December 30-min air temperature for each plot - any date \\
decabsminanyday & hottest July 30-min air temperature for each plot - any date \\
julabsmaxanyday & hottest August 30-min air temperature for each plot - any date \\
augabsmaxanyday & coldest January daily mean air temperature for each plot - any date \\
jandailyminanyday & coldest February daily mean air temperature for each plot - any date \\
febdailyminanyday & coolest July daily mean air temperature for each plot - any date \\
juldailyminanyday & coolest August daily mean air temperature for each plot - any date \\
augdailyminanyday & hottest July daily mean air temperature for each plot - any date \\
juldailymaxanyday & hottest August daily mean air temperature for each plot - any date \\
augdailymaxanyday & coldest daily mean air temperature for each plot- any date \\
absmaxanyday & annual mean from monthly means of all 30-min readings \\
absminanyday & anntempalldata
\end{tabular}


Variable

Description

\section{Soil Temperature}

febabsminanyday $0 \mathrm{~cm}$

febabsminanyday $25 \mathrm{~cm}$

febabsminanyday $50 \mathrm{~cm}$

febdailyminanyday $0 \mathrm{~cm}$

febdailyminanyday $25 \mathrm{~cm}$

febdailyminanyday $50 \mathrm{~cm}$

decabsminanyday $0 \mathrm{~cm}$

decabsminanyday $25 \mathrm{~cm}$

decabsminanyday50cm

decabsmaxanyday0cm

decabsmaxanyday $25 \mathrm{~cm}$

decabsmaxanyday $50 \mathrm{~cm}$

decdailyminanyday0cm

decdailyminanyday $25 \mathrm{~cm}$

decdailyminanyday $50 \mathrm{~cm}$

decdailymaxanyday $0 \mathrm{~cm}$

decdailymaxanyday $25 \mathrm{~cm}$

decdailymaxanyday $50 \mathrm{~cm}$

janabsminanyday $0 \mathrm{~cm}$

janabsminanyday $25 \mathrm{~cm}$

janabsminanyday $50 \mathrm{~cm}$

janabsmaxanyday0cm coldest February 1-hr soil temperature for each plot - any date

coldest February 1-hr soil temperature for each plot - any date coldest February 1-hr soil temperature for each plot - any date coldest February daily mean soil temperature for each plot - any date coldest February daily mean soil temperature for each plot - any date coldest February daily mean soil temperature for each plot - any date coldest December 1-hr soil temperature for each plot - any date coldest December 1-hr soil temperature for each plot - any date coldest December 1-hr soil temperature for each plot - any date warmest December 1-hr soil temperature for each plot - any date warmest December 1-hr soil temperature for each plot - any date warmest December 1-hr soil temperature for each plot - any date coldest December daily mean soil temperature for each plot - any date coldest December daily mean soil temperature for each plot - any date coldest December daily mean soil temperature for each plot - any date warmest December daily mean soil temperature for each plot - any date warmest December daily mean soil temperature for each plot - any date warmest December daily mean soil temperature for each plot - any date coldest January 1-hr soil temperature for each plot - any date coldest January 1-hr soil temperature for each plot - any date coldest January 1-hr soil temperature for each plot - any date warmest January 1-hr soil temperature for each plot - any date 


\begin{tabular}{|c|c|}
\hline Variable & Description \\
\hline janabsmaxanyday $25 \mathrm{~cm}$ & warmest January 1-hr soil temperature for each plot - any date \\
\hline janabsmaxanyday $50 \mathrm{~cm}$ & warmest January 1-hr soil temperature for each plot - any date \\
\hline jandailyminanyday $0 \mathrm{~cm}$ & coldest January daily mean soil temperature for each plot - any date \\
\hline jandailyminanyday $25 \mathrm{~cm}$ & coldest January daily mean soil temperature for each plot - any date \\
\hline jandailyminanyday $50 \mathrm{~cm}$ & coldest January daily mean soil temperature for each plot - any date \\
\hline jandailymaxanyday $0 \mathrm{~cm}$ & warmest January daily mean soil temperature for each plot - any date \\
\hline jandailymaxanyday $25 \mathrm{~cm}$ & warmest January daily mean soil temperature for each plot - any date \\
\hline jandailymaxanyday $50 \mathrm{~cm}$ & warmest January daily mean soil temperature for each plot - any date \\
\hline julabsminanyday $0 \mathrm{~cm}$ & coolest July 1-hr soil temperature for each plot - any date \\
\hline julabsminanyday $25 \mathrm{~cm}$ & coolest July 1-hr soil temperature for each plot - any date \\
\hline julabsminanyday $50 \mathrm{~cm}$ & coolest July 1-hr soil temperature for each plot - any date \\
\hline julabsmaxanyday $0 \mathrm{~cm}$ & warmest July 1-hr soil temperature for each plot - any date \\
\hline julabsmaxanyday $25 \mathrm{~cm}$ & warmest July 1-hr soil temperature for each plot - any date \\
\hline julabsmaxanyday $50 \mathrm{~cm}$ & warmest July 1-hr soil temperature for each plot - any date \\
\hline juldailyminanyday $0 \mathrm{~cm}$ & coolest July daily mean soil temperature for each plot - any date \\
\hline juldailyminanyday $25 \mathrm{~cm}$ & coolest July daily mean soil temperature for each plot - any date \\
\hline juldailyminanyday $50 \mathrm{~cm}$ & coolest July daily mean soil temperature for each plot - any date \\
\hline juldailymaxanyday $0 \mathrm{~cm}$ & warmest July daily mean soil temperature for each plot - any date \\
\hline juldailymaxanyday $25 \mathrm{~cm}$ & warmest July daily mean soil temperature for each plot - any date \\
\hline juldailymaxanyday $50 \mathrm{~cm}$ & warmest July daily mean soil temperature for each plot - any date \\
\hline augabsminanyday $0 \mathrm{~cm}$ & coolest August 1-hr soil temperature for each plot - any date \\
\hline augabsminanyday $25 \mathrm{~cm}$ & coolest August 1-hr soil temperature for each plot - any date \\
\hline augabsminanyday $50 \mathrm{~cm}$ & coolest August 1-hr soil temperature for each plot - any date \\
\hline
\end{tabular}




\begin{tabular}{ll}
\hline Variable & Description \\
\hline $\begin{array}{ll}\text { augabsmaxanyday0cm } \\
\text { augabsmaxanyday } 25 \mathrm{~cm}\end{array}$ & warmest August 1-hr soil temperature for each plot - any date \\
$\begin{array}{ll}\text { augabsmaxanyday } 50 \mathrm{~cm} \\
\text { augdailyminanyday0 } 0 \mathrm{~cm}\end{array}$ & warmest August 1-hr soil temperature for each plot - any date \\
$\begin{array}{l}\text { coolest August daily mean soil temperature for each plot - any date } \\
\text { augdailyminanyday } 50 \mathrm{~cm}\end{array}$ & coolest August daily mean soil temperature for each plot - any date \\
augdailymaxanyday $0 \mathrm{~cm}$ & warmest August daily mean soil temperature for each plot - any date \\
augdailymaxanyday $25 \mathrm{~cm}$ & warmest August daily mean soil temperature for each plot - any date \\
augdailymaxanyday $50 \mathrm{~cm}$ & warmest August daily mean soil temperature for each plot - any date
\end{tabular}

\section{Soil Moisture}

$\begin{array}{ll}\begin{array}{l}\text { dry } 24 \mathrm{hr} 0 \mathrm{~cm} \\ \text { dry } 24 \mathrm{hr} 25 \mathrm{~cm}\end{array} & \text { driest 24-hr mean soil moisture for each plot in May-Sept } 2016 \\ \text { dry } 24 \mathrm{hr} 50 \mathrm{~cm} & \text { driest 24-hr mean soil moisture for each plot in May-Sept } 2016 \\ \text { dry7day0cm } & \text { driest 7-day mean soil moisture for each plot in May-Sept } 2016 \\ \text { dry7day25cm } & \text { driest 7-day mean soil moisture for each plot in May-Sept } 2016 \\ \text { dry7day50cm } & \text { driest 7-day mean soil moisture for each plot in May-Sept } 2016 \\ \text { dry30day0cm } & \text { driest 30-day mean soil moisture for each plot in May-Sept } 2016 \\ \text { dry30day25cm } & \text { driest 30-day mean soil moisture for each plot in May-Sept } 2016 \\ \text { dry30day } 50 \mathrm{~cm} & \text { driest 30-day mean soil moisture for each plot in May-Sept } 2016 \\ \text { julabsminanyday0cm } & \text { driest July 1-hr soil moisture for each plot - any date } \\ \text { julabsminanyday } 25 \mathrm{~cm} & \text { driest July 1-hr soil moisture for each plot - any date } \\ \text { julabsminanyday50cm } & \text { driest July 1-hr soil moisture for each plot - any date }\end{array}$




\begin{tabular}{|c|c|}
\hline Variable & Description \\
\hline julabsmaxanyday0cm & wettest July 1-hr soil moisture for each plot - any date \\
\hline julabsmaxanyday $25 \mathrm{~cm}$ & wettest July 1-hr soil moisture for each plot - any date \\
\hline julabsmaxanyday $50 \mathrm{~cm}$ & wettest July 1-hr soil moisture for each plot - any date \\
\hline juldailyminanyday $0 \mathrm{~cm}$ & driest July daily mean soil moisture for each plot - any date \\
\hline juldailyminanyday $25 \mathrm{~cm}$ & driest July daily mean soil moisture for each plot - any date \\
\hline juldailyminanyday $50 \mathrm{~cm}$ & driest July daily mean soil moisture for each plot - any date \\
\hline juldailymaxanyday $0 \mathrm{~cm}$ & wettest July daily mean soil moisture for each plot - any date \\
\hline juldailymaxanyday $25 \mathrm{~cm}$ & wettest July daily mean soil moisture for each plot - any date \\
\hline juldailymaxanyday $50 \mathrm{~cm}$ & wettest July daily mean soil moisture for each plot - any date \\
\hline augabsminanyday $0 \mathrm{~cm}$ & driest August 1-hr soil moisture for each plot - any date \\
\hline augabsminanyday $25 \mathrm{~cm}$ & driest August 1-hr soil moisture for each plot - any date \\
\hline augabsminanyday $50 \mathrm{~cm}$ & driest August 1-hr soil moisture for each plot - any date \\
\hline augabsmaxanyday $0 \mathrm{~cm}$ & wettest August 1-hr soil moisture for each plot - any date \\
\hline augabsmaxanyday $25 \mathrm{~cm}$ & wettest August 1-hr soil moisture for each plot - any date \\
\hline augabsmaxanyday $50 \mathrm{~cm}$ & wettest August 1-hr soil moisture for each plot - any date \\
\hline augdailyminanyday $0 \mathrm{~cm}$ & driest August daily mean soil moisture for each plot - any date \\
\hline augdailyminanyday $25 \mathrm{~cm}$ & driest August daily mean soil moisture for each plot - any date \\
\hline augdailyminanyday $50 \mathrm{~cm}$ & driest August daily mean soil moisture for each plot - any date \\
\hline augdailymaxanyday $0 \mathrm{~cm}$ & wettest August daily mean soil moisture for each plot - any date \\
\hline augdailymaxanyday $25 \mathrm{~cm}$ & wettest August daily mean soil moisture for each plot - any date \\
\hline
\end{tabular}




\begin{tabular}{ll}
\hline Variable & Description \\
\hline Topographic Variables & \\
\hline aspect & linear aspect calculated using geomorphometry and gradient metrix \\
& toolbox (Evans et al., accessed 2017) \\
aacn & altitude above local stream channel \\
baselevel & elevation of nearest channel point to each pixel in its given watershed \\
converg & overall measure of concavity \\
lsfactor & slope-length factor from USLE as calculated in SAGA GIS \\
plancurv & curvature perpendicular to slope direction \\
profcurv & curvature parallel to slope direction \\
slope & slope gradient (rise/run) in fraction units \\
slpos & index from 0 (valley floor) to 100 (ridgetop) of slope position (Hatfield, \\
& 1996) \\
twi & topographic wetness index \\
\hline
\end{tabular}


Table 4. Classification of model results into low or high relative occurrence rates (ROR) for agreement/disagreement analysis. The median ROR for each model was used as the classification break point for that model.

\section{Cell Values Assigned For Each Model}

Topographic Variables Only (TV) Topographic and Microclimatic Variables

(TMV)

\begin{tabular}{lccc}
\hline Modeled Occurrence & Cell Value & Modeled Occurrence & Cell Value \\
\hline Low probability & 1 & Low probability & 4 \\
High probability & 2 & High probability & 10 \\
& Sum of Model Cell Values & \\
\hline Model Comparison & Cell Sum & Model
\end{tabular}

Both high probability

Both low probability

TV high probability, TMV low probability

TV low probability, TMV high probability
12

5

6

11
Agreement

Agreement

Disagreement

Disagreement 
Table 5. Area under the receiver operating curve (AUC) values for the four preliminary models. Model AUC Value

Topographic variables only $\quad 0.800$

Air temperature variables only 0.794

Soil temperature variables only $\quad 0.781$

Soil moisture variables only $\quad 0.690$ 
Table 6. Permutation importance (PI) values for model runs employing only topographic variables, only air temperature variables, only soil temperature variables and only soil moisture variables.

\begin{tabular}{|c|c|c|c|c|c|c|c|}
\hline \multicolumn{2}{|c|}{ Topographic Variables } & \multicolumn{2}{|c|}{ Air Temperature } & \multicolumn{2}{|l|}{ Soil Temperature } & \multicolumn{2}{|l|}{ Soil Moisture } \\
\hline Variable & PI \% & Variable & PI & Variable & PI & Variable & PI \\
\hline & & & $\%$ & & $\%$ & & $\%$ \\
\hline aacn & 70 & augabsmaxanyday & 29.9 & augabsmaxanyday $0 \mathrm{cmt}$ & 25.6 & juldailymaxanyday50cm & 25.7 \\
\hline twi & $7^{\dagger}$ & augdailyminanyday & $20^{\dagger}$ & augdailyminanyday $25 \mathrm{cmt}$ & $14^{\dagger}$ & dry $24 \mathrm{hr} 0 \mathrm{~cm}$ & 22.5 \\
\hline slpos & 6.1 & janabsminanyday & 13 & augdailyminanyday $0 \mathrm{cmt}$ & 11.3 & augdailymaxanyday $50 \mathrm{~cm}$ & $12.4^{\dagger}$ \\
\hline converg & 3.4 & febdailyminanyday & 8.8 & augdailymaxanyday $50 \mathrm{cmt}$ & 10.6 & dry 7 day $0 \mathrm{~cm}$ & 8.8 \\
\hline plancurv & 3.3 & juldailyminanyday & 6.4 & febabsminanyday $0 \mathrm{~cm}$ & 9.6 & julabsminanyday $50 \mathrm{~cm}$ & 8.2 \\
\hline aspect & 3.1 & decabsminanyday & 4 & decabsmaxanyday $25 \mathrm{cmt}$ & 8.5 & augdailymaxanyday $0 \mathrm{~cm}$ & 4.6 \\
\hline baselevel & 2.5 & novabsminanyday & 3.6 & decdailymaxanyday $25 \mathrm{cmt}$ & 7.1 & augdailymaxanyday $25 \mathrm{~cm}$ & 4 \\
\hline profcurv & 2.1 & anntempalldata & 3.5 & febabsminanyday $25 \mathrm{~cm}$ & 2.8 & julabsminanyday $0 \mathrm{~cm}$ & 3.4 \\
\hline slope & 1.8 & augdailymaxanyday & 2.2 & janabsmaxanyday $25 \mathrm{cmt}$ & 2.4 & dry7day $50 \mathrm{~cm}$ & 2.6 \\
\hline \multirow[t]{3}{*}{ lsfactor } & 0.7 & augdavgdaytime & 1.8 & decabsmaxanyday $0 \mathrm{cmt}$ & 2.1 & dry30day $50 \mathrm{~cm}$ & 2.4 \\
\hline & & absmaxanyday & 1.8 & julabsmaxanyday0cmt & 1.9 & juldailymaxanyday $0 \mathrm{~cm}$ & 1.9 \\
\hline & & juldailymaxanyday & 1.8 & decabsmaxanyday $50 \mathrm{cmt}$ & 1.4 & augabsmaxanyday $50 \mathrm{~cm}$ & 1.3 \\
\hline
\end{tabular}




\begin{tabular}{|c|c|c|c|c|c|c|}
\hline \multirow{2}{*}{$\begin{array}{l}\text { Topographic Variables } \\
\text { Variable } \quad \text { PI \% }\end{array}$} & \multicolumn{2}{|c|}{ Air Temperature } & \multicolumn{2}{|l|}{ Soil Temperature } & \multicolumn{2}{|l|}{ Soil Moisture } \\
\hline & Variable & PI & Variable & $\mathrm{PI}$ & Variable & PI \\
\hline & & $\%$ & & $\%$ & & $\%$ \\
\hline & absminanyday & 1.2 & jandailymaxanyday $25 \mathrm{cmt}$ & 1.2 & augabsmaxanyday0cm & 1 \\
\hline & febabsminanyday & 0.8 & jandailyminanyday $0 \mathrm{cmt}$ & 0.9 & augabsminanyday $0 \mathrm{~cm}$ & 0.8 \\
\hline & julabsminanyday & 0.7 & julabsminanyday $50 \mathrm{cmt}$ & 0.6 & augabsmaxanyday $25 \mathrm{~cm}$ & 0.3 \\
\hline & julavgdaytime & 0.4 & febabsminanyday $50 \mathrm{~cm}$ & 0.1 & dry $24 \mathrm{hr} 50 \mathrm{~cm}$ & 0 \\
\hline & augabsminanyday & 0.1 & janabsminanyday $0 \mathrm{cmt}$ & 0 & juldailyminanyday $50 \mathrm{~cm}$ & 0 \\
\hline & anntempbioclim & 0 & jandailymaxanyday $0 \mathrm{cmt}$ & 0 & julabsmaxanyday $0 \mathrm{~cm}$ & 0 \\
\hline & jandailyminanyday & 0 & augabsminanyday $25 \mathrm{cmt}$ & 0 & augdailyminanyday $0 \mathrm{~cm}$ & 0 \\
\hline & julabsmaxanyday & 0 & augabsmaxanyday $25 \mathrm{cmt}$ & 0 & julabsmaxanyday $50 \mathrm{~cm}$ & 0 \\
\hline & & & juldailyminanyday $50 \mathrm{cmt}$ & 0 & julabsmaxanyday $25 \mathrm{~cm}$ & 0 \\
\hline & & & augdailymaxanyday $25 \mathrm{cmt}$ & 0 & augdailyminanyday $25 \mathrm{~cm}$ & 0 \\
\hline & & & julabsmaxanyday $50 \mathrm{cmt}$ & 0 & dry $24 \mathrm{hr} 25 \mathrm{~cm}$ & 0 \\
\hline & & & janabsmaxanyday0 $\mathrm{cmt}$ & 0 & augdailyminanyday $50 \mathrm{~cm}$ & 0 \\
\hline & & & augabsmaxanyday $50 \mathrm{cmt}$ & 0 & dry 7 day $25 \mathrm{~cm}$ & 0 \\
\hline
\end{tabular}




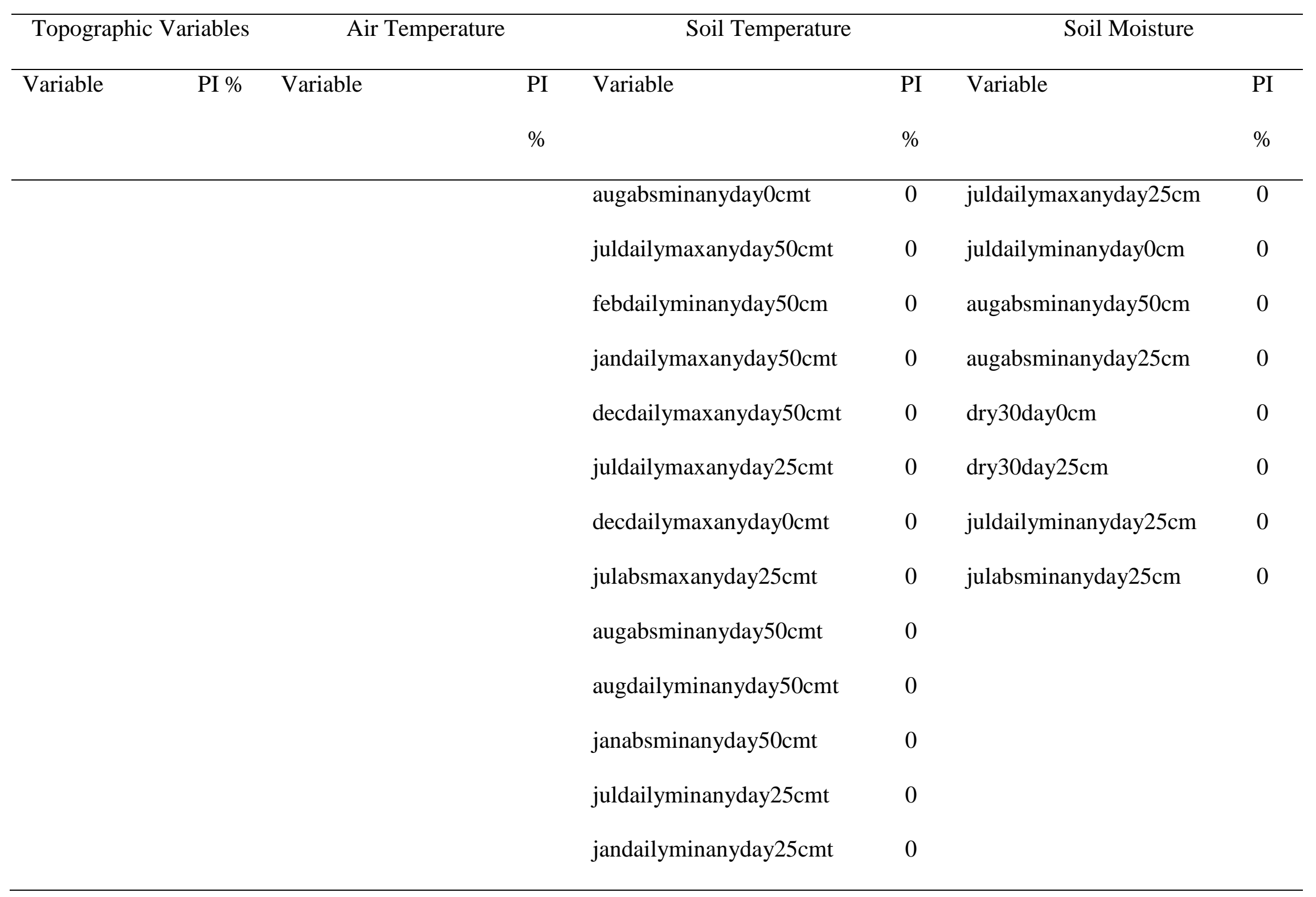




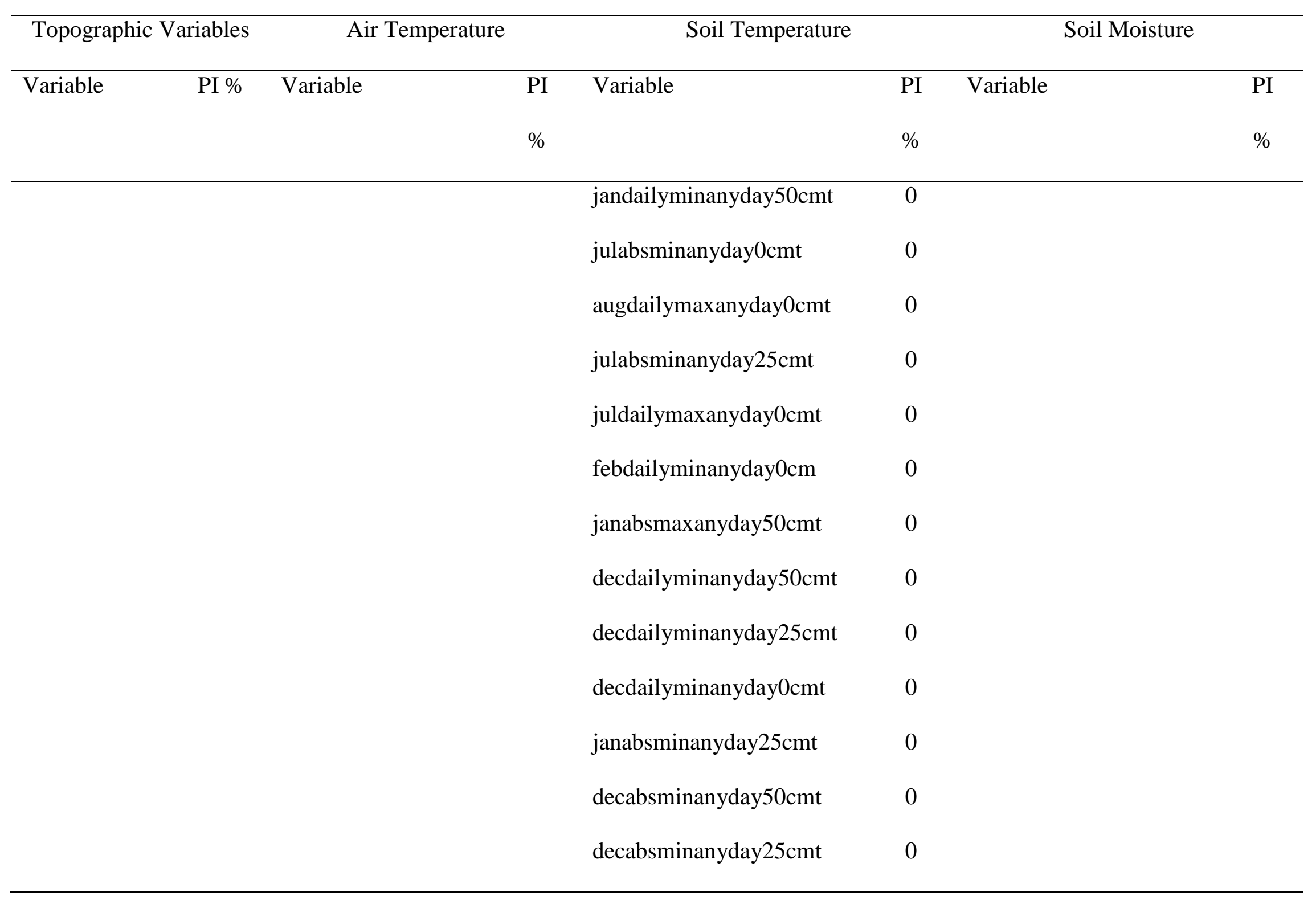




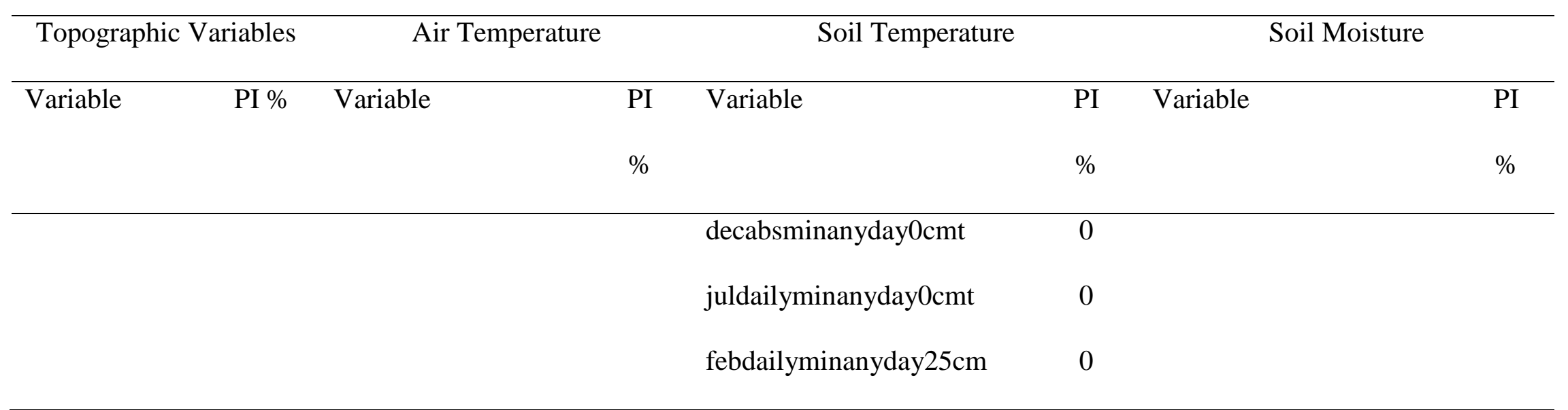

${ }^{\dagger}$ Large changes in permutation importance values indicates variables with higher permutation importance were important for the model (Kalle et al., 2013) 
Table 7. Correlation coefficients for the most important variables from the four preliminary models used in the final model.

\begin{tabular}{|c|c|c|c|c|c|}
\hline & aacn & dry $24 \mathrm{hr} 0 \mathrm{~cm}$ & $\begin{array}{l}\text { juldailymax } \\
\text { anyday50 }\end{array}$ & $\begin{array}{c}\text { augabsmax } \\
\text { anyday }\end{array}$ & $\begin{array}{l}\text { augabsmax } \\
\text { anyday0cm }\end{array}$ \\
\hline aacn & 1 & & & & \\
\hline dry $24 \mathrm{hr} 0 \mathrm{~cm}$ & -0.00822 & 1 & & & \\
\hline juldailymaxanyday $50 \mathrm{~cm}$ & 0.05387 & -0.66889 & 1 & & \\
\hline augabsmaxanyday & 0.30995 & -0.42988 & 0.21154 & 1 & \\
\hline augabsmaxanyday $0 \mathrm{~cm}$ & 0.00776 & -0.12838 & 0.23263 & -0.28272 & 1 \\
\hline
\end{tabular}


Table 8. Permutation importance values for all variables in the final model.

\begin{tabular}{lc} 
Variable & Permutation Importance (\%) \\
\hline aacn & 36.7 \\
augabsmaxanyday & 24.3 \\
augabsmaxanyday0cm & 18.3 \\
dry24hr0cm & 11.5 \\
juldailymaxanyday50cm & 9.2 \\
\hline
\end{tabular}


Table 9. Agreement/disagreement results for the topographic-only model compared to the topographic and microclimatic model, when classified into high and low relative occurrence rate (ROR) classes. The value column refers to the possible sums in Table 4.

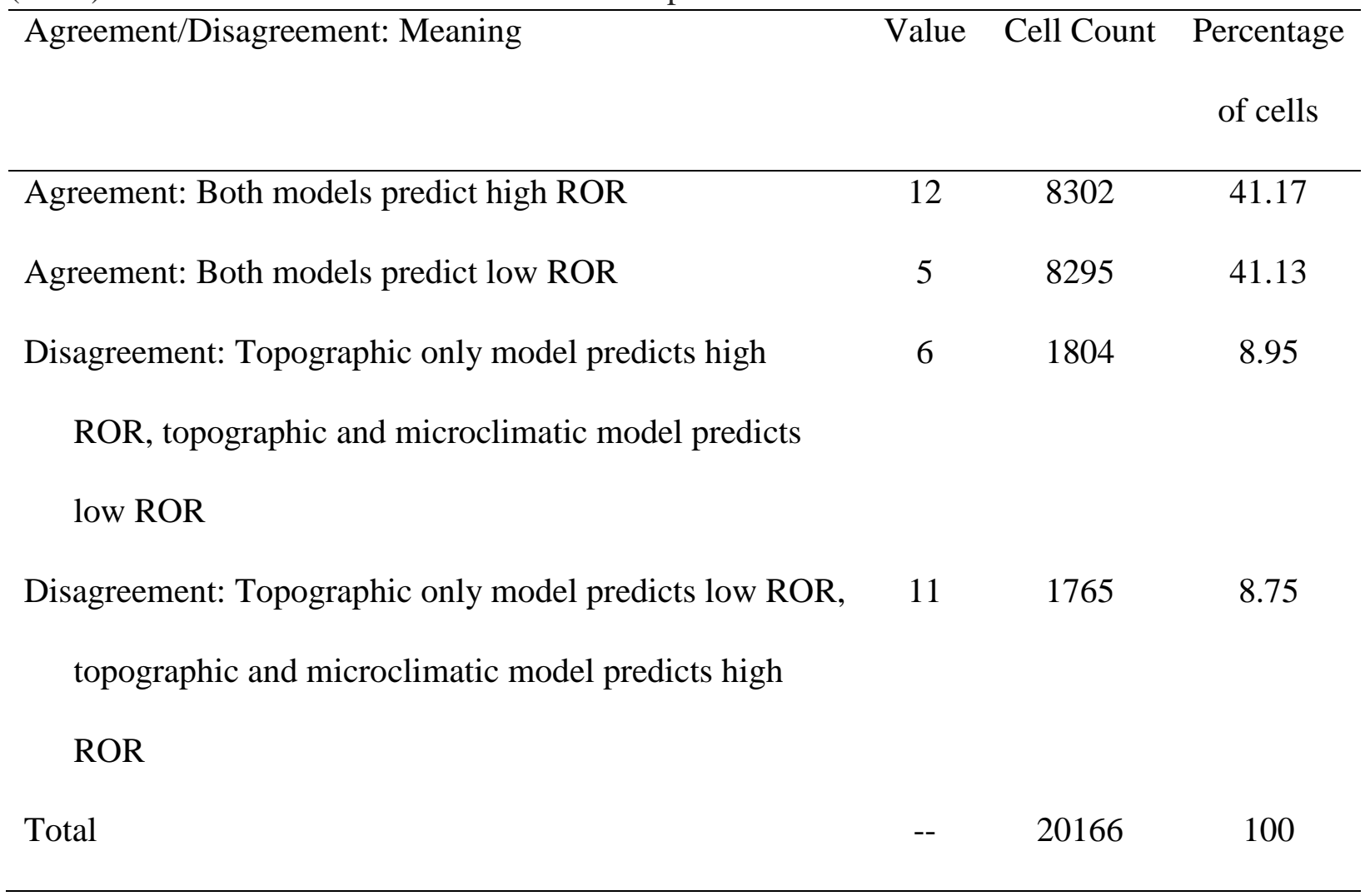


Table 10. Minimum, maximum and mean data values for topographic and microclimatic variables in areas of disagreement between the model that utilized only topographic variables and the final model that used the five most important topographic and microclimatic variables. Means within each row were significantly different ( $p<0.0001)$, except for variable baselevel ( $p$ $=0.1827)$.

\begin{tabular}{|c|c|c|c|c|c|c|}
\hline \multirow[t]{5}{*}{ Variable } & \multirow{2}{*}{\multicolumn{3}{|c|}{$\begin{array}{l}\text { Topographic-Only High ROR- } \\
\text { Topographic and Microclimatic }\end{array}$}} & \multicolumn{3}{|c|}{ Topographic-Only Low ROR- } \\
\hline & & & & \multicolumn{3}{|c|}{ Topographic and Microclimatic High } \\
\hline & \multicolumn{3}{|c|}{ Low ROR } & \multicolumn{3}{|c|}{ ROR } \\
\hline & Minimu & Maximum & Mean & Minimum & Maximum & Mean \\
\hline & $\mathrm{m}$ & & & & & \\
\hline aacn & 9.2793 & 107.2050 & 52.6698 & 0.0000 & 95.6475 & 38.7966 \\
\hline twi & 3.8263 & 9.5348 & 5.1574 & 4.0789 & 19.3429 & 9.3355 \\
\hline slpos & 10.0000 & 101.0000 & 52.7899 & 0.0000 & 101.0000 & 39.6346 \\
\hline convergence & -26.5217 & 87.1083 & 8.9820 & -84.6164 & 40.9510 & -22.7051 \\
\hline plancurvature & -0.0024 & 0.0039 & 0.0010 & -0.0053 & 0.0031 & -0.0015 \\
\hline profilecurvature & -0.0043 & 0.0052 & 0.0006 & -0.0055 & 0.0034 & -0.0007 \\
\hline baselevel & 948.9690 & 1050.2300 & 996.6314 & 931.9300 & 1046.7400 & 991.8068 \\
\hline lsfactor & 0.0015 & 8.6060 & 4.0371 & 0.0002 & 13.9482 & 3.6601 \\
\hline slope & 0.0009 & 0.5197 & 0.2741 & 0.0000 & 0.3992 & 0.1700 \\
\hline aspect & 0.0000 & 359.0000 & 186.3065 & 0.0000 & 359.00 & 241.1394 \\
\hline augabsmaxanyday & 25.6081 & 30.8500 & 27.5733 & 24.7939 & 30.6949 & 26.1414 \\
\hline augabsmaxanyday $0 \mathrm{~cm}$ & 20.6037 & 22.9676 & 21.3709 & 20.3590 & 23.6082 & 21.2077 \\
\hline juldailymaxanyday $50 \mathrm{~cm}$ & 5.0954 & 16.7808 & 10.8404 & 4.7875 & 16.4665 & 9.5597 \\
\hline dry $24 \mathrm{hr} 0 \mathrm{~cm}$ & 0.0415 & 0.1330 & 0.0703 & 0.0366 & 0.1555 & 0.0848 \\
\hline
\end{tabular}




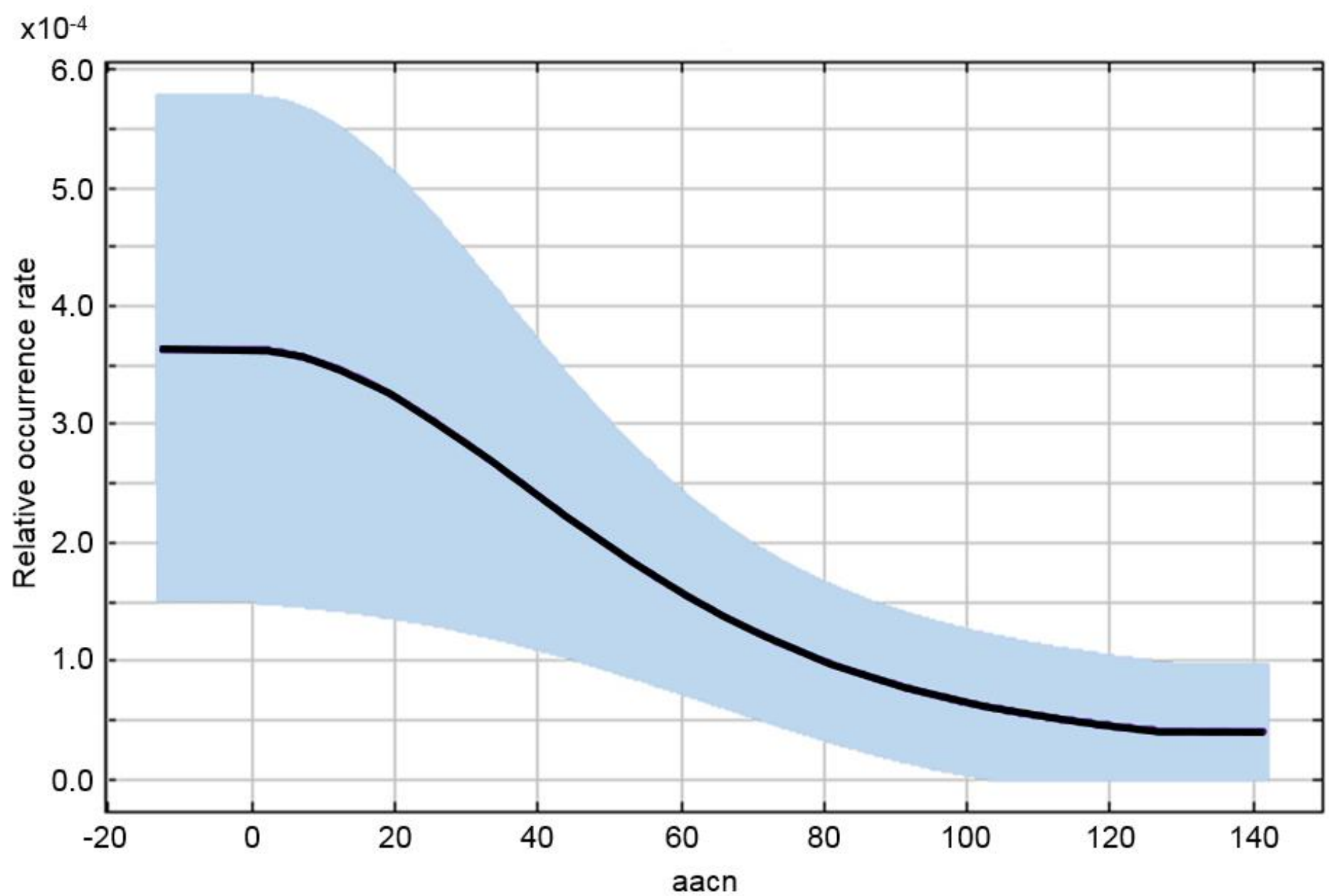

Figure 1. Response curve for topographical variable aacn when all other variables are held constant at their mean. The black line shows the mean (over 10 runs) ROR response to aacn. The mean $+/$ - one standard deviation is represented in light blue. 


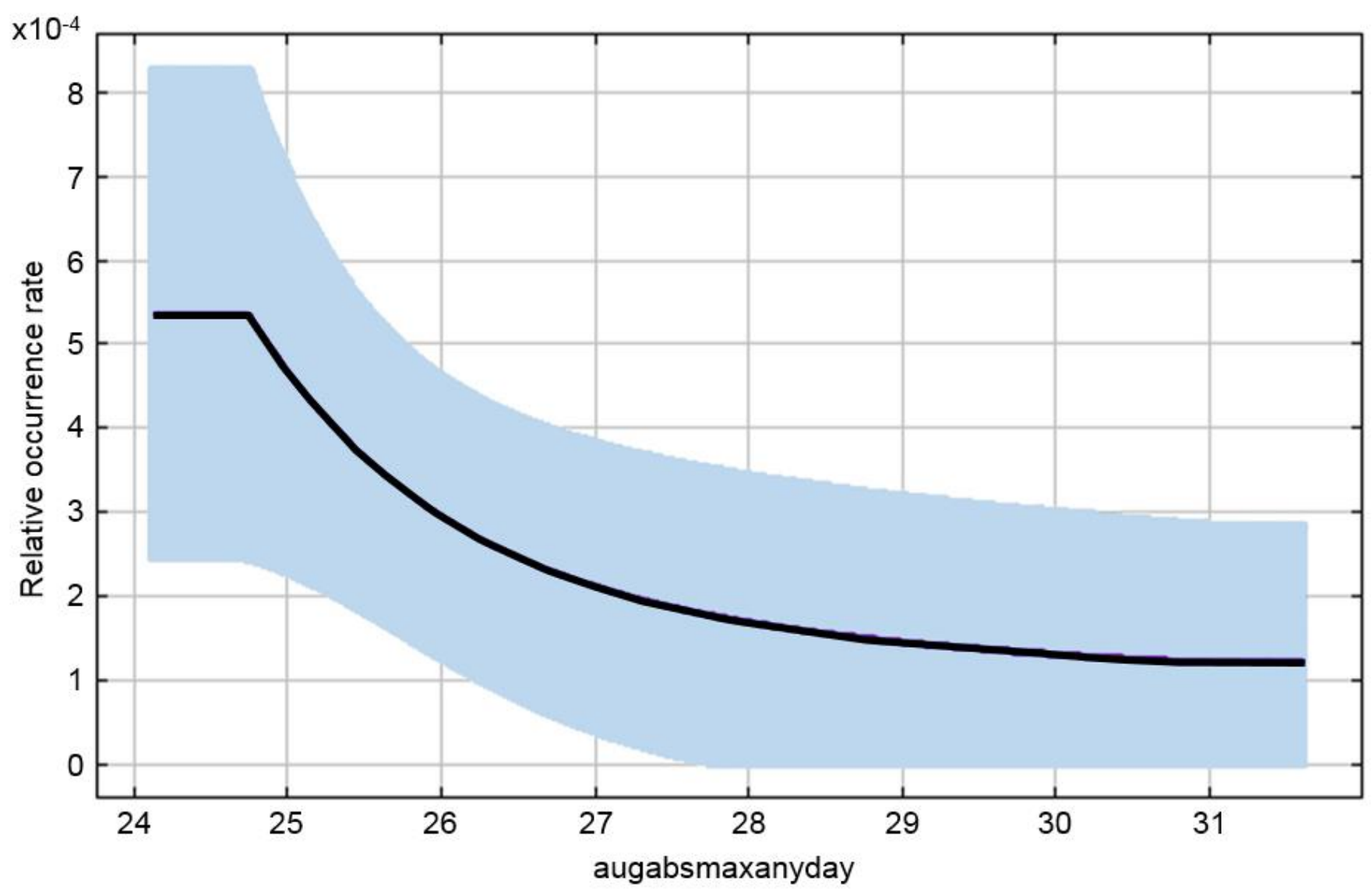

Figure 2. Response curve for air temperature variable augabsmaxanyday when all other variables are held constant at their mean. The black line shows the mean (over 10 runs) ROR response to augabsmaxanyday. The mean $+/$ - one standard deviation is represented in light blue. 


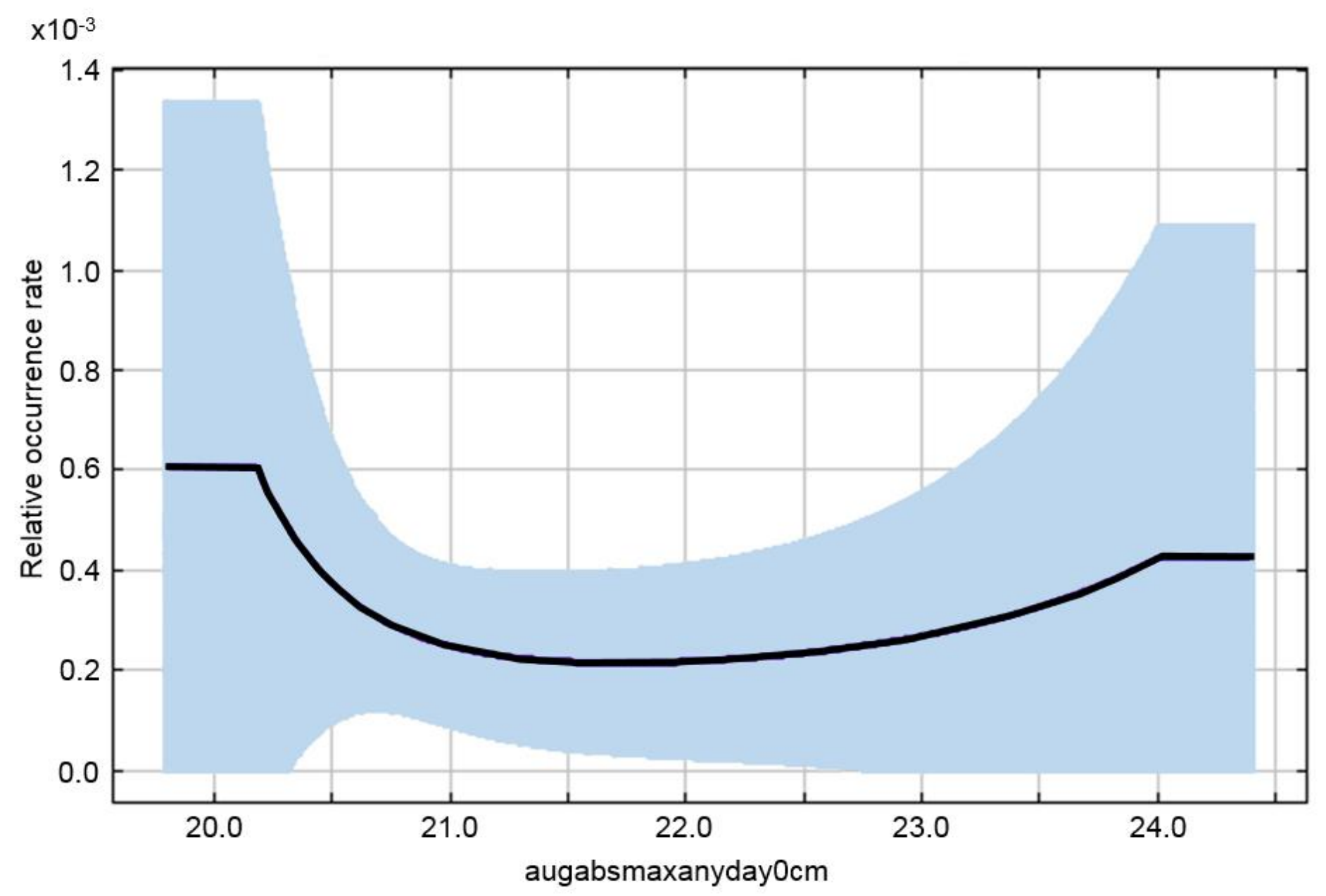

Figure 3. Response curve for air temperature variable augabsmaxanyday $0 \mathrm{~cm}$ when all other variables are held constant at their mean. The black line shows the mean (over 10 runs) ROR response to augabsmaxanyday $0 \mathrm{~cm}$. The mean $+/$ - one standard deviation is represented in light blue. 


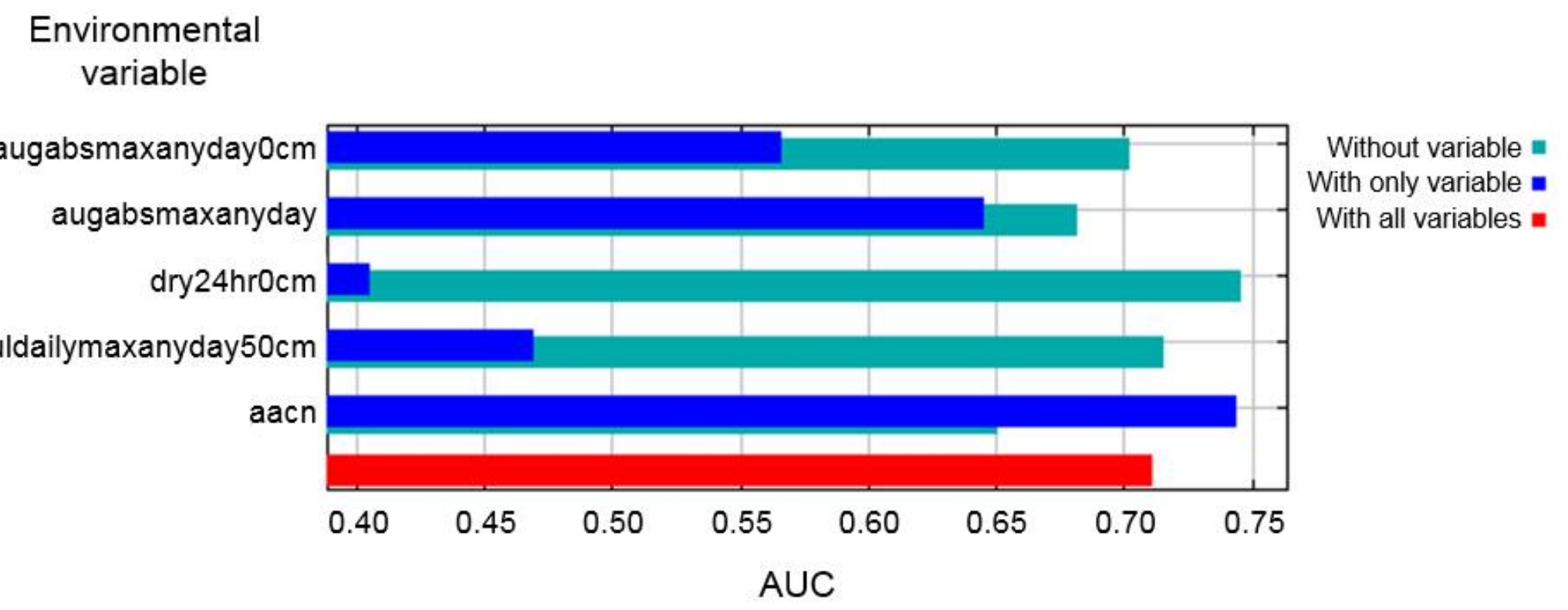

Figure 4. Jackknife analysis for final model run. The dark blue bar represents the AUC value if only that variable was used. The light blue bar represents the AUC value if that variable was omitted. The red bar at the bottom is the AUC value when all variables are included in the model. 


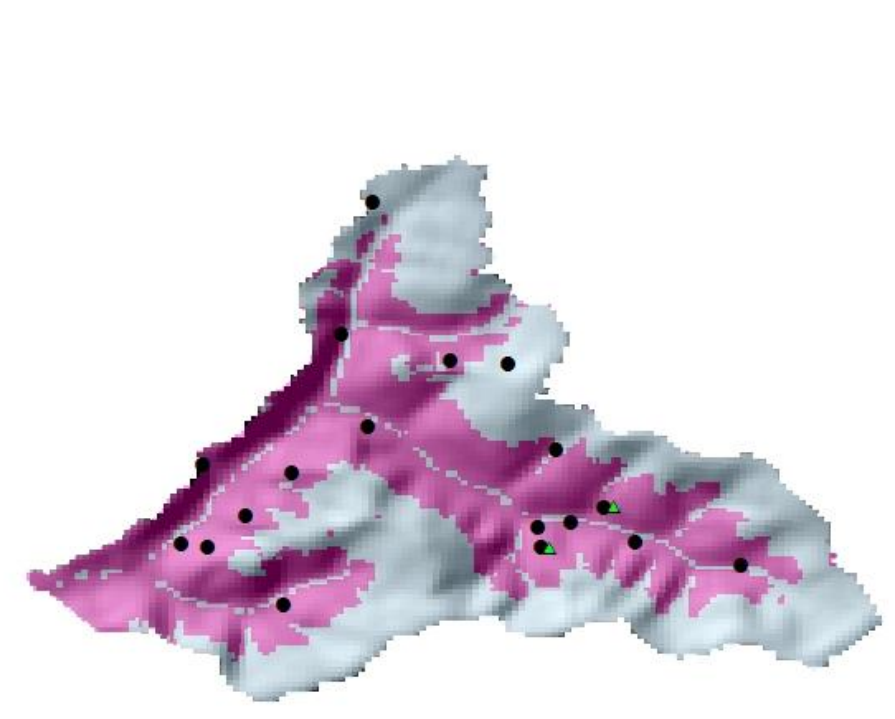

(A)

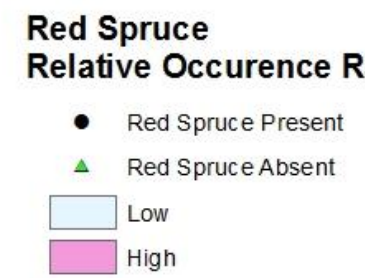

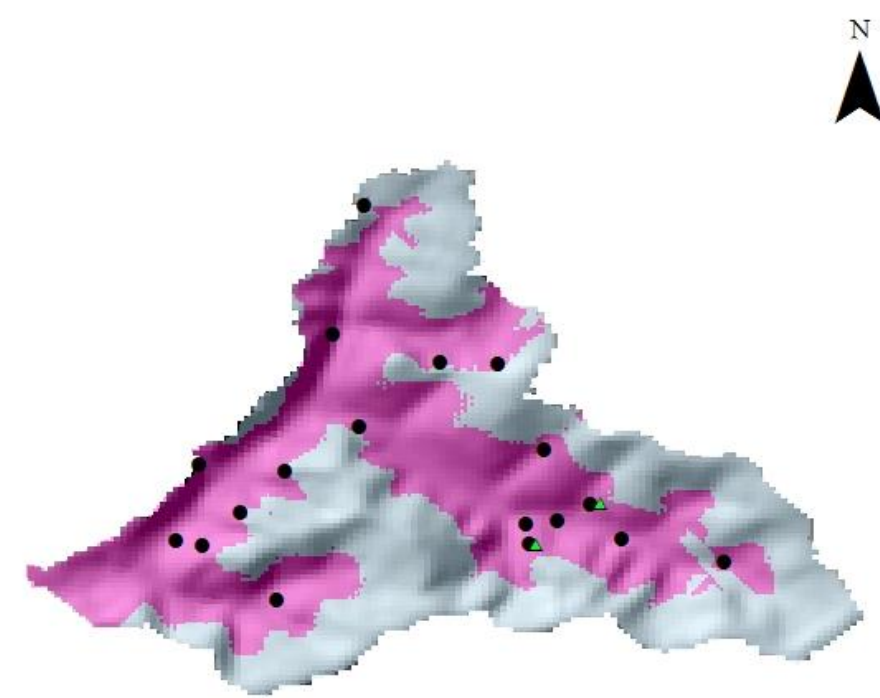

(B)
$0 \quad 0.4250 .85$
1.7 Kilometers

Figure 5. Model results using only topographic variables (A) and topographic and microclimatic variables (B). Pink color indicates high relative occurrence rate (ROR) (defined as greater than median ROR) and blue indicates low ROR (defined as less than median ROR) for red spruce. 


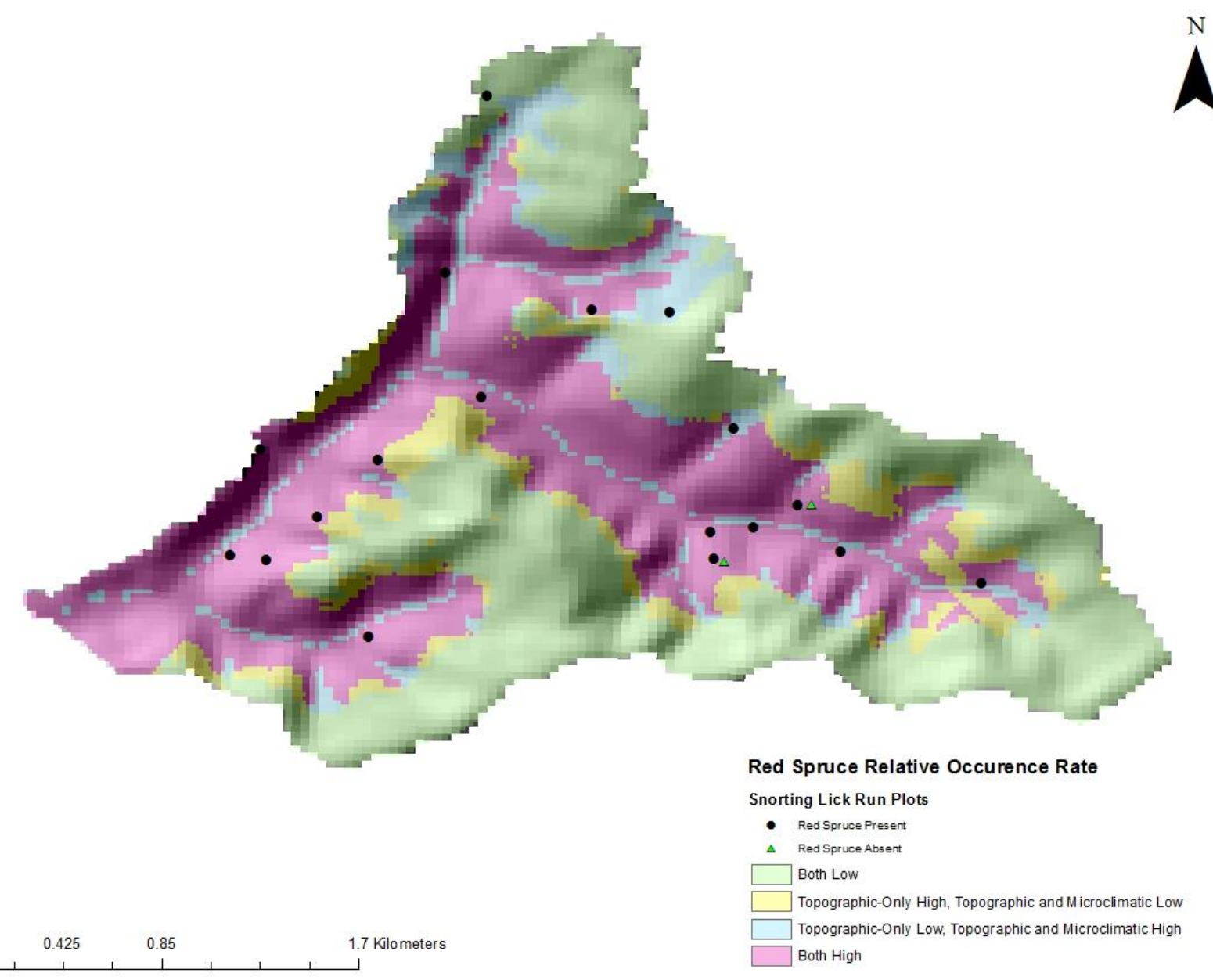

Figure 6. Agreement/disagreement comparison between the model that used only topographic variables and the model that used both topographic and microclimatic variables. 


\subsection{Conclusion}

The entirety of this research was conducted to provide information to assist in red spruce restoration efforts in the central Appalachians. The objectives of this research were twofold: evaluate the efficacy of utilizing a species distribution model (MaxEnt) to map Spodosol presence and utilize that same model in a more conventional exercise to model red spruce relative occurrence rate using topographic and fine-scale microclimatic variables. Evaluating the efficacy of utilizing MaxEnt to model presence of spodic properties is not only helpful to those attempting red spruce restoration efforts, but also may be useful in future soil mapping endeavors which are likely to consist of presence-only datasets. Previous red spruce distribution models most often utilize only topographic variables, and if climatic variables are used they are often coarse relative to microclimate influencing the local scale. This is problematic because red spruce is thought to exist in niche habitats where microclimatic conditions are not conducive to other species or where red spruce is more competitive.

The species distribution model, MaxEnt, has not been used to model soils or soil properties prior to this study. However, MaxEnt and traditional soil mapping are performed using similar approaches_-presence-only locations, in conjunction with environmental covariates on which presence is expected to depend, are used to predict presence in unsampled areas - making MaxEnt a potential approach for contemporary digital soil mapping. Recent red spruce restoration efforts also have relied on a concept known as pedomemory, which uses current soil properties to predict previous environmental conditions (Targuilian and Goryachkin, 2010; Lin, 2011; Monger and Rachal, 2013; Nauman et al., 2015a,b). In the central Appalachians, presence of spodic properties indicates historic red spruce presence (Nauman et al., 2015). However, exclusively utilizing pedomemory to inform red spruce restoration is not entirely without risk because spodic properties can degrade (i.e., depodzolization) if 
environmental conditions change. Therefore, if spodic soil properties are observed one can reasonably assume that red spruce was present in that location historically, but if spodic properties are absent, one cannot assume that red spruce was not present historically. MaxEnt was hypothesized to be ideal for modeling presence of spodic properties because as a presenceonly model it has the advantage of being able to avoid potential false absences (areas that historically had spodic properties but have since undergone depodzolization).

All data utilized in the first study was identical to that used in Nauman et al., (2015) except absence points were excluded from this effort. The presence-only data set utilized in the first study consisted of 221 soil pit observations with varying spodic intensities (SI) within 124,687 ha of the Monongahela National Forest. Spodic soil properties can exist in varying intensities ranging from no evidence of podzolization $(\mathrm{SI}=0)$ to strong evidence of podzolization $(\mathrm{SI}=2.0)$. The large data set used in this study was split into three smaller classes: one that included all locations having spodic characteristics ( $\mathrm{SI}=0.5$ to 2.0 ); one that excluded the lowest spodic intensity class ( $\mathrm{SI}=1.0$ to 2.0 ); and one that used only the locations with highest the spodic intensity ( $\mathrm{SI}=2.0$ ). Each of these classes was modeled in MaxEnt using the same 29 topographic covariates, and all produced similar results. None of the environmental covariates contributed substantially to the models. This may be because the environmental covariates were too coarse to represent the finer-scale conditions present at the original soil pits. All three models that used different spodic intensity classes modeled the highest probability of presence near the supplied presence-only data, which is likely because other areas were not sampled adequately and elevation decreased as distance from presence-only points increased.

The MaxEnt model that utilized presence points with spodic intensities from 0.5-2.0 was compared to a model output produced from a presence-absence model (i.e., random forests) 
(Nauman et al., 2015). The highest probabilities in the random forests output were distributed relatively evenly over the entire study area, compared to MaxEnt, which were primarily concentrated with and around the area containing the original soil pits. An agreement/disagreement comparison using the cells with the top $40 \%$ highest probability of presence in each model showed approximately $62 \%$ agreement and $38 \%$ disagreement between the models. Even though metrics for both MaxEnt and random forests outputs indicated good to excellent model performance for predicting spodic expression, a substantial amount of area was in disagreement between the two models. Which model most accurately describes current presence cannot be determined without field verification, but success in red spruce restoration may result by focusing restoration treatments in areas where the two models both predicted high probability of red spruce presence.

In the second study, red spruce relative occurrence rate (ROR) was modeled using MaxEnt, topographic variables, and microclimatic variables. This analysis was for a small (5.4 $\mathrm{km}^{2}$ ), high elevation (>700 m) watershed in which air temperature, soil temperature and soil moisture were measured at 20 sites for nearly one year. The microclimatic raw data were converted into specific variables (typically focusing on conditions occurring during periods with highest or lowest temperature or moisture conditions) believed to be important to red spruce presence. These point data were converted into gridded data sets using kriging and cokriging. Four preliminary models were run: one using only topographic variables, one using only air temperature variables, one using only soil temperature variables, and one using only soil moisture variables. Preliminary runs indicated that altitude above channel network, August absolute maximum air temperature, August absolute maximum soil temperature at the surface, July daily maximum soil moisture at $50 \mathrm{~cm}$ depth, and the driest 24 -hour period at $0 \mathrm{~cm}$ were the 
most important variables, in that order. The first of these five is topographic and the remaining four are microclimatic. These five variables were used together in a final model run. AUC values, which can be used to assess relative model performance, were similar for the model that utilized only topographic variables and for the final model (utilizing the five aforementioned variables). Consequently, it may be feasible to continue utilizing only topographic variables to model red spruce presence. If microclimatic variables are desired, air temperature measurements are easier to obtain than soil measurements, and the former were found to be important in this study.

Altitude above channel network was the most important variable in both the model that utilized only topographic variables and the final model run. In the topographic-only model, altitude above channel network was more important than other topographic variables by a factor of 10. It was also much more important than the four microclimatic variables in the final model run. Visual assessment of the model inputs showed that there was an inverse relationship between red spruce relative occurrence rate and altitude above channel network (as altitude above channel network increases, red spruce relative occurrence rate decreases). This indicates that higher red spruce relative occurrence rate is found in concave landscape positions like coves and cold air drainage ways. August absolute maximum air temperature also was important, but soil temperature and soil moisture variables contributed little to the final model output. This is likely due to a combination of poor interpolated surfaces (cokriging was not possible because soil temperature and soil moisture were not correlated strongly with topographic conditions to aid in surface creation) and greater occurrence of missing data for soil moisture and soil temperature than for other microclimate measurements. 
The two models agreed in approximately $82 \%$ of the cells and disagreed in only $16 \%$ of cells. Visual assessment of the preliminary model that used only topographic variables and the final model that utilized the most important topographic and microclimatic variables showed the greatest red spruce ROR occurred at the lowest elevations of the watershed (approximately 700 m). Conversely, the lowest red spruce ROR was observed at the highest elevations of the watershed, on ridges and shoulders. Conventionally, the highest elevations in this region have been targeted for red spruce restoration because this is where relic red spruce stands tend to be concentrated. In this watershed, however, red spruce was absent from the highest elevations (which is why microclimate monitoring locations were positioned at lower elevations to coincide where red spruce was present). The modeling results validate what was observed on the ground and indicate that the lower elevations of high elevation watersheds in this region are suitable for red spruce growth and can play a role in red spruce restoration; the specific locations must be landscape positions that are associated with cooler air and soil temperatures, and increased soil moisture.

Climate change projections for the central Appalachians are not definitive but suggest that this region will become warmer and have increased or more intense precipitation events (Butler et al., 2015). Some previous predictions have projected that the increase in air temperatures in this region will result in the facilitated migration of red spruce to only the highest elevations of the landscape where temperatures should be cooler (Byers and Vanderhorst, 2010; Butler et al., 2015). his research suggests that increased soil moisture may be a greater or equal driving factor of red spruce presence, cold air drainages in convex or cove sites in more midelevation areas may become particularly critical in the future as they may provide microrefugia and habitat connectivity as climate changes. 
As is typical, there are opportunities for future research regarding the use of red spruce microclimatic conditions to prioritize red spruce restoration. An obvious need in this and most modeling efforts is field validation. There is no way to definitively determine the accuracy of the model outputs generated in this research without field validation. The microclimatic conditions monitored during this research effort were taken from a relatively small area of historic and current red spruce forests in the central Appalachians. In future research efforts, it may be useful to characterize microclimatic conditions across the range of possible red spruce environments in the central Appalachians. Future research efforts should also focus on betterment of interpolation techniques, as the currently available options used in this research were not optimal and resulted in limitations.

\subsection{References}

Butler, P.R., L. Iverson, F.R. Thompson, L. Brandt, S. Handler, M. Janowiak, P.D. Shannon, C. Sweanston, K. Karriker, J. Bartig, S. Connolly, W. Dijak, S. Bearer, S. Blatt, A. Brandon, E. Byers, C. Coon, T. Culbreth, J. Daly, W. Dorsey, D. Ede, C. Euler, N. Gillies, D.M. Hix, C. Johnson, L. Lyte, S. Matthews, D. McCarthy, D. Minney, D. Murphy, C. O’Dea R. Orwan, M. Peters, A. Prasad, C. Randall, J. Reed, C. Sandeno., T. Schuler, L. Sneddon, B. Standley, A. Steele, S. Stout, R. Swaty, J. Teets, T. Tomon, J. Vanderhorst, J. Whatley, and N. Zegre. 2015. Central Appalachians forest ecosystem vulnerability assessment and synthesis; a report from Central Appalachians climate change response framework project. Gen. Tech. Rep. NRS-146. Newtown Square, PA: U.S. Department of Agriculture, Forest Service, Northern Research Station. 310 p.

Byers, E.A., Vanderhorst, J.P. and B.P. Streets. 2010. Classification and conservation assessment of upland red spruce communities in West Virginia. WV DNR. 
Lin, H., 2011. Three principles of soil change and pedogenesis in time and space. Soil Sci. Soc. Am. J. 75.6, 2049-2070.

Monger, C., Rachal, D.M., 2013. Soil and landscape memory of climate change- how sensitive, how connected? Soc. Sediment. Geol. 104, 63-70.

Nauman, T.W., Thompson, J.A., Teets, S.J., Dilliplane, T.A., Bell, J.W., Connolly, S.J., Liebermann, H.J., Yoast, K.M., 2015a. Ghosts of the forest: mapping pedomemory to guide restoration. Geoderma. 247, 51-64.

Nauman, T.W., Thompson, J.A., Teets, J., Dilliplane, T., Bell, J.W., Connolly, S.J., Liebermann, H.J., K. Yoast. 2015b. Pedoecological modeling to guide forest restoration using ecological site descriptions. Soil Sci. Soc. Am. Jo. 79.5, 1406-1419.

Targulian, V.O., Goryachkin, S.V., 2010. Soil memory and environmental reconstructions. Eurasian Soil Sci. 44(4), 464-465. 


\subsection{Appendices}

Appendix A. First-order autocorrelation regression fit statistics for climate variables with missing data. The Total $\mathrm{R}^{2}$ measures the fit of the model with autoregressive error correction (SAS Institude, Inc., 2013).

\begin{tabular}{|c|c|c|c|c|c|}
\hline Plot & Predictor plots & $\begin{array}{c}\text { Mean square } \\
\text { error }\end{array}$ & $\begin{array}{c}\text { Mean } \\
\text { absolute error }\end{array}$ & $\begin{array}{c}\text { Mean } \\
\text { absolute } \\
\text { percentage } \\
\text { error }\end{array}$ & Total $\mathrm{R}^{2}$ \\
\hline \multicolumn{6}{|c|}{ air temperature } \\
\hline 9 & 19 & 0.0401 & 0.1385 & 3.01 & 0.9991 \\
\hline 17 & 6 & 0.1270 & 0.2341 & 10.38 & 0.9987 \\
\hline \multicolumn{6}{|c|}{ soil moisture $-0 \mathrm{~cm}$} \\
\hline 0 & 2,22 & 0.00006 & 0.0029 & 1.04 & 0.9994 \\
\hline 1 & $2,17,22,24$ & 0.00001 & 0.0014 & 0.63 & 0.9998 \\
\hline 3 & $2,22,24$ & 0.000005 & 0.0012 & 2.27 & 0.9992 \\
\hline 4 & $17,22,24$ & 0.00002 & 0.0016 & 0.72 & 0.9998 \\
\hline 5 & $2,17,22,24$ & 0.000009 & 0.0010 & 0.48 & 0.9998 \\
\hline 6 & $2,22,24$ & 0.000005 & 0.0009 & 0.92 & 0.9995 \\
\hline 9 & $2,22,24$ & 0.000007 & 0.0013 & 1.51 & 0.9997 \\
\hline 10 & $2,17,22$ & 0.00004 & 0.0021 & 1.06 & 0.9993 \\
\hline 11 & $2,17,22,24$ & 0.000003 & 0.0010 & 14.47 & 0.9998 \\
\hline 12 & $17,22,24$ & 0.00001 & 0.0021 & 0.64 & 0.9999 \\
\hline 13 & $17,22,24$ & 0.000005 & 0.0009 & 1.43 & 0.9995 \\
\hline 14 & $2,22,24$ & 0.000005 & 0.0008 & 0.35 & 0.9999 \\
\hline 16 & $2,17,22$ & 0.000002 & 0.0009 & 0.35 & 1.0000 \\
\hline 17 & 22,24 & 0.000005 & 0.0010 & 0.86 & 0.9996 \\
\hline 19 & 2,17 & 0.000003 & 0.0007 & 0.41 & 0.9999 \\
\hline 21 & 2,22 & 0.000003 & 0.0006 & 69.38 & 0.9982 \\
\hline 23 & 22,24 & 0.000005 & 0.0010 & 0.59 & 0.9999 \\
\hline \multicolumn{6}{|c|}{ soil moisture $-25 \mathrm{~cm}$} \\
\hline 0 & $2,21,24$ & 0.00005 & 0.0028 & 0.97 & 0.9994 \\
\hline 1 & 21,24 & 0.000002 & 0.0007 & 0.20 & 1.0000 \\
\hline 3 & $2,21,24$ & 0.000001 & 0.0006 & 0.19 & 1.0000 \\
\hline 4 & 2,24 & 0.00001 & 0.0012 & 0.57 & 0.9998 \\
\hline 5 & 2,24 & 0.00001 & 0.0012 & 0.39 & 0.9998 \\
\hline 6 & 21,2224 & 0.00001 & 0.0010 & 0.42 & 0.9998 \\
\hline 9 & $2,22,24$ & 0.000009 & 0.0010 & 0.47 & 0.9998 \\
\hline 10 & $2,21,24$ & 0.00003 & 0.0011 & 0.57 & 0.9997 \\
\hline 11 & 2,24 & 0.00002 & 0.0013 & 0.49 & 0.9997 \\
\hline 12 & 21,22 & 0.000002 & 0.0004 & 0.19 & 0.9999 \\
\hline 13 & 22,24 & 0.00001 & 0.0011 & 0.36 & 0.9999 \\
\hline
\end{tabular}




\begin{tabular}{|c|c|c|c|c|c|}
\hline Plot & Predictor plots & $\begin{array}{l}\text { Mean square } \\
\text { error }\end{array}$ & $\begin{array}{c}\text { Mean } \\
\text { absolute error }\end{array}$ & $\begin{array}{c}\text { Mean } \\
\text { absolute } \\
\text { percentage } \\
\text { error }\end{array}$ & Total $\mathrm{R}^{2}$ \\
\hline 14 & 21,22 & 0.000003 & 0.0004 & 0.12 & 1.0000 \\
\hline 16 & 21,24 & 0.000002 & 0.0005 & 0.16 & 1.0000 \\
\hline 17 & 21,24 & 0.000001 & 0.0005 & 0.16 & 1.0000 \\
\hline 19 & 21,24 & 0.000001 & 0.0003 & 0.14 & 1.0000 \\
\hline 23 & 2,24 & 0.000003 & 0.0007 & 0.22 & 1.0000 \\
\hline \multicolumn{6}{|c|}{ soil moisture $-50 \mathrm{~cm}$} \\
\hline 0 & $2,4,22$ & 0.00025 & 0.0056 & 1.57 & 0.9976 \\
\hline 1 & $2,4,21$ & 0.000003 & 0.0010 & 0.33 & 1.0000 \\
\hline 3 & $2,4,22$ & 0.000002 & 0.0011 & 0.35 & 1.0000 \\
\hline 5 & $2,4,21,22$ & 0.000005 & 0.0008 & 0.27 & 0.9999 \\
\hline 6 & $4,21,22$ & 0.00004 & 0.0011 & 0.39 & 0.9993 \\
\hline 9 & $2,4,21$ & 0.000002 & 0.0005 & 0.19 & 1.0000 \\
\hline 10 & $2,4,21$ & 0.00004 & 0.0011 & 0.60 & 0.9996 \\
\hline 11 & $4,21,22$ & 0.00001 & 0.0009 & 0.39 & 0.9997 \\
\hline 12 & 4,21 & 0.000001 & 0.0005 & 0.23 & 1.0000 \\
\hline 13 & $4,21,22$ & 0.000008 & 0.0006 & 0.18 & 0.9999 \\
\hline 14 & $2,4,21$ & 0.000001 & 0.0003 & 0.18 & 1.0000 \\
\hline 16 & $2,4,21,22$ & 0.00006 & 0.0016 & 0.51 & 0.9991 \\
\hline 17 & 4,21 & 0.000002 & 0.0004 & 0.12 & 1.0000 \\
\hline 19 & 2,21 & 0.000007 & 0.0014 & 0.37 & 1.0000 \\
\hline 23 & $4,21,22$ & 0.00002 & 0.0012 & 0.36 & 0.9997 \\
\hline 24 & $4,21,22$ & 0.00001 & 0.0011 & 0.31 & 0.9998 \\
\hline \multicolumn{6}{|c|}{ soil temperature $-0 \mathrm{~cm}$} \\
\hline 0 & 2 & 0.2195 & 0.2087 & 6.94 & 0.9984 \\
\hline 1 & 2 & 0.0261 & 0.0983 & 1.53 & 0.9998 \\
\hline 3 & 2 & 0.0370 & 0.1191 & 1.88 & 0.9997 \\
\hline 4 & 2 & 0.3372 & 0.2263 & 12.39 & 0.9975 \\
\hline 5 & 2 & 0.0140 & 0.0710 & 2.23 & 0.9999 \\
\hline 6 & 2 & 0.0222 & 0.0947 & 3.12 & 0.9998 \\
\hline 9 & 24 & 0.2202 & 0.2421 & 11.45 & 0.9986 \\
\hline 10 & 21 & 0.4946 & 0.2115 & 6.41 & 0.9967 \\
\hline 11 & 21 & 0.0237 & 0.0975 & 1.83 & 0.9998 \\
\hline 12 & 22 & 0.0105 & 0.0654 & 1.27 & 0.9999 \\
\hline 13 & 2 & 0.0178 & 0.0838 & 2.16 & 0.9999 \\
\hline 14 & 2 & 0.0105 & 0.0646 & 1.00 & 0.9999 \\
\hline 16 & 24 & 0.0764 & 0.1568 & 4.93 & 0.9995 \\
\hline 17 & 24 & 0.2489 & 0.2230 & 6.12 & 0.9978 \\
\hline 19 & 21 & 0.0236 & 0.0958 & 4.85 & 0.9998 \\
\hline 23 & 24 & 0.0332 & 0.1059 & 2.47 & 0.9995 \\
\hline \multicolumn{6}{|c|}{ soil temperature $-25 \mathrm{~cm}$} \\
\hline 0 & 2 & 0.0816 & 0.1173 & 1.69 & 0.9992 \\
\hline
\end{tabular}




\begin{tabular}{|c|c|c|c|c|c|}
\hline Plot & Predictor plots & $\begin{array}{c}\text { Mean square } \\
\text { error }\end{array}$ & $\begin{array}{c}\text { Mean } \\
\text { absolute error }\end{array}$ & $\begin{array}{c}\text { Mean } \\
\text { absolute } \\
\text { percentage } \\
\text { error }\end{array}$ & Total $\mathrm{R}^{2}$ \\
\hline 1 & 22 & 0.0027 & 0.0337 & 0.40 & 1.0000 \\
\hline 3 & 22 & 0.0026 & 0.0307 & 0.37 & 1.0000 \\
\hline 4 & 22 & 0.3111 & 0.2185 & 3.51 & 0.9977 \\
\hline 5 & 21 & 0.0022 & 0.0240 & 0.35 & 1.0000 \\
\hline 6 & 22 & 0.0023 & 0.0305 & 0.39 & 1.0000 \\
\hline 9 & 2 & 0.0023 & 0.0262 & 0.33 & 1.0000 \\
\hline 10 & 22 & 0.3730 & 0.2069 & 4.55 & 0.9970 \\
\hline 11 & 22 & 0.0028 & 0.0324 & 0.39 & 1.0000 \\
\hline 12 & 22 & 0.0022 & 0.0297 & 0.36 & 1.0000 \\
\hline 13 & 2 & 0.0025 & 0.0273 & 0.36 & 1.0000 \\
\hline 14 & 2 & 0.0020 & 0.0278 & 0.39 & 1.0000 \\
\hline 16 & 2 & 0.0031 & 0.0282 & 0.36 & 1.0000 \\
\hline 17 & 22 & 0.0024 & 0.0281 & 0.41 & 1.0000 \\
\hline 19 & 22 & 0.0019 & 0.0271 & 0.38 & 1.0000 \\
\hline 23 & 24 & 0.0030 & 0.0273 & 0.45 & 1.0000 \\
\hline \multicolumn{6}{|c|}{ soil temperature $-50 \mathrm{~cm}$} \\
\hline 0 & 2 & 0.0632 & 0.1018 & 1.49 & 0.9993 \\
\hline 1 & 4 & 0.0016 & 0.0213 & 0.28 & 1.0000 \\
\hline 3 & 4 & 0.0013 & 0.0153 & 0.19 & 1.0000 \\
\hline 5 & 21 & 0.0015 & 0.0178 & 0.23 & 1.0000 \\
\hline 6 & 22 & 0.0013 & 0.0203 & 0.27 & 1.0000 \\
\hline 9 & 2 & 0.0013 & 0.0175 & 0.22 & 1.0000 \\
\hline 10 & 22 & 0.3964 & 0.2189 & 3.82 & 0.9967 \\
\hline 11 & 4 & 0.1595 & 0.1427 & 1.54 & 0.9990 \\
\hline 12 & 22 & 0.0013 & 0.0210 & 0.23 & 1.0000 \\
\hline 13 & 2 & 0.0011 & 0.0184 & 0.22 & 1.0000 \\
\hline 14 & 4 & 0.0015 & 0.0176 & 0.25 & 1.0000 \\
\hline 16 & 2 & 0.0011 & 0.0164 & 0.20 & 1.0000 \\
\hline 17 & 22 & 0.0013 & 0.0188 & 0.25 & 1.0000 \\
\hline 19 & 2 & 0.0010 & 0.0184 & 0.24 & 1.0000 \\
\hline 23 & 2 & 0.0017 & 0.0205 & 0.30 & 1.0000 \\
\hline 24 & 22 & 0.0013 & 0.0205 & 0.24 & 1.0000 \\
\hline
\end{tabular}


Appendix B. Climate Summary Variables

\begin{tabular}{|c|c|}
\hline Variable & Description \\
\hline JulAvgDaytime & average July daytime air temperature for each plot \\
\hline AugAvgDaytime & average August daytime air temperature for each plot \\
\hline NovAbsRng & November air temperature range - monthly max-monthly min \\
\hline DecAbsRng & December air temperature range - monthly max-monthly min \\
\hline JanAbsRng & January air temperature range - monthly max-monthly min \\
\hline FebAbsRng & February air temperature range - monthly max-monthly min \\
\hline MarAbsRng & March air temperature range - monthly max-monthly min \\
\hline NovMaxDailyRng & November maximum daily range (max-min) in air temperature \\
\hline DecMaxDailyRng & December maximum daily range (max-min) in air temperature \\
\hline JanMaxDailyRng & January maximum daily range (max-min) in air temperature \\
\hline FebMaxDailyRng & February maximum daily range (max-min) in air temperature \\
\hline MarMaxDailyRng & March maximum daily range (max-min) in air temperature \\
\hline NovAvgDailyRng & November average daily range (max-min) in air temperature \\
\hline DecAvgDailyRng & December average daily range (max-min) in air temperature \\
\hline JanAvgDailyRng & January average daily range (max-min) in air temperature \\
\hline FebAvgDailyRng & February average daily range (max-min) in air temperature \\
\hline MarAvgDailyRng & March average daily range (max-min) in air temperature \\
\hline DayCnt15to20C & number of days with high temperatures $>15$ and $<=20$ degrees $C$ \\
\hline DayCnt20to25C & number of days with high temperatures $>20$ and $<=25$ degrees $C$ \\
\hline DayCnt25to30C & number of days with high temperatures $>25$ and $<=30$ degrees $\mathrm{C}$ \\
\hline DayCnt30plusC & number of days with high temperatures $>30$ degrees $\mathrm{C}$ \\
\hline DayCnt32to40C & number of days with high temperatures $>32$ and $<=40$ degrees $C$ \\
\hline JanAbsMinAnyDay & coldest January 30-min air temperature for each plot - any date \\
\hline FebAbsMinAnyDay & coldest February 30-min air temperature for each plot - any date \\
\hline JulAbsMinAnyDay & coolest July 30-min air temperature for each plot - any date \\
\hline AugAbsMinAnyDay & coolest August 30-min air temperature for each plot - any date \\
\hline NovAbsMinAnyDay & coldest November 30-min air temperature for each plot - any date \\
\hline DecAbsMinAnyDay & coldest December 30-min air temperature for each plot - any date \\
\hline JulAbsMaxAnyDay & hottest July 30-min air temperature for each plot - any date \\
\hline AugAbsMaxAnyDay & hottest August 30-min air temperature for each plot - any date \\
\hline JanAbsMinAnyDayAM & coldest daytime January 30-min air temperature for each plot - any date \\
\hline FebAbsMinAnyDayAM & coldest daytime February 30-min air temperature for each plot - any date \\
\hline JulAbsMinAnyDayAM & coolest daytime July 30-min air temperature for each plot - any date \\
\hline AugAbsMinAnyDayAM & coolest daytime August 30-min air temperature for each plot - any date \\
\hline NovAbsMinAnyDayAM & $\begin{array}{l}\text { coldest daytime November 30-min air temperature for each plot - any } \\
\text { date }\end{array}$ \\
\hline DecAbsMinAnyDayAM & $\begin{array}{l}\text { coldest daytime December 30-min air temperature for each plot - any } \\
\text { date }\end{array}$ \\
\hline JulAbsMaxAnyDayAM & hottest daytime July 30-min air temperature for each plot - any date \\
\hline
\end{tabular}




\begin{tabular}{|c|c|}
\hline Variable & Description \\
\hline AugAbsMaxAnyDayAM & hottest daytime August 30-min air temperature for each plot - any date \\
\hline JanAbsMinAnyDayPM & coldest nighttime January 30-min air temperature for each plot - any date \\
\hline FebAbsMinAnyDayPM & $\begin{array}{l}\text { coldest nighttime February 30-min air temperature for each plot - any } \\
\text { date }\end{array}$ \\
\hline JulAbsMinAnyDayPM & coolest nighttime July 30-min air temperature for each plot - any date \\
\hline AugAbsMinAnyDayPM & coolest nighttime August 30-min air temperature for each plot - any date \\
\hline NovAbsMinAnyDayPM & $\begin{array}{l}\text { coldest nighttime November 30-min air temperature for each plot - any } \\
\text { date }\end{array}$ \\
\hline DecAbsMinAnyDayPM & $\begin{array}{l}\text { coldest nighttime December 30-min air temperature for each plot - any } \\
\text { date }\end{array}$ \\
\hline JulAbsMaxAnyDayPM & hottest nighttime July 30 -min air temperature for each plot - any date \\
\hline AugAbsMaxAnyDayPM & hottest nighttime August 30-min air temperature for each plot - any date \\
\hline JanDailyMinAnyDay & coldest January daily mean air temperature for each plot - any date \\
\hline FebDailyMinAnyDay & coldest February daily mean air temperature for each plot - any date \\
\hline JulDailyMinAnyDay & coolest July daily mean air temperature for each plot - any date \\
\hline AugDailyMinAnyDay & coolest August daily mean air temperature for each plot - any date \\
\hline JulDailyMaxAnyDay & hottest July daily mean air temperature for each plot - any date \\
\hline AugDailyMaxAnyDay & hottest August daily mean air temperature for each plot - any date \\
\hline JanDailyMinAnyDayAM & $\begin{array}{l}\text { coldest daytime January daily mean air temperature for each plot - any } \\
\text { date }\end{array}$ \\
\hline FebDailyMinAnyDayAM & $\begin{array}{l}\text { coldest daytime February daily mean air temperature for each plot - any } \\
\text { date }\end{array}$ \\
\hline JulDailyMinAnyDayAM & coolest daytime July daily mean air temperature for each plot - any date \\
\hline AugDailyMinAnyDayAM & $\begin{array}{l}\text { coolest daytime August daily mean air temperature for each plot - any } \\
\text { date }\end{array}$ \\
\hline JulDailyMaxAnyDayAM & hottest daytime July daily mean air temperature for each plot - any date \\
\hline AugDailyMaxAnyDayAM & $\begin{array}{l}\text { hottest daytime August daily mean air temperature for each plot - any } \\
\text { date }\end{array}$ \\
\hline JanDailyMinAnyDayPM & $\begin{array}{l}\text { coldest nighttime January daily mean air temperature for each plot - any } \\
\text { date }\end{array}$ \\
\hline FebDailyMinAnyDayPM & $\begin{array}{l}\text { coldest nighttime February daily mean air temperature for each plot - any } \\
\text { date }\end{array}$ \\
\hline JulDailyMinAnyDayPM & coolest nighttime July daily mean air temperature for each plot - any date \\
\hline AugDailyMinAnyDayPM & $\begin{array}{l}\text { coolest nighttime August daily mean air temperature for each plot - any } \\
\text { date }\end{array}$ \\
\hline JulDailyMaxAnyDayPM & hottest nighttime July daily mean air temperature for each plot - any date \\
\hline AugDailyMaxAnyDayPM & $\begin{array}{l}\text { hottest nighttime August daily mean air temperature for each plot - any } \\
\text { date }\end{array}$ \\
\hline JanAbsMinOneDay & coldest January 30-min air temperature for each plot on Jan 20, 2016 \\
\hline FebAbsMinOneDay & coldest February 30-min air temperature for each plot on Feb 12, 2016 \\
\hline JulAbsMinOneDay & coolest July 30-min air temperature for each plot on Jul 11, 2016 \\
\hline AugAbsMinOneDay & coolest August 30-min air temperature for each plot on Aug 23, 2016 \\
\hline NovAbsMinOneDay & coldest November 30-min air temperature for each plot on Nov 23, 2015 \\
\hline DecAbsMinOneDay & coldest December 30-min air temperature for each plot on Dec 19, 2015 \\
\hline JulAbsMaxOneDay & hottest July 30-min air temperature for each plot on Jul 23, 2016 \\
\hline
\end{tabular}




\begin{tabular}{|c|c|}
\hline Variable & Description \\
\hline AugAbsMaxOneDay & hottest August 30-min air temperature for each plot on Aug 11, 2016 \\
\hline JanAbsMinOneDayAM & $\begin{array}{l}\text { coldest daytime January 30-min air temperature for each plot on Jan 20, } \\
2016\end{array}$ \\
\hline FebAbsMinOneDayAM & $\begin{array}{l}\text { coldest daytime February 30-min air temperature for each plot on Feb 14, } \\
2016\end{array}$ \\
\hline JulAbsMinOneDayAM & coolest daytime July 30-min air temperature for each plot on Jul 21, 2016 \\
\hline AugAbsMinOneDayAM & $\begin{array}{l}\text { coolest daytime August 30-min air temperature for each plot on Aug 23, } \\
2016\end{array}$ \\
\hline NovAbsMinOneDayAM & $\begin{array}{l}\text { coldest daytime November 30-min air temperature for each plot on Nov } \\
23,2015\end{array}$ \\
\hline DecAbsMinOneDayAM & $\begin{array}{l}\text { coldest daytime December 30-min air temperature for each plot on Dec } \\
20,2015\end{array}$ \\
\hline JulAbsMaxOneDayAM & hottest daytime July 30-min air temperature for each plot on Jul 23, 2016 \\
\hline AugAbsMaxOneDayAM & $\begin{array}{l}\text { hottest daytime August 30-min air temperature for each plot on Aug 11, } \\
2016\end{array}$ \\
\hline JanAbsMinOneDayPM & $\begin{array}{l}\text { coldest nighttime January 30-min air temperature for each plot on Jan 20, } \\
2016\end{array}$ \\
\hline FebAbsMinOneDayPM & $\begin{array}{l}\text { coldest nighttime February 30-min air temperature for each plot on Feb } \\
12,2016\end{array}$ \\
\hline JulAbsMinOneDayPM & $\begin{array}{l}\text { coolest nighttime July } 30 \text {-min air temperature for each plot on Jul 11, } \\
2016\end{array}$ \\
\hline AugAbsMinOneDayPM & $\begin{array}{l}\text { coolest nighttime August 30-min air temperature for each plot on Aug } \\
23,2016\end{array}$ \\
\hline NovAbsMinOneDayPM & $\begin{array}{l}\text { coldest nighttime November 30-min air temperature for each plot on Nov } \\
23,2015\end{array}$ \\
\hline DecAbsMinOneDayPM & $\begin{array}{l}\text { coldest nighttime December 30-min air temperature for each plot on Dec } \\
19,2015\end{array}$ \\
\hline JulAbsMaxOneDayPM & $\begin{array}{l}\text { hottest nighttime July 30-min air temperature for each plot on Jul } 24 \text {, } \\
2016\end{array}$ \\
\hline AugAbsMaxOneDayPM & $\begin{array}{l}\text { hottest nighttime August 30-min air temperature for each plot on Aug 11, } \\
2016\end{array}$ \\
\hline JanDailyMinOneDay & coldest January daily mean air temperature for each plot on Jan 19, 2016 \\
\hline FebDailyMinOneDay & $\begin{array}{l}\text { coldest February daily mean air temperature for each plot on Feb 13, } \\
2016\end{array}$ \\
\hline JulDailyMinOneDay & coolest July daily mean air temperature for each plot on Jul 3, 2016 \\
\hline AugDailyMinOneDay & coolest August daily mean air temperature for each plot on Aug 23, 2016 \\
\hline JulDailyMaxOneDay & hottest July daily mean air temperature for each plot on Jul 24, 2016 \\
\hline AugDailyMaxOneDay & hottest August daily mean air temperature for each plot on Aug 26, 2016 \\
\hline JanDailyMinOneDayAM & coldest January daily mean air temperature for each plot on Jan 18, 2016 \\
\hline FebDailyMinOneDayAM & $\begin{array}{l}\text { coldest February daily mean air temperature for each plot on Feb 13, } \\
2016\end{array}$ \\
\hline JulDailyMinOneDayAM & coolest July daily mean air temperature for each plot on Jul 3, 2016 \\
\hline AugDailyMinOneDayAM & coolest August daily mean air temperature for each plot on Aug 22, 2016 \\
\hline JulDailyMaxOneDayAM & hottest July daily mean air temperature for each plot on Jul 24, 2016 \\
\hline AugDailyMaxOneDayAM & hottest August daily mean air temperature for each plot on Aug 26, 2016 \\
\hline JanDailyMinOneDayPM & coldest January daily mean air temperature for each plot on Jan 19, 2016 \\
\hline FebDailyMinOneDayPM & $\begin{array}{l}\text { coldest February daily mean air temperature for each plot on Feb } 14 \text {, } \\
2016\end{array}$ \\
\hline JulDailyMinOneDayPM & coolest July daily mean air temperature for each plot on Jul 11, 2016 \\
\hline
\end{tabular}




\begin{tabular}{|c|c|}
\hline Variable & Description \\
\hline AugDailyMinOneDayPM & coolest August daily mean air temperature for each plot on Aug 23, 2016 \\
\hline JulDailyMaxOneDayPM & hottest July daily mean air temperature for each plot on Jul 26, 2016 \\
\hline AugDailyMaxOneDayPM & hottest August daily mean air temperature for each plot on Aug 13, 2016 \\
\hline DecAbsRng0cm & December soil temperature range - monthly max-monthly min \\
\hline JanAbsRng0cm & January soil temperature range - monthly max-monthly min \\
\hline FebAbsRng0cm & February soil temperature range - monthly max-monthly min \\
\hline MarAbsRng0cm & March soil temperature range - monthly max-monthly min \\
\hline DecAbsRng25cm & December soil temperature range - monthly max-monthly min \\
\hline JanAbsRng $25 \mathrm{~cm}$ & January soil temperature range - monthly max-monthly min \\
\hline FebAbsRng25cm & February soil temperature range - monthly max-monthly min \\
\hline MarAbsRng25cm & March soil temperature range - monthly max-monthly min \\
\hline DecAbsRng50cm & December soil temperature range - monthly max-monthly min \\
\hline JanAbsRng50cm & January soil temperature range - monthly max-monthly min \\
\hline FebAbsRng50cm & February soil temperature range - monthly max-monthly min \\
\hline MarAbsRng $50 \mathrm{~cm}$ & March soil temperature range - monthly max-monthly min \\
\hline DecMaxDailyRng0cm & December maximum daily range (max-min) in soil temperature \\
\hline JanMaxDailyRng0cm & January maximum daily range (max-min) in soil temperature \\
\hline FebMaxDailyRng0cm & February maximum daily range ( $\max -\mathrm{min}$ ) in soil temperature \\
\hline MarMaxDailyRng0cm & March maximum daily range (max-min) in soil temperature \\
\hline DecMaxDailyRng25cm & December maximum daily range (max-min) in soil temperature \\
\hline JanMaxDailyRng $25 \mathrm{~cm}$ & January maximum daily range (max-min) in soil temperature \\
\hline FebMaxDailyRng $25 \mathrm{~cm}$ & February maximum daily range (max-min) in soil temperature \\
\hline MarMaxDailyRng $25 \mathrm{~cm}$ & March maximum daily range (max-min) in soil temperature \\
\hline DecMaxDailyRng50cm & December maximum daily range (max-min) in soil temperature \\
\hline JanMaxDailyRng50cm & January maximum daily range (max-min) in soil temperature \\
\hline FebMaxDailyRng50cm & February maximum daily range ( $\max -\mathrm{min}$ ) in soil temperature \\
\hline MarMaxDailyRng50cm & March maximum daily range (max-min) in soil temperature \\
\hline DecAvgDailyRng0cm & December average daily range (max-min) in soil temperature \\
\hline JanAvgDailyRng0cm & January average daily range (max-min) in soil temperature \\
\hline FebAvgDailyRng0cm & February average daily range (max-min) in soil temperature \\
\hline MarAvgDailyRng0cm & March average daily range (max-min) in soil temperature \\
\hline DecAvgDailyRng25cm & December average daily range (max-min) in soil temperature \\
\hline JanAvgDailyRng $25 \mathrm{~cm}$ & January average daily range (max-min) in soil temperature \\
\hline FebAvgDailyRng25cm & February average daily range (max-min) in soil temperature \\
\hline MarAvgDailyRng25cm & March average daily range (max-min) in soil temperature \\
\hline DecAvgDailyRng $50 \mathrm{~cm}$ & December average daily range (max-min) in soil temperature \\
\hline JanAvgDailyRng50cm & January average daily range (max-min) in soil temperature \\
\hline FebAvgDailyRng $50 \mathrm{~cm}$ & February average daily range (max-min) in soil temperature \\
\hline MarAvgDailyRng50cm & March average daily range (max-min) in soil temperature \\
\hline DayCnt20to30C_0cm & number of days with high temperatures $>20$ and $<=30$ degrees $\mathrm{C}$ \\
\hline
\end{tabular}




\begin{tabular}{|c|c|}
\hline Variable & Description \\
\hline FebAbsMinAnyDay0cm & coldest February 1-hr soil temperature for each plot - any date \\
\hline FebAbsMinAnyDay $25 \mathrm{~cm}$ & coldest February 1-hr soil temperature for each plot - any date \\
\hline FebAbsMinAnyDay50cm & coldest February 1-hr soil temperature for each plot - any date \\
\hline FebAbsMinAnyDayAM0cm & coldest daytime February 1-hr soil temperature for each plot - any date \\
\hline FebAbsMinAnyDayAM25cm & coldest daytime February 1-hr soil temperature for each plot - any date \\
\hline FebAbsMinAnyDayAM50cm & coldest daytime February 1-hr soil temperature for each plot - any date \\
\hline FebAbsMinAnyDayPM0cm & coldest nighttime February 1-hr soil temperature for each plot - any date \\
\hline FebAbsMinAnyDayPM25cm & coldest nighttime February 1-hr soil temperature for each plot - any date \\
\hline FebAbsMinAnyDayPM50cm & coldest nighttime February 1-hr soil temperature for each plot - any date \\
\hline FebDailyMinAnyDay0cm & coldest February daily mean soil temperature for each plot - any date \\
\hline FebDailyMinAnyDay $25 \mathrm{~cm}$ & coldest February daily mean soil temperature for each plot - any date \\
\hline FebDailyMinAnyDay50cm & coldest February daily mean soil temperature for each plot - any date \\
\hline FebDailyMinAnyDayAM0cm & $\begin{array}{l}\text { coldest daytime February daily mean soil temperature for each plot - any } \\
\text { date }\end{array}$ \\
\hline FebDailyMinAnyDayAM25cm & $\begin{array}{l}\text { coldest daytime February daily mean soil temperature for each plot - any } \\
\text { date }\end{array}$ \\
\hline FebDailyMinAnyDayAM50cm & $\begin{array}{l}\text { coldest daytime February daily mean soil temperature for each plot - any } \\
\text { date }\end{array}$ \\
\hline FebDailyMinAnyDayPM0cm & $\begin{array}{l}\text { coldest nighttime February daily mean soil temperature for each plot - } \\
\text { any date }\end{array}$ \\
\hline FebDailyMinAnyDayPM25cm & $\begin{array}{l}\text { coldest nighttime February daily mean soil temperature for each plot - } \\
\text { any date }\end{array}$ \\
\hline FebDailyMinAnyDayPM50cm & $\begin{array}{l}\text { coldest nighttime February daily mean soil temperature for each plot - } \\
\text { any date }\end{array}$ \\
\hline FebAbsMinOneDay0cm & coldest February 1-hr soil temperature for each plot on Feb 6, 2016 \\
\hline FebAbsMinOneDay $25 \mathrm{~cm}$ & coldest February 1-hr soil temperature for each plot on Feb 16, 2016 \\
\hline FebAbsMinOneDay $50 \mathrm{~cm}$ & coldest February 1-hr soil temperature for each plot on Feb 22, 2016 \\
\hline FebAbsMinOneDayAM0cm & $\begin{array}{l}\text { coldest daytime February 1-hr soil temperature for each plot on Feb 6, } \\
2016\end{array}$ \\
\hline FebAbsMinOneDayAM25cm & $\begin{array}{l}\text { coldest daytime February 1-hr soil temperature for each plot on Feb 21, } \\
2016\end{array}$ \\
\hline FebAbsMinOneDayAM50cm & $\begin{array}{l}\text { coldest daytime February 1-hr soil temperature for each plot on Feb 22, } \\
2016\end{array}$ \\
\hline FebAbsMinOneDayPM0cm & $\begin{array}{l}\text { coldest nighttime February 1-hr soil temperature for each plot on Feb 6, } \\
2016\end{array}$ \\
\hline FebAbsMinOneDayPM25cm & $\begin{array}{l}\text { coldest nighttime February 1-hr soil temperature for each plot on Feb 16, } \\
2016\end{array}$ \\
\hline FebAbsMinOneDayPM50cm & $\begin{array}{l}\text { coldest nighttime February 1-hr soil temperature for each plot on Feb 22, } \\
2016\end{array}$ \\
\hline FebDailyMinOneDay0cm & $\begin{array}{l}\text { coldest February daily mean soil temperature for each plot on Feb 6, } \\
2016\end{array}$ \\
\hline FebDailyMinOneDay $25 \mathrm{~cm}$ & $\begin{array}{l}\text { coldest February daily mean soil temperature for each plot on Feb 16, } \\
2016\end{array}$ \\
\hline FebDailyMinOneDay50cm & $\begin{array}{l}\text { coldest February daily mean soil temperature for each plot on Feb 22, } \\
2016\end{array}$ \\
\hline FebDailyMinOneDayAM0cm & $\begin{array}{l}\text { coldest daytime February daily mean soil temperature for each plot on } \\
\text { Feb } 5,2016\end{array}$ \\
\hline
\end{tabular}




\begin{tabular}{|c|c|}
\hline Variable & Description \\
\hline FebDailyMinOneDayAM25cm & $\begin{array}{l}\text { coldest daytime February daily mean soil temperature for each plot on } \\
\text { Feb } 16,2016\end{array}$ \\
\hline FebDailyMinOneDayAM50cm & $\begin{array}{l}\text { coldest daytime February daily mean soil temperature for each plot on } \\
\text { Feb } 22,2016\end{array}$ \\
\hline FebDailyMinOneDayPM0cm & $\begin{array}{l}\text { coldest nighttime February daily mean soil temperature for each plot on } \\
\text { Feb } 6,2016\end{array}$ \\
\hline FebDailyMinOneDayPM25cm & $\begin{array}{l}\text { coldest nighttime February daily mean soil temperature for each plot on } \\
\text { Feb } 16,2016\end{array}$ \\
\hline FebDailyMinOneDayPM50cm & $\begin{array}{l}\text { coldest nighttime February daily mean soil temperature for each plot on } \\
\text { Feb 22, } 2016\end{array}$ \\
\hline Dry $24 \mathrm{Hr} 0 \mathrm{~cm}$ & driest 24-hr mean soil moisture for each plot in May-Sept 2016 \\
\hline Dry $24 \mathrm{Hr} 25 \mathrm{~cm}$ & driest 24-hr mean soil moisture for each plot in May-Sept 2016 \\
\hline Dry $24 \mathrm{Hr} 50 \mathrm{~cm}$ & driest 24-hr mean soil moisture for each plot in May-Sept 2016 \\
\hline Dry7Day0cm & driest 7-day mean soil moisture for each plot in May-Sept 2016 \\
\hline Dry7Day $25 \mathrm{~cm}$ & driest 7-day mean soil moisture for each plot in May-Sept 2016 \\
\hline Dry7Day $50 \mathrm{~cm}$ & driest 7-day mean soil moisture for each plot in May-Sept 2016 \\
\hline Dry30Day0cm & driest 30-day mean soil moisture for each plot in May-Sept 2016 \\
\hline Dry30Day $25 \mathrm{~cm}$ & driest 30-day mean soil moisture for each plot in May-Sept 2016 \\
\hline Dry30Day $50 \mathrm{~cm}$ & driest 30-day mean soil moisture for each plot in May-Sept 2016 \\
\hline JulDailyAvg0cm & mean daily soil moisture for July \\
\hline JulDailyAvg $25 \mathrm{~cm}$ & mean daily soil moisture for July \\
\hline JulDailyAvg $50 \mathrm{~cm}$ & mean daily soil moisture for July \\
\hline AugDailyAvg0cm & mean daily soil moisture for August \\
\hline AugDailyAvg $25 \mathrm{~cm}$ & mean daily soil moisture for August \\
\hline AugDailyAvg $50 \mathrm{~cm}$ & mean daily soil moisture for August \\
\hline JulAbsMinAnyDay0cm & driest July 1-hr soil moisture for each plot - any date \\
\hline JulAbsMinAnyDay $25 \mathrm{~cm}$ & driest July 1-hr soil moisture for each plot - any date \\
\hline JulAbsMinAnyDay $50 \mathrm{~cm}$ & driest July 1-hr soil moisture for each plot - any date \\
\hline JulAbsMaxAnyDay0cm & wettest July 1-hr soil moisture for each plot - any date \\
\hline JulAbsMaxAnyDay $25 \mathrm{~cm}$ & wettest July 1-hr soil moisture for each plot - any date \\
\hline JulAbsMaxAnyDay50cm & wettest July 1-hr soil moisture for each plot - any date \\
\hline JulDailyMinAnyDay0cm & driest July daily mean soil moisture for each plot - any date \\
\hline JulDailyMinAnyDay $25 \mathrm{~cm}$ & driest July daily mean soil moisture for each plot - any date \\
\hline JulDailyMinAnyDay50cm & driest July daily mean soil moisture for each plot - any date \\
\hline JulDailyMaxAnyDay0cm & wettest July daily mean soil moisture for each plot - any date \\
\hline JulDailyMaxAnyDay25cm & wettest July daily mean soil moisture for each plot - any date \\
\hline JulDailyMaxAnyDay50cm & wettest July daily mean soil moisture for each plot - any date \\
\hline AugAbsMinAnyDay0cm & driest August 1-hr soil moisture for each plot - any date \\
\hline AugAbsMinAnyDay $25 \mathrm{~cm}$ & driest August 1-hr soil moisture for each plot - any date \\
\hline AugAbsMinAnyDay $50 \mathrm{~cm}$ & driest August 1-hr soil moisture for each plot - any date \\
\hline AugAbsMaxAnyDay0cm & wettest August 1-hr soil moisture for each plot - any date \\
\hline
\end{tabular}




\begin{tabular}{|c|c|}
\hline Variable & Description \\
\hline AugAbsMaxAnyDay $25 \mathrm{~cm}$ & wettest August 1-hr soil moisture for each plot - any date \\
\hline AugAbsMaxAnyDay $50 \mathrm{~cm}$ & wettest August 1 -hr soil moisture for each plot - any date \\
\hline AugDailyMinAnyDay0cm & driest August daily mean soil moisture for each plot - any date \\
\hline AugDailyMinAnyDay $25 \mathrm{~cm}$ & driest August daily mean soil moisture for each plot - any date \\
\hline AugDailyMinAnyDay $50 \mathrm{~cm}$ & driest August daily mean soil moisture for each plot - any date \\
\hline AugDailyMaxAnyDay0cm & wettest August daily mean soil moisture for each plot - any date \\
\hline AugDailyMaxAnyDay $25 \mathrm{~cm}$ & wettest August daily mean soil moisture for each plot - any date \\
\hline AugDailyMaxAnyDay $50 \mathrm{~cm}$ & wettest August daily mean soil moisture for each plot - any date \\
\hline JulAbsMinOneDay0cm & driest July 1-hr soil moisture for each plot on Jul 27, 2016 \\
\hline JulAbsMinOneDay $25 \mathrm{~cm}$ & driest July 1-hr soil moisture for each plot on Jul 28, 2016 \\
\hline JulAbsMinOneDay $50 \mathrm{~cm}$ & driest July 1-hr soil moisture for each plot on Jul 28, 2016 \\
\hline JulAbsMaxOneDay0cm & wettest July 1-hr soil moisture for each plot on Jul 7, 2016 \\
\hline JulAbsMaxOneDay $25 \mathrm{~cm}$ & wettest July 1-hr soil moisture for each plot on Jul 8, 2016 \\
\hline JulAbsMaxOneDay50cm & wettest July 1-hr soil moisture for each plot on Jul 8, 2016 \\
\hline JulDailyMinOneDay0cm & driest July daily mean soil moisture for each plot on Jul 27, 2016 \\
\hline JulDailyMinOneDay $25 \mathrm{~cm}$ & driest July daily mean soil moisture for each plot on Jul 27, 2016 \\
\hline JulDailyMinOneDay50cm & driest July daily mean soil moisture for each plot on Jul 28, 2016 \\
\hline JulDailyMaxOneDay0cm & wettest July daily mean soil moisture for each plot on Jul 5, 2016 \\
\hline JulDailyMaxOneDay $25 \mathrm{~cm}$ & wettest July daily mean soil moisture for each plot on Jul 5, 2016 \\
\hline JulDailyMaxOneDay50cm & wettest July daily mean soil moisture for each plot on Jul 6, 2016 \\
\hline AugAbsMinOneDay0cm & driest August 1-hr soil moisture for each plot on Aug 1, 2016 \\
\hline AugAbsMinOneDay $25 \mathrm{~cm}$ & driest August 1-hr soil moisture for each plot on Aug 31, 2016 \\
\hline AugAbsMinOneDay $50 \mathrm{~cm}$ & driest August 1-hr soil moisture for each plot on Aug 15, 2016 \\
\hline AugAbsMaxOneDay0cm & wettest August 1-hr soil moisture for each plot on Aug 21, 2016 \\
\hline AugAbsMaxOneDay $25 \mathrm{~cm}$ & wettest August 1-hr soil moisture for each plot on Aug 15, 2016 \\
\hline AugAbsMaxOneDay50cm & wettest August 1-hr soil moisture for each plot on Aug 15, 2016 \\
\hline AugDailyMinOneDay0cm & driest August daily mean soil moisture for each plot on Aug 1, 2016 \\
\hline AugDailyMinOneDay $25 \mathrm{~cm}$ & driest August daily mean soil moisture for each plot on Aug 31, 2016 \\
\hline AugDailyMinOneDay50cm & driest August daily mean soil moisture for each plot on Aug 14, 2016 \\
\hline AugDailyMaxOneDay0cm & wettest August daily mean soil moisture for each plot on Aug 18, 2016 \\
\hline AugDailyMaxOneDay $25 \mathrm{~cm}$ & wettest August daily mean soil moisture for each plot on Aug 16, 2016 \\
\hline AugDailyMaxOneDay $50 \mathrm{~cm}$ & wettest August daily mean soil moisture for each plot on Aug 16, 2016 \\
\hline
\end{tabular}


Appendix C. Kriging and cokriging accuracy metrics.

\begin{tabular}{|c|c|c|c|}
\hline Variable & $\begin{array}{c}\text { Standardized Root Mean Square } \\
\text { Prediction Error (RMSSE) } \\
\end{array}$ & $\begin{array}{c}\text { Root Mean Square Prediction } \\
\text { Error (RMSE) })^{\mathrm{b}}\end{array}$ & $\begin{array}{c}\text { Standardized Average } \\
\text { Prediction Error }\end{array}$ \\
\hline $\begin{array}{l}\text { Air Temperature Variables } \\
\text { julavgdaytime } \\
\text { augavgdaytime } \\
\text { janabsminanyday } \\
\text { febabsminanyday } \\
\text { julabsminanyday } \\
\text { augabsminanyday } \\
\text { novabsminanyday } \\
\text { decabsminanyday } \\
\text { julabsmaxanyday } \\
\text { augabsmaxanyday } \\
\text { jandailyminanyday } \\
\text { febdailyminanyday } \\
\text { juldailyminanyday } \\
\text { augdailyminanyday } \\
\text { juldailymaxanyday } \\
\text { augdailymaxanyday } \\
\text { absmaxanyday } \\
\text { absminanyday } \\
\text { anntempalldata } \\
\text { anntempbioclim }\end{array}$ & $\begin{array}{l}0.910151593 \\
0.904746792 \\
1.153982389 \\
2.970297523 \\
1.295087187 \\
0.912262706 \\
0.995491776 \\
3.813109994 \\
1.057685859 \\
0.001063049 \\
0.000965468 \\
0.000900618 \\
0.001295708 \\
0.000981086 \\
0.000920089 \\
0.001302657 \\
-0.01491 \\
0.007121 \\
0.094238 \\
0.059987\end{array}$ & $\begin{array}{c}0.421678884 \\
0.365973115 \\
0.806889994 \\
0.9312551 \\
0.457725898 \\
0.575998851 \\
0.524181629 \\
0.621780298 \\
2.132762025 \\
0.001063049 \\
0.000965468 \\
0.000900618 \\
0.001295708 \\
0.000981086 \\
0.000920089 \\
0.001302657 \\
1.102737727 \\
0.921309335 \\
1.78149298 \\
0.723106418\end{array}$ & $\begin{array}{c}0.469974757 \\
0.409912487 \\
0.724509897 \\
0.563662449 \\
0.508806619 \\
0.65363653 \\
0.533217877 \\
0.371184089 \\
1.671947692 \\
0.001063049 \\
0.000965468 \\
0.000900618 \\
0.001295708 \\
0.000981086 \\
0.000920089 \\
0.001302657 \\
2.097112 \\
2.130692 \\
0.383006 \\
1.894289\end{array}$ \\
\hline $\begin{array}{l}\text { Soil Temperature Variables } \\
\text { febabsminanyday } 0 \mathrm{~cm} \\
\text { febabsminanyday } 25 \mathrm{~cm} \\
\text { febabsminanyday } 50 \mathrm{~cm} \\
\text { febdailyminanyday } 0 \mathrm{~cm} \\
\text { febdailyminanyday } 25 \mathrm{~cm} \\
\text { febdailyminanyday } 50 \mathrm{~cm}\end{array}$ & $\begin{array}{c}1.045658718 \\
1.001569909 \\
0.929225268 \\
1.005279311 \\
0.9368979 \\
1.052644841 \\
\end{array}$ & $\begin{array}{l}0.723770736 \\
0.475475391 \\
0.464688208 \\
0.487191821 \\
0.369838729 \\
0.370234943 \\
\end{array}$ & $\begin{array}{l}0.691030257 \\
0.478711132 \\
0.517127462 \\
0.486238802 \\
0.408284883 \\
0.420435363 \\
\end{array}$ \\
\hline
\end{tabular}

\footnotetext{
${ }^{\mathrm{a}}$ Optimal results with RMSSE as close to one as possible, ${ }^{\mathrm{b}}$ Optimal results with RMSE as small as possible, ${ }^{\mathrm{c}}$ Optimal results when as close to RMSE as possible
} 


\begin{tabular}{|c|c|c|c|}
\hline Variable & $\begin{array}{l}\text { Standardized Root Mean Square } \\
\text { Prediction Error (RMSSE) }\end{array}$ & $\begin{array}{l}\text { Root Mean Square Prediction } \\
\text { Error }(\mathrm{RMSE})^{\mathrm{b}}\end{array}$ & $\begin{array}{l}\text { Standardized Average } \\
\text { Prediction Error }^{\mathrm{c}}\end{array}$ \\
\hline decabsminanyday0cm & 1.035174511 & 0.742689 & 0.718316 \\
\hline decabsminanyday $25 \mathrm{~cm}$ & 0.887199465 & 0.501353 & 0.590624 \\
\hline decabsminanyday $50 \mathrm{~cm}$ & 0.888977081 & 0.460366 & 0.548902 \\
\hline decabsmaxanyday0 $\mathrm{cm}$ & 1.062631363 & 0.771075 & 0.721087 \\
\hline decabsmaxanyday $25 \mathrm{~cm}$ & 0.860379478 & 0.420108 & 0.49221 \\
\hline decabsmaxanyday $50 \mathrm{~cm}$ & 0.939287448 & 0.385202 & 0.415363 \\
\hline decdailyminanyday $0 \mathrm{~cm}$ & 1.025860974 & 0.742573 & 0.726012 \\
\hline decdailyminanyday $25 \mathrm{~cm}$ & 0.906798393 & 0.633897 & 0.718314 \\
\hline decdailyminanyday $50 \mathrm{~cm}$ & 0.866453218 & 0.563248 & 0.725648 \\
\hline decdailymaxanyday $0 \mathrm{~cm}$ & 0.893283962 & 0.450839 & 0.534902 \\
\hline decdailymaxanyday $25 \mathrm{~cm}$ & 0.875502689 & 0.415265 & 0.4815 \\
\hline decdailymaxanyday $50 \mathrm{~cm}$ & 0.914948829 & 0.37452 & 0.416952 \\
\hline janabsminanyday0cm & 0.979459839 & 0.828824 & 0.859307 \\
\hline janabsminanyday $25 \mathrm{~cm}$ & 0.947074491 & 0.458318 & 0.491376 \\
\hline janabsminanyday $50 \mathrm{~cm}$ & 0.940590367 & 0.388633 & 0.45327 \\
\hline janabsmaxanyday $0 \mathrm{~cm}$ & 1.069334884 & 0.935224 & 0.874273 \\
\hline janabsmaxanyday $25 \mathrm{~cm}$ & 0.815448966 & 0.427013 & 0.541619 \\
\hline janabsmaxanyday $50 \mathrm{~cm}$ & 0.951535494 & 0.349031 & 0.384315 \\
\hline jandailyminanyday $0 \mathrm{~cm}$ & 0.971894557 & 0.700499 & 0.73025 \\
\hline jandailyminanyday $25 \mathrm{~cm}$ & 0.915149033 & 0.500038 & 0.556972 \\
\hline jandailyminanyday $50 \mathrm{~cm}$ & 0.8852913 & 0.429298 & 0.51442 \\
\hline jandailymaxanyday $0 \mathrm{~cm}$ & 1.06962938 & 0.924564 & 0.863266 \\
\hline jandailymaxanyday $25 \mathrm{~cm}$ & 0.784441157 & 0.427461 & 0.573823 \\
\hline jandailymaxanyday $50 \mathrm{~cm}$ & 0.970694543 & 0.366315 & 0.396825 \\
\hline julabsminanyday $0 \mathrm{~cm}$ & 1.094681765 & 2.356865 & 2.143089 \\
\hline julabsminanyday $25 \mathrm{~cm}$ & 0.983733735 & 0.667997 & 0.672042 \\
\hline julabsminanyday $50 \mathrm{~cm}$ & 0.955380747 & 0.925678 & 0.977401 \\
\hline julabsmaxanyday $0 \mathrm{~cm}$ & 1.007036642 & 1.364091 & 1.363719 \\
\hline julabsmaxanyday $25 \mathrm{~cm}$ & 0.93757174 & 0.645145 & 0.690163 \\
\hline julabsmaxanyday $50 \mathrm{~cm}$ & 0.882744385 & 0.991701 & 1.137421 \\
\hline
\end{tabular}

${ }^{\mathrm{a}}$ Optimal results with RMSSE as close to one as possible, ${ }^{\mathrm{b}}$ Optimal results with RMSE as small as possible, ${ }^{\mathrm{c}}$ Optimal results when as close to RMSE as possible 


\begin{tabular}{|c|c|c|c|}
\hline Variable & $\begin{array}{l}\text { Standardized Root Mean Square } \\
\text { Prediction Error (RMSSE) }\end{array}$ & $\begin{array}{l}\text { Root Mean Square Prediction } \\
\text { Error }(\mathrm{RMSE})^{\mathrm{b}}\end{array}$ & $\begin{array}{l}\text { Standardized Average } \\
\text { Prediction Error }\end{array}$ \\
\hline juldailyminanyday0cm & 0.900929312 & 0.805715 & 0.907591 \\
\hline juldailyminanyday $25 \mathrm{~cm}$ & 0.92834607 & 0.573623 & 0.628895 \\
\hline juldailyminanyday $50 \mathrm{~cm}$ & 0.953561179 & 0.931685 & 0.98571 \\
\hline juldailymaxanyday $0 \mathrm{~cm}$ & 0.922946538 & 1.063861 & 1.170778 \\
\hline juldailymaxanyday $25 \mathrm{~cm}$ & 0.940314437 & 0.632458 & 0.677602 \\
\hline juldailymaxanyday $50 \mathrm{~cm}$ & 0.894099026 & 1.003682 & 1.134484 \\
\hline augabsminanyday $0 \mathrm{~cm}$ & 0.919888649 & 0.985766 & 1.076025 \\
\hline augabsminanyday $25 \mathrm{~cm}$ & 1.131054509 & 0.731353 & 0.646064 \\
\hline augabsminanyday $50 \mathrm{~cm}$ & 0.87070127 & 0.908184 & 1.057091 \\
\hline augabsmaxanyday $0 \mathrm{~cm}$ & 1.16961416 & 1.043831 & 0.863675 \\
\hline augabsmaxanyday $25 \mathrm{~cm}$ & 1.064508758 & 0.700363 & 0.663968 \\
\hline augabsmaxanyday $50 \mathrm{~cm}$ & 1.006936509 & 0.684184 & 0.682101 \\
\hline augdailyminanyday $0 \mathrm{~cm}$ & 0.976574394 & 0.772874 & 0.797371 \\
\hline augdailyminanyday $25 \mathrm{~cm}$ & 1.140106996 & 0.712413 & 0.621644 \\
\hline augdailyminanyday $50 \mathrm{~cm}$ & 0.872041516 & 0.91577 & 1.063853 \\
\hline augdailymaxanyday $0 \mathrm{~cm}$ & 1.083062373 & 0.558458 & 0.523286 \\
\hline augdailymaxanyday $25 \mathrm{~cm}$ & 1.059018089 & 0.716684 & 0.685368 \\
\hline augdailymaxanyday $50 \mathrm{~cm}$ & 1.005586339 & 0.698348 & 0.696169 \\
\hline \multicolumn{4}{|l|}{ Soil Moisture Variables } \\
\hline dry $24 \mathrm{hr} 0 \mathrm{~cm}$ & 0.960995075 & 0.046245975 & 0.048256968 \\
\hline dry $24 \mathrm{hr} 25 \mathrm{~cm}$ & 1.029247856 & 0.044930332 & 0.043630897 \\
\hline dry $24 \mathrm{hr} 50 \mathrm{~cm}$ & 1.150706998 & 0.059002284 & 0.048477269 \\
\hline dry7day0cm & 0.974305732 & 0.048908099 & 0.050778765 \\
\hline dry 7 day $25 \mathrm{~cm}$ & 1.028661098 & 0.045161408 & 0.043863182 \\
\hline dry 7 day $50 \mathrm{~cm}$ & 1.1525662 & 0.05981204 & 0.049365033 \\
\hline dry 30 day $0 \mathrm{~cm}$ & 0.964936231 & 0.054415527 & 0.057006271 \\
\hline dry30day $25 \mathrm{~cm}$ & 1.003330528 & 0.043588878 & 0.043522005 \\
\hline dry 30 day $50 \mathrm{~cm}$ & 1.137522695 & 0.062238329 & 0.052588262 \\
\hline julabsminanyday $0 \mathrm{~cm}$ & 0.986481193 & 0.07907635 & 0.080166382 \\
\hline
\end{tabular}

${ }^{\mathrm{a}}$ Optimal results with RMSSE as close to one as possible, ${ }^{\mathrm{b}}$ Optimal results with RMSE as small as possible, ${ }^{\mathrm{c}}$ Optimal results when as close to RMSE as possible 


\begin{tabular}{|c|c|c|c|}
\hline Variable & $\begin{array}{l}\text { Standardized Root Mean Square } \\
\text { Prediction Error (RMSSE) }\end{array}$ & $\begin{array}{l}\text { Root Mean Square Prediction } \\
\text { Error }(\mathrm{RMSE})^{\mathrm{b}}\end{array}$ & $\begin{array}{l}\text { Standardized Average } \\
\text { Prediction Error }\end{array}$ \\
\hline julabsminanyday $25 \mathrm{~cm}$ & 0.953735874 & 0.044334557 & 0.046688121 \\
\hline julabsminanyday $50 \mathrm{~cm}$ & 1.0595105 & 0.062267378 & 0.056371136 \\
\hline julabsmaxanyday $0 \mathrm{~cm}$ & 0.982155832 & 0.098530383 & 0.101389505 \\
\hline julabsmaxanyday $25 \mathrm{~cm}$ & 1.004092142 & 0.097169096 & 0.096517132 \\
\hline julabsmaxanyday $50 \mathrm{~cm}$ & 0.959144296 & 0.086819407 & 0.09178233 \\
\hline juldailyminanyday $0 \mathrm{~cm}$ & 1.003596279 & 0.081649106 & 0.081364668 \\
\hline juldailyminanyday $25 \mathrm{~cm}$ & 0.955458619 & 0.045109183 & 0.047428781 \\
\hline juldailyminanyday $50 \mathrm{~cm}$ & 1.060817828 & 0.062284385 & 0.056158424 \\
\hline juldailymaxanyday $0 \mathrm{~cm}$ & 0.985495275 & 0.093886867 & 0.096374195 \\
\hline juldailymaxanyday $25 \mathrm{~cm}$ & 0.978506712 & 0.067803119 & 0.069452485 \\
\hline juldailymaxanyday $50 \mathrm{~cm}$ & 0.942019365 & 7.90564226 & 8.357748987 \\
\hline augabsminanyday $0 \mathrm{~cm}$ & 0.990352167 & 0.072674468 & 0.073452775 \\
\hline augabsminanyday $25 \mathrm{~cm}$ & 0.955365046 & 0.04542276 & 0.047801229 \\
\hline augabsminanyday $50 \mathrm{~cm}$ & 1.066323573 & 0.063447199 & 0.058286145 \\
\hline augabsmaxanyday $0 \mathrm{~cm}$ & 1.006142479 & 0.096754208 & 0.096504005 \\
\hline augabsmaxanyday $25 \mathrm{~cm}$ & 0.959226409 & 0.063933669 & 0.066915326 \\
\hline augabsmaxanyday $50 \mathrm{~cm}$ & 0.965416154 & 0.070486938 & 0.073279554 \\
\hline augdailyminanyday $0 \mathrm{~cm}$ & 0.989110187 & 0.07389788 & 0.074800996 \\
\hline augdailyminanyday $25 \mathrm{~cm}$ & 0.941563811 & 0.044205201 & 0.047205038 \\
\hline augdailyminanyday $50 \mathrm{~cm}$ & 1.071856779 & 0.063462128 & 0.057876104 \\
\hline augdailymaxanyday $0 \mathrm{~cm}$ & 0.997586788 & 0.090943468 & 0.091733178 \\
\hline augdailymax anyday $25 \mathrm{~cm}$ & 0.953396639 & 0.049544945 & 0.052241864 \\
\hline augdailymaxanyday $50 \mathrm{~cm}$ & 1.009662203 & 0.065000428 & 0.064614963 \\
\hline
\end{tabular}

${ }^{\mathrm{a}}$ Optimal results with RMSSE as close to one as possible, ${ }^{\mathrm{b}}$ Optimal results with RMSE as small as possible, ${ }^{\mathrm{c}}$ Optimal results when as close to RMSE as possible 